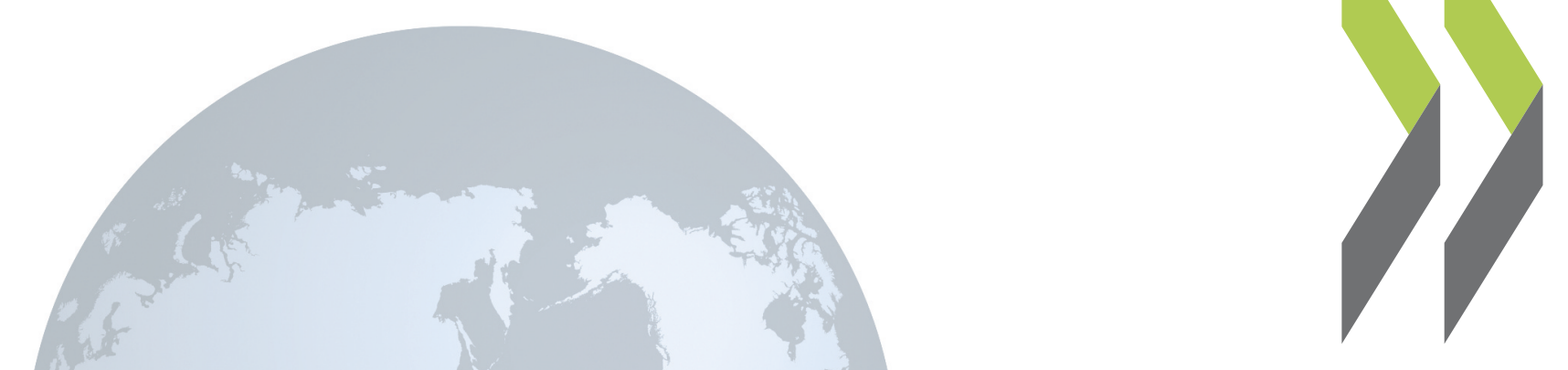

OECD Public Governance Policy Papers No. 04

\title{
Promoting research and innovation in the Slovak Republic through an effective use of European funds
} OECD 
OECD Public Governance Policy Papers

\section{Promoting research and innovation in the Slovak Republic through an effective use of European funds}


This document was produced with the financial assistance of the European Union. The views expressed herein can in no way be taken to reflect the official opinion of the European Union.

This paper is published under the responsibility of the Secretary-General of the OECD. The opinions expressed and the arguments employed herein do not necessarily reflect the official views of OECD member countries. This document, as well as any data and map included herein, are without prejudice to the status of or sovereignty over any territory, to the delimitation of international frontiers and boundaries and to the name of any territory, city or area.

This paper was authorised for publication by the OECD Director of Public Governance, Elsa Pilichowski.

(C) OECD (2021)

The use of this work, whether digital or print, is governed by the Terms and Conditions to be found at http://www.oecd.org/termsandconditions. 


\section{Abstract}

This policy paper analyses current practices related to the implementation of European Structural and Investment Funds (ESIF) in the Slovak Republic, in particular, the Operational Programme Research and Innovation (R\&l). The Slovak Republic benefits from one of the largest shares of European Structural and Investment Funds (ESIF). However, the country ranks amongst the EU member states with the lowest absorption of R\&I ESIF. In 2017, administrative inefficiencies and irregularities resulted in further decommitments by the European Commission. This paper identifies bottlenecks in the ESIF projects' implementation across the entire project life cycle, from the preparation of calls to the execution of selected projects. It offers the Slovak Republic tailored policy recommendations to support the effective implementation of European funds for research and innovation and avoid further decommissioning. To ensure lasting changes, this policy paper proposes an action plan where all relevant stakeholders would contribute to effectively implementing transformational reforms. 


\section{Acknowledgments}

Under the direction and oversight of Elsa Pilichowski, OECD Director for Public Governance, Andrew Wyckoff, OECD Director for Science, Technology and Innovation, Edwin Lau, Head of the Infrastructure and Public Procurement Division, and Alessandra Colecchia, Head of the Science and Technology Policy Division, this review was co-ordinated by Paulo Magina, Deputy Head of the Infrastructure and Public Procurement Division, and Alan Paic, Senior Policy Analyst of the Science and Technology Policy Division.

The authors of this report are Matthieu Cahen, Masayuki Omote from the Infrastructure and Public Procurement Division and Christian Biesmans from the Science and Technology Policy Division. Francesco Vogelezang contributed to inputs and data analysis at an early stage of the review. Elisabetta Pilati and Jennifer Allain provided editorial assistance. Lauren Thwaites and Beatrice Jeffries provided administrative assistance.

The OECD expresses its gratitude to the Ministry of Transport and Construction of the Slovak Republic as the Managing Authority of the Operational Programme Integrated Infrastructure (OPII) for its fruitful cooperation and leadership. In particular, the OECD would like to thank, Mr. Pavol Bžán, Director of Programming and Monitoring Department of the Division of Projects Management, and Milan Pukančík, Monitoring Manager of the Division of Projects Management, for serving as the point of contact for the coordination with the OECD. The collaboration of the Intermediate Bodies for OPII were critical for the successful completion of this review. In particular, the OECD would like to thank Mr. Edmund Škorvaga, Director of the Operational Programs and Methodology Management Department of the Ministry of Economy of the Slovak Republic, Mr. L'ubomír Grznárik, Nominee Director for ERDF Programmes Department and Mr. Martin Valo, Monitoring and Evaluation Manager of the EU Structural Funds Division at the Ministry of Education, Science, Research and Sports of the Slovak Republic, and Mr. Eduard Jambor, Director of the Department of Cross-sectoral Activities of the Research Agency, for providing information for the analysis. Furthermore, the report also benefited from the valuable insights and perspectives of different stakeholders from the public and private sectors that were consulted by the OECD through specific questionnaires and/or interviews: Ministry of Investments, Regional Development and Informatisation of the Slovak Republic as the Central Co-ordination Authority (CCA), Certifying Authority and Audit Authority of the Ministry of Finance of the Slovak Republic, Public Procurement Office of the Slovak Republic, Supreme Audit Office of the Slovak Republic, Slovak Investment Holding, European AntiFraud Office (OLAF), and a number of beneficiaries and suppliers. Their collaboration enriched the analysis of the OECD.

The OECD also would like to express sincere gratitude to managing authorities, intermediate bodies, and/or public procurement authorities of some EU member states for their cooperation on the benchmarking exercise of the ESIF management practices: the Czech Republic (Ministry of Education, Youth and Sports, Ministry of Industry and Trade, Prague City Hall), Estonia (Estonian Research Council, Enterprise Estonia, State Shared Service Centre), Lithuania (Public Procurement Office, European Social Fund Agency, Central Project Management Agency, Environmental Projects Management Agency, and Lithuanian Business Support Agency), Poland (Public Procurement Office and the Ministry of Development 
Funds and Regional Policy) and Slovenia (Public Procurement Directorate of the Ministry of Public Administration).

The OECD expresses its gratitude to the DG Reform of the European Commission for their financial support to this project, particularly Mr. Daniele Dotto, Head of Unit, Ms. Phivi Haratsi, and Mr. Peter Petrik. 


\section{Table of contents}

Abstract 3

$\begin{array}{ll}\text { Acknowledgments } & 4\end{array}$

$\begin{array}{ll}\text { Executive summary } & 10\end{array}$

$\begin{array}{ll}\text { Introduction } & 13\end{array}$

1. Performance of ESIF implementation in the Slovak Republic 15

1.1. EU budget allocations in research and innovation $\quad 15$

1.2. Implementation within research and innovation by country 17

1.3. Implementation in the Slovak Republic by thematic objective 19

1.4. Analysis of implementation within the research and innovation thematic area in the Slovak Republic 20

2. The European Structural and Investment Funds' implementation ecosystem 24

2.1. Institutional framework 25

2.2. Regulatory framework $\quad 29$

2.3. Classification of projects $\quad 31$

3. The project life cycle 33

3.1. Preparation and publication of calls for proposals 33

3.2. Project evaluation, selection and contracting $\quad 34$

3.3 Public procurement procedures under ESIF projects 35

4. Impediments to ESIF implementation in the preparation of calls and project selection stage 37

4.1. Difficulties with call preparation, publication and execution 38

Ministry of Education, Science, Research and Sports/Research Agency 39

Ministry of Economy/Slovak Innovation and Energy Agency 46

4.2. Difficulties concerning project evaluation $\quad 53$

Symptoms $\quad 53$

Causes 53

Way forward 56

4.3. Excessive administrative requirements and gold-plating 57

Symptoms $\quad 57$

Causes $\quad 58$

$\begin{array}{ll}\text { Way forward } & 60\end{array}$ 
5. Impediments to ESIF implementation in the public procurement procedures

5.1. The complex and multi-layered control system lacks legal certainty and creates delays $\quad 63$

Overview of the control system of public procurement under ESIF projects in the

Slovak Republic: Ex ante and ex post controls are both carried out intensely

Control procedures of ESIF public procurement delay project implementation, putting high

administrative and bureaucratic burdens on beneficiaries

Conflicting opinions among different stakeholders brings legal uncertainty on the control

system of ESIF public procurement

5.2. ITMS2014+ creates additional administrative burdens and does not facilitate performance measurement

ITMS2014+ is not user-friendly and intuitive, bringing excessive administrative burdens to beneficiaries

ITMS2014+ does not function as an effective data collection system to measure the

performance of the ESIF public procurement procedures

5.3. Reinforcing the competitiveness of the market and the attractiveness of participating in ESIF projects

Market research requirements for low-value contracts are one of the highest administrative

burdens under the ESIF administration

Unreasonable cancellation of tenders due to single bids

5.4. Procedures related to contracts add significant administrative burdens

Register of Public Sector Partners

Payment procedures

5.5. Additional support could be provided to reinforce capacities and capabilities of the public procurement workforce of ESIF projects

Way forward

5.6. Strategies for using public procurement to foster innovation are underused

Way forward

\section{Moving forward: Implementing the action plan to reform ESIF administration for} research and innovation

References

Annex A. List of calls

\section{Tables}

Table 2.1. Methodological guidelines related to public procurement issued by the central co-ordination authority

Table 2.2. Classification of projects under the thematic objective research and innovation

Table 4.1. Benchmarking of administrative capacities per staff member

Table 4.2. Allocations in the National Development Fund II under the Operational Programme Integrated Infrastructure for the implementation of the Minisrty of Education, Science, Research and Sport's financial instruments

Table 5.1. Entities of EU countries that responded to the short questionnaire on good practices of ESIF public procurement procedures

Table 5.2. Thresholds for public procurement control under ESIF projects

Table 5.3. Control system of public procurement under ESIF projects in the Slovak Republic

Table 5.4. Overview of the public procurement control system under ESIF projects in elect EU countries

Table 5.5. Documents required for public procurement control under the ESIF

Table 5.6. Training courses taken by control officers in the intermediate bodies (2016-19) 
Table 5.9. Potential performance indicators for European Structural and Investment Funds public procurement 76 Table 5.10. Threshold for a low-value contract (effective since 1 January 2020) 78

Table 5.11. Threshold of a low-value contract applicable to Methodological Guideline No. 14

Table 5.12. Regulations on obtaining price quotations $\quad 80$

Table 5.13. Cancellation of procurement procedures with a single bid 82

Table 6.1. Action plan to reform the administration of the European Structural and Investment Funds in the

Slovak Republic

Table A.1. Research Agency calls

112

Table A.2. Ministry of Education, Science, Research and Sport's national projects 113

Table A.3. Ministry of Economy's calls and national projects

\section{Figures}

Figure 1.1. Average European Structural and Investment Funds allocation, 2014-20 *

Figure 1.2. European Structural and Investment Funds implementation progress for research and innovation by country, 2014-20

Figure 1.3. European Structural and Investment Funds implementation progress across thematic objectives in the Slovak Republic

Figure 1.4. Distribution of funds for calls in Specific objective 9.5

Figure 1.5. European Structural and Investment Funds implementation per call

Figure 2.1. Institutional framework for the implementation of European Structural and Investment Funds in the Slovak Republic, November 2020

Figure 2.2. Key actors involved in the public procurement process under ESIF projects

Figure 2.3. Regulatory frameworks governing public procurement under ESIF projects

Figure 3.1. Public procurement procedures under ESIF projects

Figure 5.1. Challenging procurement areas for beneficiaries in terms of strengthening capacity building

Figure 5.2. Evolution of the strategic use of public procurement in OECD countries

\section{Boxes}

Box 2.1. Comparing the institutional framework around ESIF implementation with the Czech Republic and Estonia

Box 4.1. Misconduct in the evaluation process and the audit authority's findings

Box 4.2. Examples of findings concerning the Research Agency's performance

Box 4.3. Comparing project management tools and administrative capacities with the Czech Republic and Estonia

Box 4.4. Measures to improve the efficiency of the Slovak Innovation and Energy Agency

Box 4.5. Benchmarking the preparation of beneficiaries and the use of financial instruments with the Czech Republic and Estonia

Box 4.6. List of corrective actions and simplifications implemented by the Slovak Ministry of Economy along the process (improvements introduced in 2020 vs. issues identified in 2017/18)

Box 4.7. Comparing challenges in finding evaluators with the Czech Republic and Estonia 55

Box 4.8. Comparing administrative requirements in the Czech Republic and Estonia $\quad 59$

Box 5.1. Control system of the Environmental Projects Management Agency of Lithuania 67

Box 5.2. Committee for Control in Public Procurement in Poland 72

Box 5.3. OECD Recommendation of the Council on Public Procurement: Evaluation $\quad 75$

Box 5.4. Excel spreadsheet of individual public procurement procedures in Mexico 77

Box 5.5. Market price list of the Lithuanian European Social Fund Agency 81

Box 5.6. OECD Recommendation of the Council on Public Procurement: Capacity 84

Box 5.7. Promotion of public procurement for innovation by the National Centre for Research and

Development of Poland under the ESIF R\&I programme

Box 5.8. Methodological document for public procurement for innovation prepared by the Ministry of Economy 91 Box 5.9. Methodological assistance provided by the Public Procurement Office of Poland for public procurement for innovation 


\section{Executive summary}

Sustainable growth is increasingly dependent on the capacity of economies to innovate and transform, adapting to an ever-changing and more competitive environment. This incentivises countries to devote greater efforts to create ecosystems that encourage innovation. The European Commission (EC) is allocating significant funds to European Union (EU) member states to support this endeavour.

The Slovak Republic receives one of the largest shares of the European Structural and Investment Funds (ESIF) as a percentage of GDP. It received EUR 15.32 billion from the ESIF over the programme period 2014-20, EUR 2.2 billion of which were allocated to the Operational Programme Research and Innovation (R\&l). Yet, investments in this programme will provide benefits to the extent they are effectively spent on projects that drive innovation in the country. However, the Slovak Republic ranks among the member states with the lowest absorption of R\&I ESIF. In 2017, administrative inefficiencies and irregularities resulted in further decommitments by the EC.

To support the Slovak Republic improve its ESIF absorption capacity in the context of the Operational Programme R\&I and avoid further decommissioning, this report analyses current practices related to the implementation of the ESIF in the Slovak Republic to identify bottlenecks across the entire project life cycle, from the preparation of calls and project selection stage through the public procurement stage. Prepared jointly by the OECD Public Governance, and Sciente, Technology \& Innovation Directorates, the analysis was carried out based on the current regulatory frameworks of ESIF administration and intensive fact-finding interviews with stakeholders, including the managing authority, intermediate bodies, audit institutions, the Public Procurement Office and beneficiaries. It also benchmarked Slovak practices against those of some EU member states.

\section{Key findings}

\section{Difficulties in call preparation, publication and execution}

- Pursuant to audit findings concerning inadequate evaluator selection by the Research Agency in 2017, all ESIF calls have been temporarily halted and implementation was significantly delayed. As of 2020 , progress in the absorption of funds has improved significantly. However, staff qualification, in particular knowledge about the realities of scientific research, remain a concern and two major long-term research calls under the auspices of the Research Agency were cancelled by the Ministry of Education, Science, Research and Sports.

- Much of the Ministry of Economy's support to beneficiaries derives from financial instruments which were launched to support small and medium-sized enterprises during the COVID-19 pandemic with flexibility granted by the EC. Compared to the benchmarking countries, which allocated $2-13 \%$ through financial instruments, the Slovak Republic's share of $28 \%$ is considerably higher. 


\section{Selection of evaluators}

- A bad reputation, increased qualification requirements and low remuneration have resulted in a lack of adequate evaluators. In addition, the workload in view of the time allotted to perform the work is often not realistic; in particular, the very long manuals have raised concerns.

\section{ITMS2014+}

- ITMS2014+, a central IT system of ESIF management, is not user-friendly and does not function as an effective data-collection system for measuring the performance of the ESIF implementation.

\section{Administrative burdens}

- High administrative requirements slow down progress in the administrative verification phase. These were increased in response to the 2017 audit findings and demand repetitive, multi-layer controls of small and medium-sized enterprise status and timesheets for employees, among others.

- The control system for ESIF-financed projects delays procurement processes due to the administrative burdens created by intensive ex ante and ex post controls and requirements for submitting the same documents for the different controls. Conflict of opinions among different stakeholders (managing authority, intermediate bodies, the Public Procurement Office, the audit authority, beneficiaries) further brings legal uncertainty on the control system.

- Both legislation and practice are further unnecessarily hindering the swift roll-out of procurement processes. It is mandatory to obtain two price quotations for determining the estimated value of the contract for a low-value procurement. While this is not mandated by the regulations, in practice, public procurement procedures with a single bid are cancelled.

\section{Public procurement for innovation}

- While internationally recognised as a powerful tool to create demand-driven innovation, public procurement for innovation (PPI) is not a common practice in the Slovak Republic, where very few examples of using PPI under ESIF-funded R\&I projects exist.

\section{Capabilities}

- Administrative staff are in part insufficiently prepared to handle research projects, in particular notably due to a lack of knowledge about the realities of scientific research and operational inefficiencies.

- Currently, no comprehensive capacity-building system exists for beneficiaries, yet they are central to the effective absorption of ESIF funds. Beneficiaries face challenges in understanding the legal framework, setting contract award criteria and implementing procurement processes.

\section{Key recommendations}


- As part of the evaluation of the specific objectives, an analysis into the achieved outcome of the financial instruments (loans, venture capital, pandemic aid loans) should be included. OECD experience shows that retaining $R \& I$ funding even in crisis situations supports the sustainable development of knowledge-based economies.

- Higher compensation could increase the supply of potential evaluators. Evaluation manuals should be simplified and shortened. Stricter evaluator selection criteria in response to the audit findings are justified, although some flexibility for niche areas could help increase the pool of suitable evaluators. Evaluation criteria should be as objective as possible and give weight to innovativeness.

- Effective communication and support for beneficiaries could help decrease failure rates in the administrative verification. To this end, pre-formatted documents and guidelines anticipating beneficiaries' needs are effective instruments. Communication should be electronic where feasible.

- ITMS2014+, the technological backbone of ESIF-funded projects, should be updated through an inclusive and user-centric approach.

- Administrative procedures could be simplified. For instance, timesheets should be reduced to key activities and personnel and include monthly remuneration rather than hourly wages. Document submission should be made electronically where feasible.

- Reviewing the overall control system of ESIF public procurement would be beneficial, with an evidence-based analysis on the trade-off between administrative burdens (cost and time) and transparency/effectiveness in preventing errors in public procurement. Documents shall be submitted once (e.g. only electronically through ITMS2014+). Collaboration among control and audit authorities could be further reinforced to share and harmonise different views.

- Consider the possibility of streamlining market research requirements, in addition to preparing reference price lists. Tenders where a single bid is received should not be cancelled as long as the situation is justified.

- Consider the possibility of setting a target for PPI implementation for ESIF R\&I projects through pilot projects and raising awareness on the benefits of PPI through more capacity-building opportunities for stakeholders.

- Staff training initiatives and internal control measures could improve processing capabilities considerably. While measures are in place in Slovak authorities, there appears to be room to improve effectiveness. More recently implemented training initiatives and control tools should be evaluated and applied to all relevant intermediate bodies and co-operating agencies where necessary.

- Structured capacity-building mechanisms for ESIF beneficiaries should be developed, including targeted training (e.g. induction sessions for beneficiaries), guidelines, manuals and a help desk. 


\section{Introduction}

The Slovak Republic represents one of the largest shares of the European Structural and Investment Funds (ESIF) among European Union (EU) member states. It received EUR 15.32 billion from the ESIF over the programme period 2014-20, EUR 2.2 billion of which were allocated to the Operational Programme Research and Innovation $(\mathrm{R} \& \mathrm{l}),{ }^{1}$ with the following priorities:

- support research, technological development and innovation

- enhance the competitiveness and growth of small and medium-sized enterprises (SMEs).

The expected impacts of the Operational Programme R\&l include increasing the share of enterprises engaging in research, development and innovation; increasing the share of SMEs in export and in the value added of the business sector; growth of employment overall, and in particular for researchers in enterprises.

The 2020 European Semester Slovakia country report ${ }^{2}$ notes that administrative inefficiencies in the administration of the R\&I ESIF implementation resulted in decommitments ${ }^{3}$ in 2017 and 2018. Identified inefficiencies include lengthy evaluation, selection and administrative procedures. The Slovak government reacted by merging the Operational Programme R\&I with the Operational Programme Integrated Infrastructure and thus avoided a further decommitment in 2019. Substantial improvements in the efficiency of the management and control system should follow to avoid an additional loss of ESIF earmarked for R\&l.

For this reason, the Slovak Republic requested support from the European Commission (EC) under the Structural Reform Support Programme (SRSP Regulation). The EC agreed to provide support to the Slovak Republic, together with the OECD in the area of management of EU funds, with the purpose of developing an Action Plan to improve the absorption of the ESIF for R\&I and avoid further decommitments of EU funds, for the programming period 2021-27.

The specific outcomes should be:

1. understand practices and problems in the absorption of the ESIF in the R\&I sector and identify areas for improvement

2. improve the management and implementation capacity of Slovak authorities for R\&I ESIF.

This report analyses current practices related to the implementation of the administration of the ESIF in the Slovak Republic in order to identify bottlenecks to implementing ESIF-funded projects across the entire project life cycle, from the preparation of calls and project selection stage to the public procurement stage.

\footnotetext{
${ }^{1}$ Precisely EUR 2204059380.

${ }^{2}$ https://ec.europa.eu/info/sites/info/files/2020-european semester country-report-slovakia en.pdf.

3 If a sum committed to a programme has not been claimed by the end of the third year following the programme's adoption, any unpaid money ceases to be available to that programme, i.e. it is "decommitted". 
The analysis was carried out based on extensive desk research of the current regulatory frameworks of the administration of the ESIF, intensive fact-finding interviews and questionnaires with various stakeholders from the following institutions: the Ministry of Transport and Construction as the managing authority; the Ministry of Education, Science, Research and Sports and the Ministry of Economy as the intermediate bodies; the Research Agency; audit institutions; the Public Procurement Office; and beneficiaries. The OECD organised three workshops with the presence of the EC and Slovak stakeholders in November 2020, February 2021 and April 2021 to update the progress of the project, including sharing key findings and presenting the draft action plan. It also benchmarked Slovak practices against those of the following EU member states: the Czech Republic, Estonia, Lithuania, Poland and Slovenia.

This report aims to assist the Slovak Republic in reforming the administration of the ESIF by providing tailor-made recommendations and an action plan. It will thus contribute to improving ESIF absorption capacity and avoid further decommissioning of R\&I ESIF under the programming period 2014-20 and for the new programming period 2021-27. 


\title{
1. Pertormance eftssir implementation in the Slovak Republic
}

\begin{abstract}
This chapter provides an initial evaluation of the performance of the implementation of the European Structural and Investment Funds (ESIF) in the Slovak Republic. It presents the overall budget allocations for the thematic objective of research and innovation (R\&l), followed by a European benchmark of implementation within this domain; a national benchmark of $R \& I$ compared to other thematic areas; and a detailed analysis within the Slovak $R \& I$ according to priority area and per call.
\end{abstract}

\subsection{EU budget allocations in research and innovation}

The European Union's (EU) ESIF is made up of five different funds through which EU financial support may be allocated to member states: 1) the European Regional Development Fund (ERDF); 2) the European Social Fund; 3) Cohesion Funds; 4) the European Agricultural Fund for Rural Development; and 5) the European Maritime and Fisheries Fund.

ESIFs are allocated across 11 thematic areas: R\&l; information and communication technologies; competitiveness of small and medium-sized enterprises (SMEs); low-carbon economy; climate change adaptation and risk prevention; environmental protection and resource efficiency; network infrastructure in transport and energy; sustainable and quality employment; social inclusion; educational and vocational training; and efficient public administration.

The thematic area of R\&l is one of the most supported objectives, accounting for one of the highest amounts of planned funds for the 2014-20 multi-annual financial framework. The total allocated budget amounts to almost EUR 59 billion, while EUR 56 billion have been determined to be eligible for spending 
as part of the selected projects. EUR 22.35 billion have been reported as disbursed as of 2020 (European Commission, 2021 $\left.{ }_{[1]}\right)$. The two instruments accounting for its total funding are the ERDF (94.5\%) and the European Agricultural Fund for Rural Development (5.5\%).

The Slovak Republic is one of the largest recipients relative to GDP of the ESIF for the thematic objective of R\&I. Figure 1.1 depicts ESIF allocation in R\&I for all EU countries (and the United Kingdom). Receiving funding amounting to $2.4 \%$ of GDP for the period 2014-20, the Slovak Republic is second only to Estonia, which receives $3.9 \%$ of its GDP for the same objective.

\section{Figure 1.1. Average European Structural and Investment Funds allocation, 2014-20*}

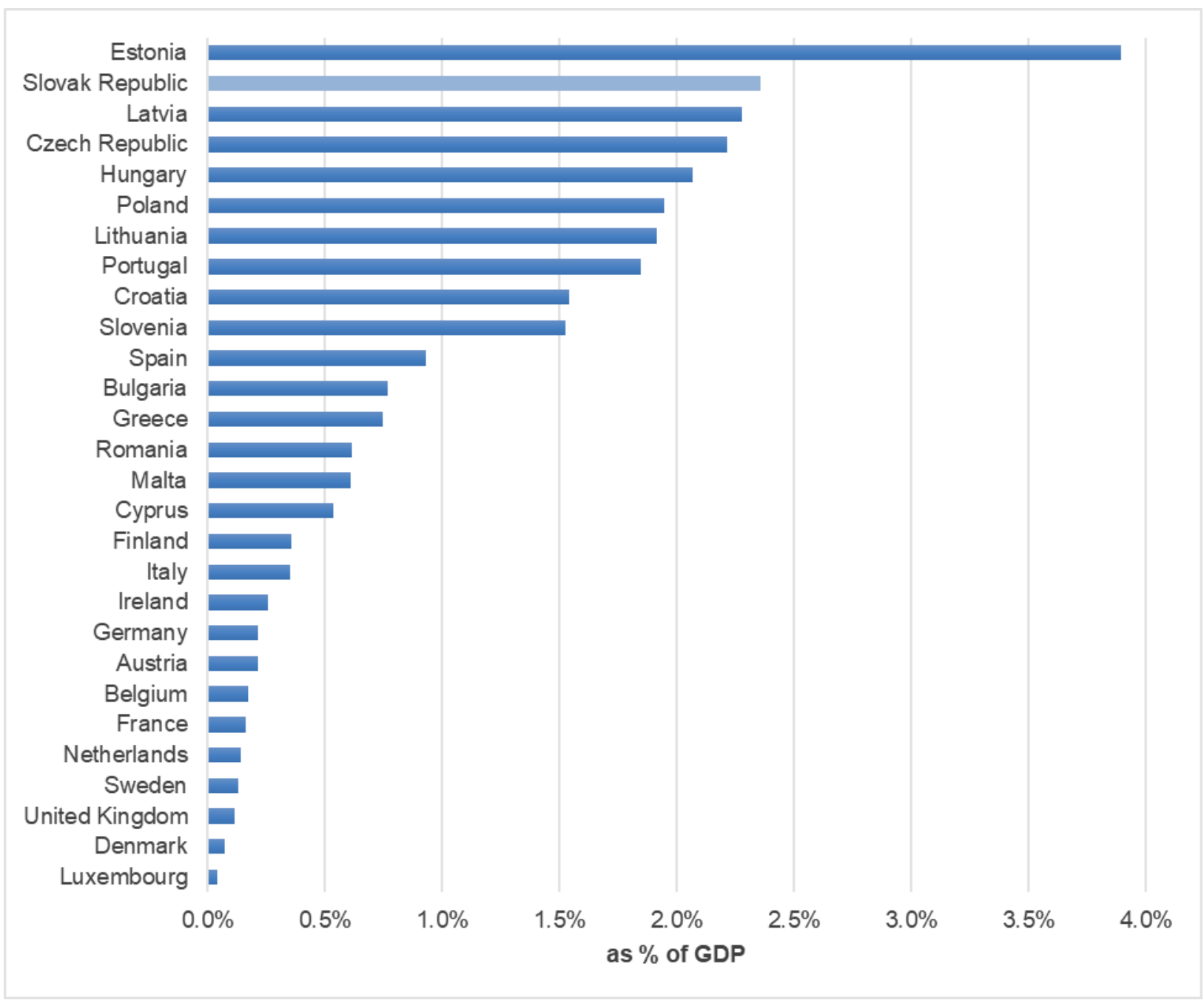

* Note by Turkey: The information in this document with reference to "Cyprus" relates to the southern part of the Island. There is no single authority representing both Turkish and Greek Cypriot people on the Island. Turkey recognises the Turkish Republic of Northern Cyprus (TRNC). Until a lasting and equitable solution is found within the context of the United Nations, Turkey shall preserve its position concerning the "Cyprus issue".

Note by all the European Union Member States of the OECD and the European Union: The Republic of Cyprus is recognised by all members of the United Nations with the exception of Turkey. The information in this document relates to the area under the effective control of the Government of the Republic of Cyprus."

Notes: The average GDP for 2014-19 was used as the denominator. The European Structural and Investment Funds allocation includes European Union funds and national co-financing.

Source: OECD calculations based on data from European Commission (2021 $\left.1_{[1]}\right)$. 


\subsection{Implementation within research and innovation by country}

The Slovak Republic scores very low in its financial implementation compared to other countries, as illustrated in Figure 1.2, which reports implementation by country per R\&I thematic allocation. According to the European Commission's ESIF financial implementation dataset, the three main budgetary voices are:

- planned: budget allocation for the programme

- decided: financial resources allocated to selected projects (approved for signature of contract)

- spent: total disbursement of funds. 
Figure 1.2. European Structural and Investment Funds implementation progress for research and innovation by country, 2014-20

As a percentage of planned funds

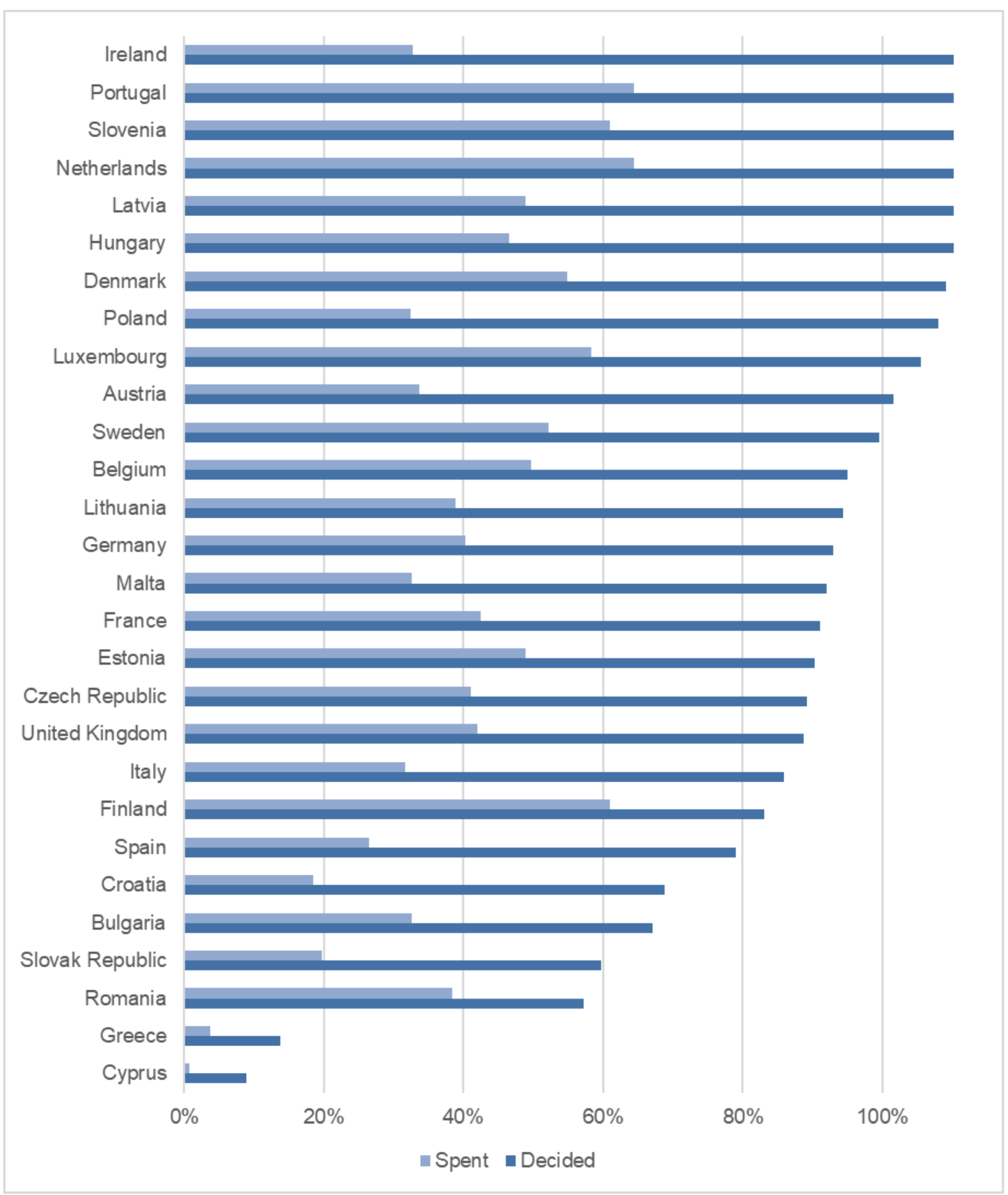

Source: European Commission (2020[2]).

The allocation of ESIF funds in the Slovak Republic significantly increased between June and December 2020. While in June around $60 \%$ of funds had been decided as a share of planned funds, the fourth-lowest allocation in the EU, six months later that number had risen to $85 \%$. This improvement is reflective of the 
considerable achievements in ESIF implementation in the Slovak Republic in 2020. A large portion of the outstanding funds has been contracted, and thus become available for spending. The funds spent as a percentage of planned funds amounted to $28 \%$ in December, which is relatively low on the whole, yet higher than where it stood in June (20\%), and will likely catch-up soon in correspondence to the fund allocations.

\subsection{Implementation in the Slovak Republic by thematic objective}

Projects within the R\&I thematic objective are financed under the ERDF. Nevertheless, overall implementation remains low.

Figure 1.3 illustrates the weighted average of allocated funds as a percentage of the planned resources across the thematic objectives in the Slovak Republic. Progress in 2020 means that performance for the thematic objective of R\&I is no longer lower than the other ones. This contrasts to the situation in June 2020 , when R\&I was the objective with the lowest absorption. In spite of this progress, with much of the spending yet to occur, R\&I implementation measured in spending as a share of planned resources is low compared to the other thematic areas. On average, only $20 \%$ of the planned budget had been realised as of December 2020. This represents a significant underperformance, with adverse effects amplified by the fact that the Slovak Republic receives the second-highest share of the ESIF, as mentioned above. However, as is elaborated throughout the report, relatively swift catch-up in spending is expected.

Figure 1.3. European Structural and Investment Funds implementation progress across thematic objectives in the Slovak Republic

As a percentage of planned funds

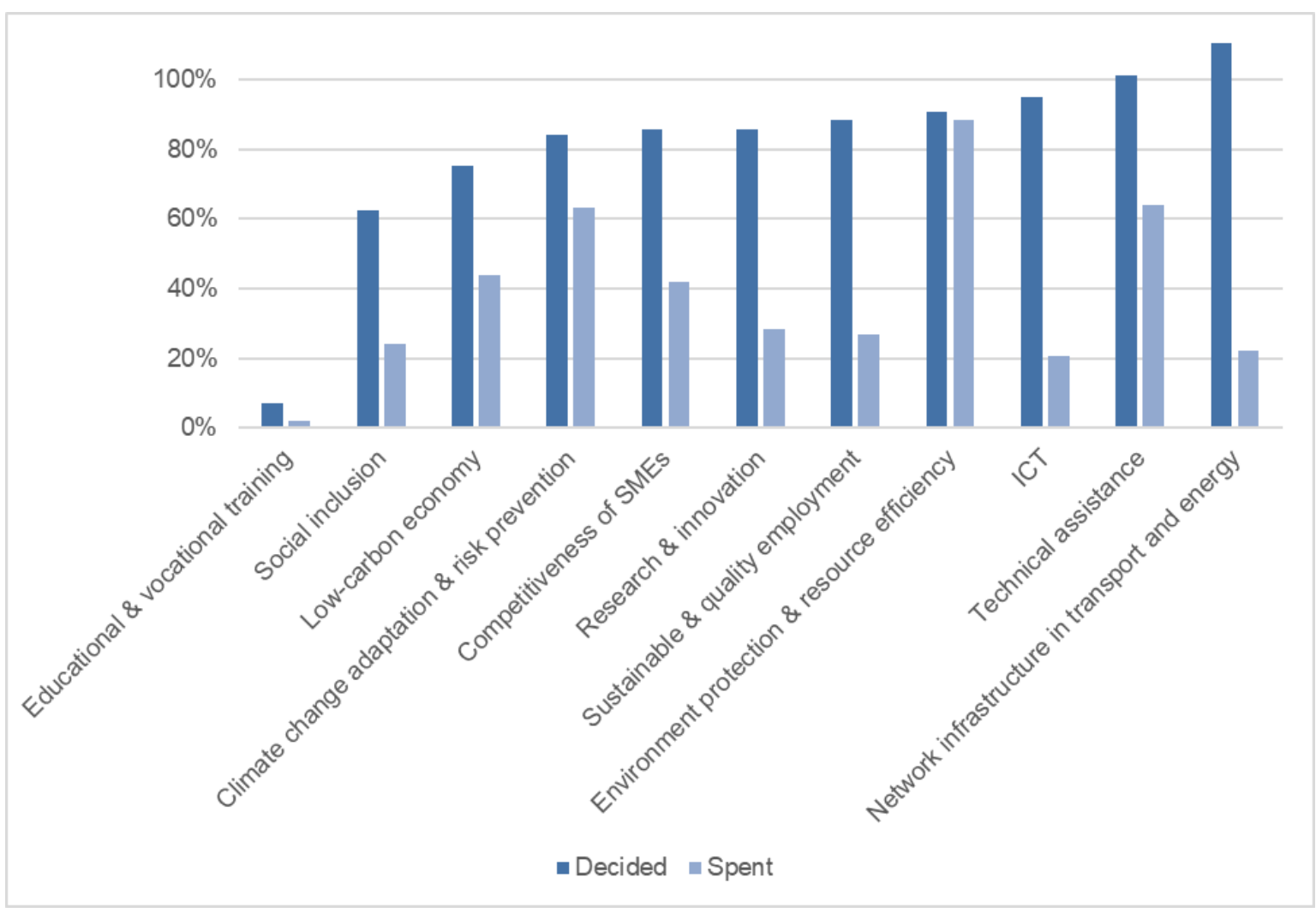

Note: SME: small and medium-sized enterprise; ICT: information and communication technology.

Source: OECD calculations based on data from European Commission (2020[2]). 


\subsection{Analysis of implementation within the research and innovation thematic area in the Slovak Republic}

Following irregularities in ESIF implementation processes which resulted in significant delays, the Slovak Republic's ESIF system was confronted with decommitments of funds in 2017 and 2018. In agreement with the European Commission, it was decided that as of 13 December 2019, the Operational Programme (OP) Research and Innovation would be merged with the OP Integrated Infrastructure. This was an attempt to avoid any further decommitments, as the merging of the OPs effectively meant that together, sufficient resources had been contracted.

Within the OP Integrated Infrastructure, ESI funds are allocated according to several investment priorities as defined by Specific objectives 9-13. Most of the funds have already been contracted, and the focus is now on the actual implementation of the signed contracts, public procurement and disbursement of funds. Specific objective 9.5 (previously Priority axis 9.2) was the most problematic one in terms of the outstanding volume of funds that remained to be contracted and spent. However, as explained in Chapter 4 of this report, absorption of most remaining calls has progressed, and some calls were cancelled.

The gaps between planned, decided and spent funds are illustrated in Figure 1.4 for a few calls within Specific objective 9.5, which had previously exhibited particularly slow drawdown of funds. Most of the calls in this area were delayed. The calls with the highest amount of spending to be contracted are: innovation and technology transfer; industry for the 21st century; and smart innovation in industry.

\section{Figure 1.4. Distribution of funds for calls in Specific objective 9.5}

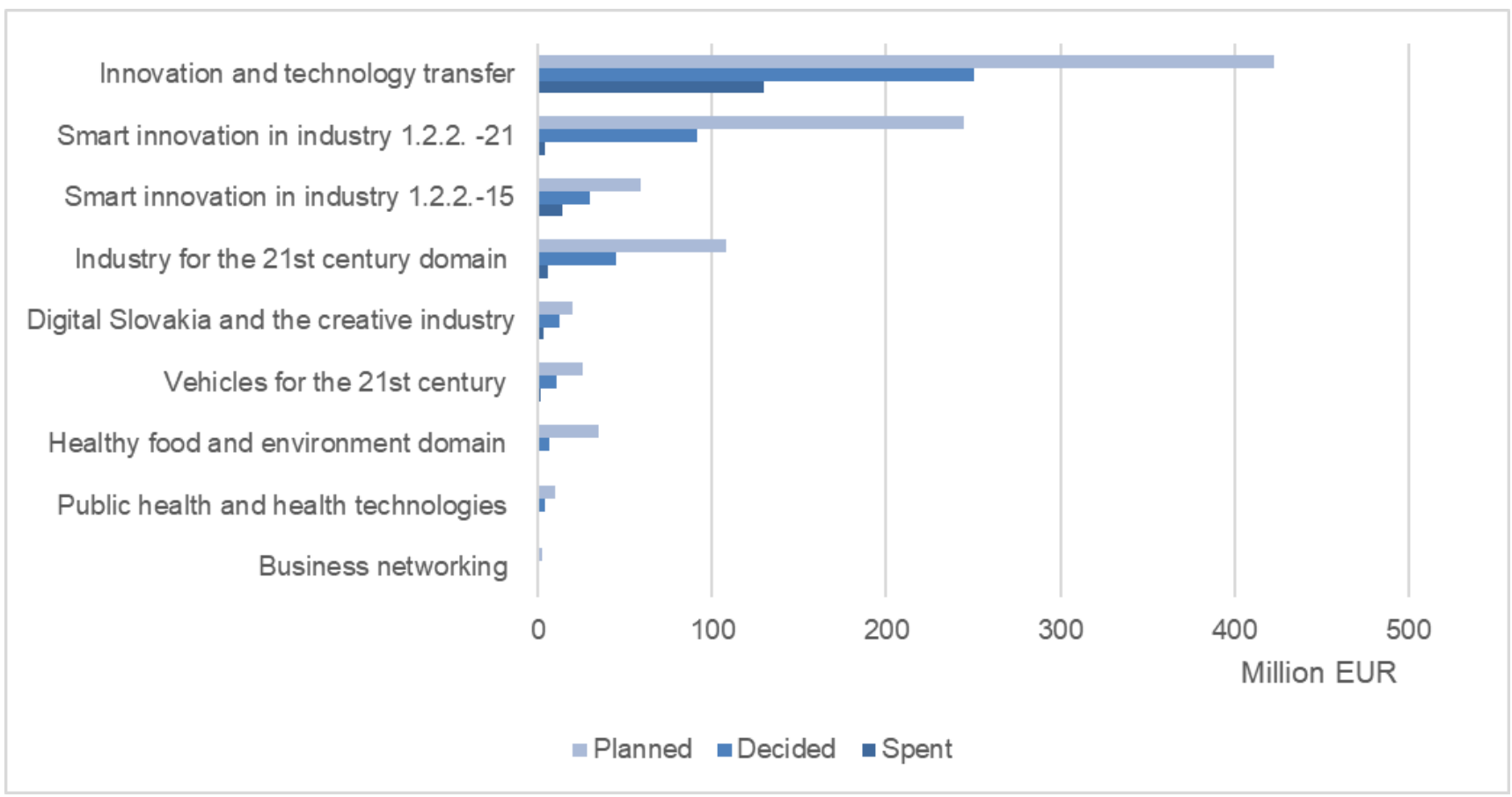

Source: Based on data from the Ministry of Economy, February 2021.

While all of these calls of the Ministry of Economy still show relatively low spending as a share of planned funds, the prevalent discrepancy can be explained through reallocation of the outstanding funds to other launched calls. This is because in many cases, beneficiaries refrained from signing contracts because of other forms of finance becoming available or the project no longer being market relevant and thus no longer pursued. In addition, for many of the calls, the absorption capacity was smaller than planned or the projects 
started with their R\&D phase, which is typically not as cost-intensive as the later stages of equipment acquisition, which sees more drawdown of funds.

For an analysis of the low ESIF implementation within the R\&I objective, Figure 1.5 illustrates the progress of the contracting procedure for closed calls as at November 2020, according to the date of the closing. According to the guidelines for applicants, the deadline for issuing a decision on the outcome of the application is 70 working days after the closure of the respective evaluation round of the call. Figure 1.5 shows that, while a certain number of calls had been fully contracted, a significant number of them were still far from this objective in November, more than a year after the closure.

Figure 1.5. European Structural and Investment Funds implementation per call

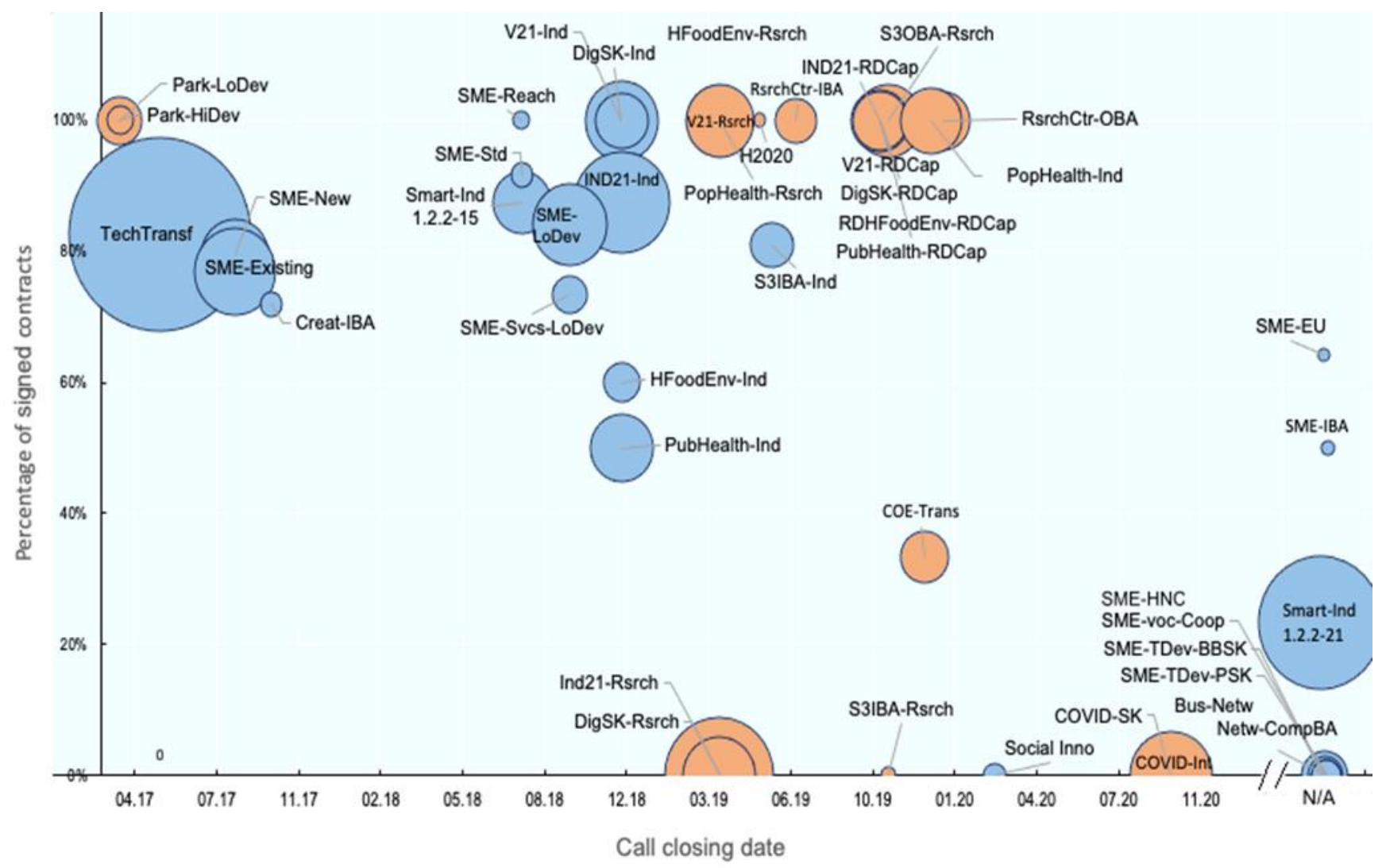

Notes: The percentage of signed contracts is computed as the number of signed contracts in November 2020 divided by all contracts which potentially could be signed, i.e. those which had been received and not yet rejected. The horizontal axis shows the call closing date. Open calls are marked as N/A.

Bubble size is proportional to fund allocation in a specific call. Blue symbols correspond to calls by the Ministry of Economy and orange symbols to calls by the Research Agency.

Bus-Netw: business networking

COE-Trans: centres of excellence of transnational importance - II. stage

COVID-Int: the participation of Slovak research institutions in international research projects aimed at combating the COVID-19 pandemic

COVID-SK: the mobilisation and use of the potential of research institutions in combating the COVID-19 pandemic and reducing the negative effects of the pandemic

Creat-IBA: small and medium-sized enterprises in the field of creative industries in the Bratislava region

DigSK-Ind: innovation through industrial research and experimental development within the domain Digital Slovakia and the creative industry IBA: innovation through industrial research and experimental development in all RIS3 SK domains in the Bratislava region

DigSK-RDCap: research and development capacities in the field of Digital Slovakia and the creative industry

DigSK-Rsrch: long-term strategic research - Digital Slovakia and the creative industries

H2020: international research projects approved under the Horizon 2020 programme

HFoodEnv-Ind: innovation through industrial research and experimental development under the healthy food and environment domain 
HFoodEnv-RDCap: research and development capacities in the field of healthy food and the environment

HFoodEnv-Rsrch: long-term strategic research - Healthy food and the environment

IND21-Ind: innovation through industrial research and experimental development under the industry for the 21st century domain

IND21-RDCap: research and development capacities in the field of industry for the 21st century

IND21-Rsrch: long-term strategic research - Industry for the 21st century

Netw-CompBA: networking of companies in the Bratislava region

Park-HiDev: phased projects of university science parks and research centres (Phase II) for a more developed region

Park-LoDev: phased projects of university science parks and research centres (Phase II) for less developed regions

PopHealth-Ind: the systemic public research infrastructure in the domain of population health and health technologies

PopHealth-Rsrch: long-term strategic research - Population health and health technologies

PubHealth-Ind: innovation through industrial research and experimental development under the domains of public health and health technologies

PubHealth-RDCap: research and development capacities in the field of public health and health technologies

RsrchCtr-IBA: team research centres in the Bratislava region

RsrchCtr-OBA: team research centres outside the Bratislava region

S3IBA-Ind: innovation through industrial research and experimental development in all RIS3 SK domains in the Bratislava region

S3IBA-Rsrch: the mobilisation of excellent research teams in the areas of specialisation RIS3 SK in the Bratislava region

S3OBA-Rsrch: the mobilisation of excellent research teams in the areas of specialisation RIS3 SK outside the Bratislava region

Smart-Ind 1.2.2-15/22: smart innovation in industry

SME-EU: involvement of small and medium-sized enterprises in EU programmes

SME-Existing: existing micro, small and medium-sized enterprises

SME-HNC: the development of small and medium-sized enterprises within the European Commission's initiative aimed at the transformation of the Horná Nitra coal region

SME-IBA: involvement of small and medium-sized enterprises in the Bratislava region

SME-LoDev: small and medium-sized enterprises in the least developed districts

SME-New: new and start-up micro, small and medium-sized enterprises

SME-REACH: the raising of performance and functionality standards for micro, small and medium-sized enterprises through the implementation of REACH

SME-Std: the raising of performance and functionality standards for micro, small and medium-sized enterprises

SME-Svcs-LoDev: micro, small and medium-sized enterprises operating in the field of service provision in the least developed districts

SME-TDev-BBSK: small and medium-sized enterprises within the endogenous potential of tourism development in selected regions of the Banská Bystrica self-governing region (BBSK) within the EC Catching-up regions Initiative

SME-TDev-PSK: small and medium-sized enterprises within the endogenous potential of tourism development in selected regions of the Prešov Self-Governing Region (PSK) within the EC Catching-up Regions Initiative

SME-voc-Coop: the development of small and medium-sized enterprise entrepreneurship and co-operation with secondary vocational schools Social Inno: the implementation of social innovation in the small and medium-sized enterprise environment

TechTransf: innovation and technology transfer

V21-Ind: innovation through industrial research and experimental development within the field of vehicles for the 21st century

V21-RDCap: research and development capacities in the field of vehicles for the 21st century

V21-Rsrch: long-term strategic research - Vehicles for the 21st century

Source: OECD analysis based on data from the Ministry of Economy and the Research Agency, November 2020.

Already in November 2020, the Research Agency had most of its calls fully contracted, with the two most significant ones with huge delays being the long-term strategic research calls ("Industry for the 21 st century" and "Digital Slovakia"). The two long-term strategic research calls were cancelled by the Ministry of Education, Science, Research and Sport in January 2021, in particular due the high risk of projects not being completed before the end of 2023 and to support companies during the COVID-19 crisis and its economic impacts. Of the EUR 120 million becoming available due to these cancellations, around EUR 100 million have been reallocated to the Ministry of Economy and its Anti-Corona Guarantee schemes. The remaining EUR 20 million were attributed to a recent call for research projects to combat COVID-19, which is also still in process, but this is also acceptable since the call only closed in the autumn of 2020.

With regard to the Ministry of Economy, the only call that had not been contracted in November 2020, "Social innovation in SME environment" has since been cancelled. This was due to the high absorption capacity of the SIHAZ scheme's financial instruments explained in Chapter 4. In addition, this was a pilot call in Priority axis 11 and the conclusion was that most projects were out of the scope of this call, i.e. they did not support social innovation. 
Most of the Ministry of Economy's calls have been closed and the funds have been reallocated. A lot of the reallocations took place in late 2020 and 2021, in large part from the problematic Specific objective 9.5 and towards Specific objectives 11 and 12, which has meant the diversion of funds towards Anti-Corona Guarantee schemes. As discussed later in this report, the objective was to support SMEs in an uncertain market to enable them to continue with their business activities, although without the requirement that these activities promote innovation. Within the OP Integrated Infrastructure, the Ministry of Economy supports the European Commission's thematic objective of R\&I within the Smart Specialisation Strategy, as well as the thematic objective of support for SMEs. The 2020 reallocations were directed towards support for SMEs, which previously had a requirement to involve projects in process or product innovation. However, due to the crisis, this requirement has been lifted. Altogether, significant amounts of funds from the Ministry of Economy; the Ministry of Education, Science, Research and Sport; and the Ministry of Environment were distributed through these financial instruments.

Two new calls have been launched, with one in the field of value chains for batteries. The R\&D phase will be supported in the ongoing programming period and the second phase in the next period. Both the Ministry of Education, Science, Research and Sport and the Ministry of Economy will plan with allocation towards these multi-annual projects out of the Structural Funds. In addition, the Ministry of Economy will be engaged in supporting foreign investments and existing domestic investors innovating in industry as part of another call. 


\section{The European Structural and Investment Funds' implementation ecosystem}

This chapter describes the key stakeholders and regulatory frameworks related to the implementation of the ESIF-funded research and innovation $(R \& I)$ projects in the Slovak Republic. Sound regulatory and institutional frameworks are essential for project implementation. The chapter describes the institutional frameworks and regulatory frameworks in the implementation of the ESIF projects across the entire ESIF project life cycle. It also describes different types of calls in the Operational Programme Integrated Infrastructure (OPII). 
Sound regulatory and institutional frameworks are essential for project implementation. If poorly designed and managed, with amplifying factors such as lack of professional skills and competences, they can negatively affect the smooth implementation of projects, causing unnecessary delays or overruns. This chapter describes the key stakeholders and regulatory frameworks related to the implementation of the ESIF-funded research and innovation (R\&l) projects in the Slovak Republic as well as different types of calls in the Operational Programme Integrated Infrastructure (OPII).

\subsection{Institutional framework}

Figure 2.1 depicts the institutional framework through which the disbursement of the ESIF is planned, co-ordinated and managed in the Slovak Republic.

Figure 2.1. Institutional framework for the implementation of European Structural and Investment Funds in the Slovak Republic, November 2020

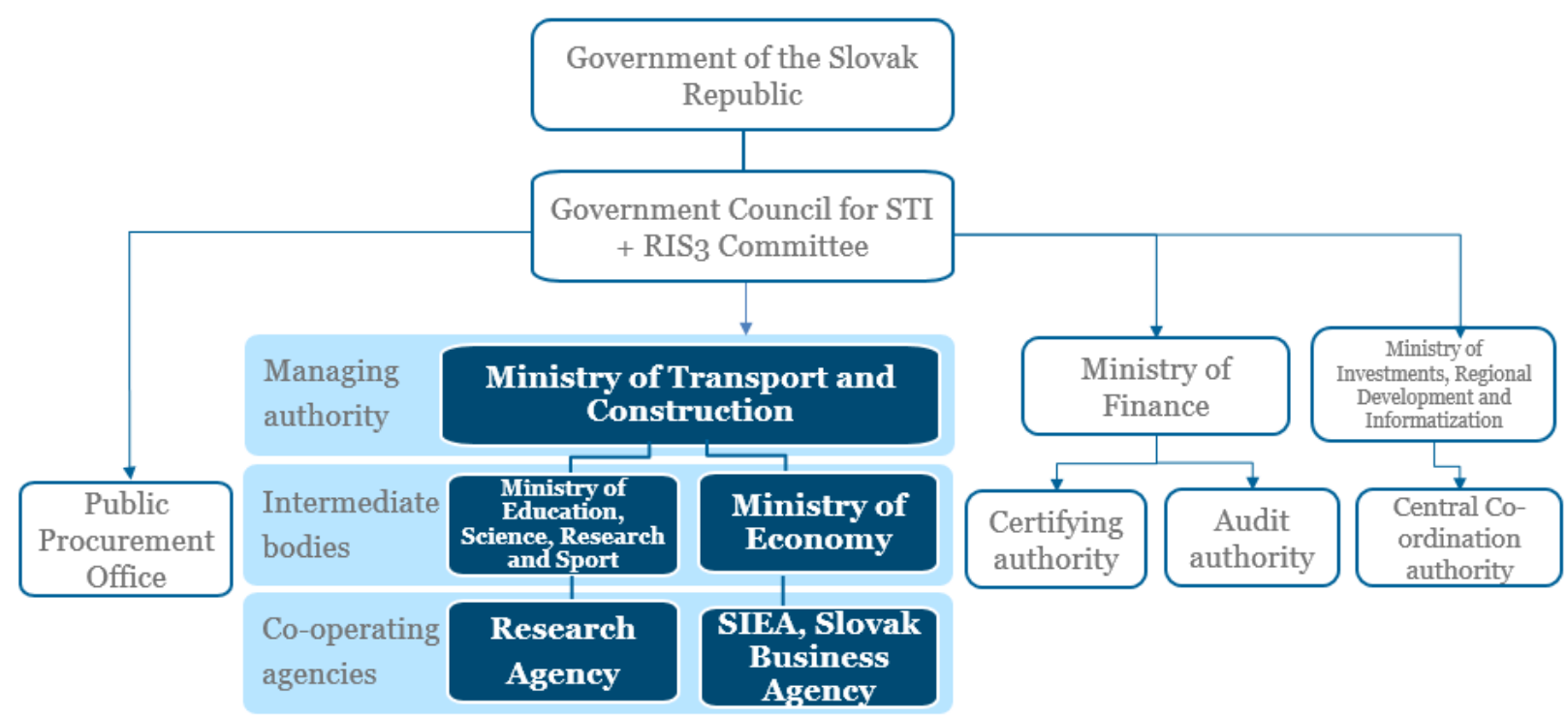

Source: $\mathrm{OECD}$, based on interviews.

The Slovak government delegates responsibilities across various bodies, designating the responsibilities and roles of the managing authority and the intermediate bodies, as well as the financial unit. Further, the approval of operational programmes, partnership agreements and the management system falls under the government's competencies. In July 2020, the government decided to establish the new Ministry of Investments, Regional Development and Informatization (MIRRI), which will act as the managing authority for the new programming period 2021-27. For the remainder of the current programming period, it replaces the Deputy Prime Minister's Office for Investments and Informatization as the central public authority for the management and supervision of European Union (EU) funds.

Through its central co-ordination authority (CCA), MIRRI sets the relevant ESIF rules and oversees the entire implementation system. It is also part of the Monitoring Committee. As such, the CCA drafts the requirements for the publication of calls in accordance with the Smart Specialisation Strategy, and is involved in the final approval of draft calls. Its role during the evaluation phase entails monitoring and evaluating progress and the fulfilment of set goals within the operating programme (OP). Subsequently, it 
provides methodological guidance, co-ordinates relevant implementing bodies, and controls adherence to the binding plan on financial and other outcomes.

The Ministry of Finance is also part of the Monitoring Committee, which is the main authority regarding the supervision and evaluation of the implementation of the OP. Its main competencies lie in audits to detect possible financial correction, the verification of costs and the certification of expenses through its two main authorities:

- The certifying authority $(C A)$ verifies expenditures submitted to the $C A$ in the summary payment request and certifies the reliability of the expenditures prior to the declaration to the European Commission (EC). Additionally, the CA carries out in-depth verification of selected expenditures on the level of the managing authority or intermediate bodies, including verification of the processes enacted by the above-mentioned bodies.

- The audit authority is engaged in the ex post control of expenditures, i.e. after the expenditures have been declared to the EC, as the primary external control body of ESIF funds. This renders the audit authority effectively as the last instance of control in the process. System audits are performed to ensure the effective functioning of the ESIF Management System, while operational audits are oriented to specific ESIF projects in order to identify possible irregularities and eventual financial corrections.

The Slovak Government Council for STI constitutes an expert and advisory group, which serves as the initiating and co-ordinating arm of the Slovak government in the field of science, technology and innovation. Its adjoined Committee for the Smart Specialisation Strategy (RIS3) works under the MIRRI to ensure the achievement of strategic objectives defined as part of the RIS3 strategy.

The subset illustrated in Figure 2.1 forms the core framework of institutions directly involved in the process, from call preparation to implementation. The managing authority is the Ministry of Transport and Construction (MoTC). It leads consultations with the EC and co-ordinates the meetings of the Monitoring Committee. In addition, the managing authority controls the competences delegated to the intermediate bodies and gathers their inputs on the progress of the implementation process for the annual report.

The roles of the Ministry of Education, Science, Research and Sport (MoESRS) and the Ministry of Economy as intermediate bodies entail the preparation and publication of the call and the schedule thereof as well as of national project ideas. Furthermore, the ministries hold key functions in setting the criteria for grants and the evaluation process in addition to the monitoring of progress and cost eligibility, the contracting of beneficiaries, and project and financial management. The intermediate bodies are responsible for supervising the implementation of pubic procurement projects and carrying out public procurement control under the ESIF-funded R\&l projects. The intermediate bodies' mandates are delegated and entrusted by the managing authority.

The Ministry of Economy has two supporting functions. The first regards research, development and innovation (RDI) projects, which is similar to the MoESRS' projects, but entails a greater emphasis on the innovative part of the productive processes. Second, it provides support for small and medium-sized enterprises (SMEs), which consists of three instruments, namely: 1) grants, which vary in size; 2) non-financial support (about $10 \%$ of all allocations) provided by the Slovak Innovation and Energy Agency (SIEA); and 3) the Slovak Business Agency, in the form of counselling, training and acceleration programmes. In addition, the Slovak Investment Holding allocates significant amounts through financial instruments, including guarantees, loan instruments and risk capitalisation assets. Examples include support for co-operation between businesses and R\&D institutes to strengthen collaborative innovative activities and private spending on R\&D (2013) and support for SMEs by ensuring the feasibility of innovative solutions aimed at building smart cities in the Slovak Republic (2018).

Both intermediate bodies collaborate with their respective co-operating agencies. The Research Agency provides support to the MoESRS in preparing and publishing calls and national project ideas. For the 
preparation of the related call schedules, it is responsible for delivering the R\&I part. The Research Agency is furthermore responsible for project and financial management, the contracting of beneficiaries, setting the criteria for evaluation and selecting evaluators, monitoring progress, and controlling cost eligibility.

Correspondingly, the Ministry of Economy co-operates with the SIEA, which provides support for the same activities as the Research Agency, although the Research Agency focuses on technology and innovation projects as opposed to $R \& I$.

Under the ESIF-funded projects, the Public Procurement Office (PPO) controls public procurement procedures, especially during the tender phase before signing the contract, of the goods and services whose estimated value is above EUR 600000 , as well as of construction work whose estimated value is above the threshold of an above-limit contract (EUR 5.35 million in 2020). In the current programming period, the MoTC is fully responsible for confirmig expenditures and procurement. It is expected that these competences will be delegated to the PPO in the next programming period to ensure compliance with the Public Procurement Act. For this purpose, the PPO will mostly obtain staff from the intermediate bodies. It will further be responsible for methodological explanations, while discussions are ongoing about whether the PPO will also be in charge of legislation regarding procurement aspects.

The Supreme Audit Office (NKU) performs controls on all national public bodies and all public expenditures, including ESIF funds, reviewing procurement procedures for compliance with the regulatory frameworks and issuing recommendations to the PPO.

The Antimonopoly Office is an independent oversight institution related to the competition of the public procurement process. Its main responsibilities include investigating bid rigging and cartels. Under the ESIF-funded projects, the Antimonopoly Office acts in accordance with the CCA methodological Guideline No. $35 ",{ }^{4}$ which sets up the risk indicators for possible infringements of the competition protection rules. Accumulation of specific indicators in the public procurement process indicates an increased risk of the possible violation of Act No. 136/2001 Coll. on the protection of competition. In addition to the accumulation of specific indicators, the request for co-operation depends on the estimated value of the contract or the total value of the relevant contracts that shall be more than EUR 100000 excluding value-added tax.

The European Anti-fraud Office is the only EU body mandated to detect, investigate and stop fraud of EU funds. It carries out independent investigations into fraud and corruption involving EU funds, including ESIF funds.

Beneficiaries (or contracting authorities) are the legal entities, usually businesses, government authorities (e.g. line ministries, agencies or municipal governments, etc.), non-governmental organisations or universities which apply for and can receive ESIF funds. They are in charge of carrying out the public procurement processes which are subject to control by the intermediate bodies.

Figure 2.2 maps out the key actors involved in the public procurement process under ESIF projects.

\footnotetext{
${ }^{4}$ Co-operation with the Antimonopoly Office in the field of public procurement control and the procedure of the managing authority in identifying a possible violation of the rules to protect competition or its violation within the control of public procurement.
} 
Figure 2.2. Key actors involved in the public procurement process under ESIF projects

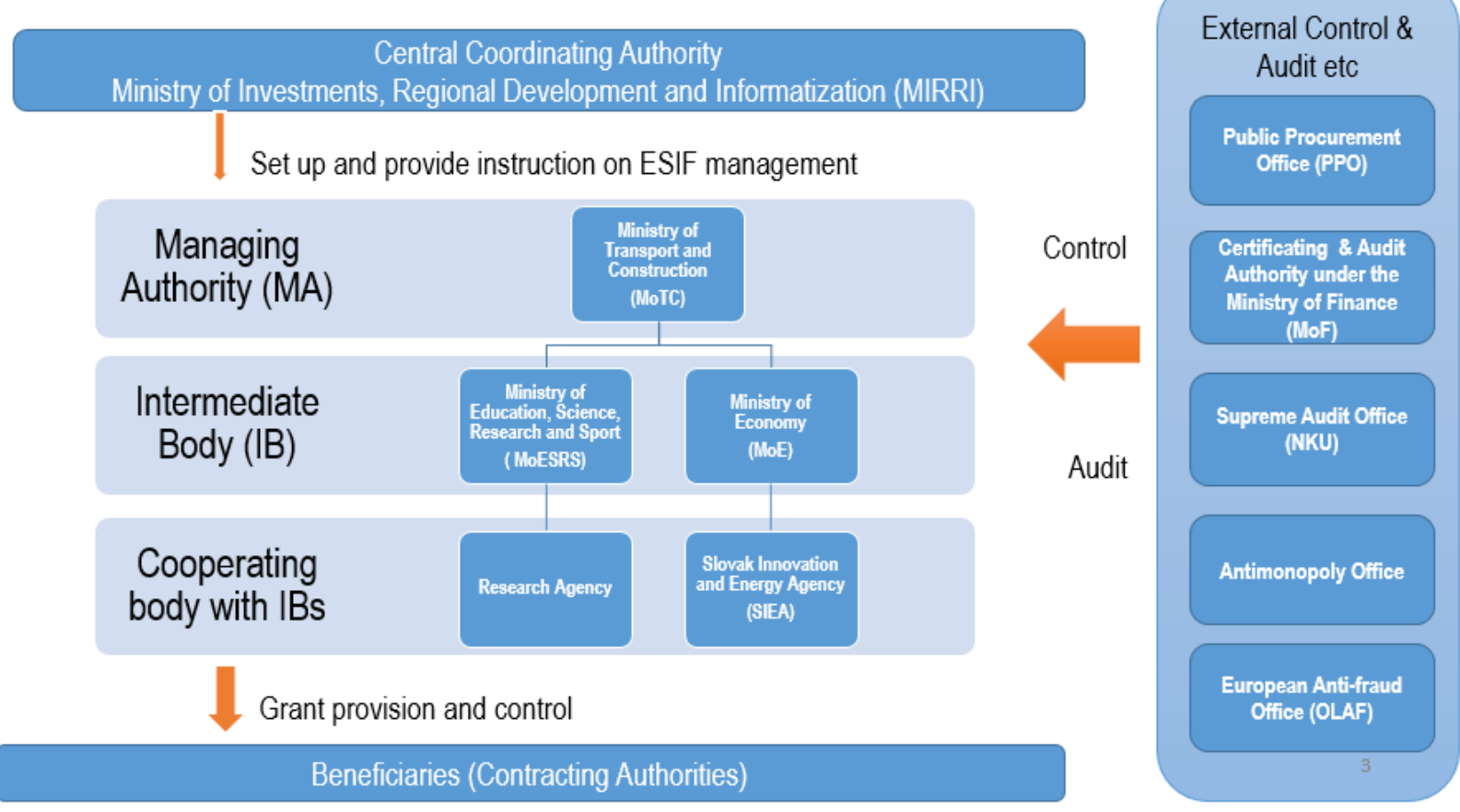

For the next programming period, as mentioned above, the Slovak government has decided in conjunction with the European Commission to delegate responsibility to one managing authority (MIRRI) for this OP. More specifically, envisioned changes include reducing the number of intermediate bodies in the overall ESIF ecosystem. There are 35 in the current programming period. The proposal foresees the inclusion of the Ministry of Economy, the MoTC, the MoESRS, the Ministry of Environment and the PPO. The objective of the new framework is to spur the efficacy of the process by concentrating the best human resources in a few bodies.

Box 2.1 showcases the institutional set-up of Estonia and the Czech Republic. In Estonia, the involvement of fewer intermediate bodies and co-operating agencies has effectively meant fewer frictions and misunderstandings regarding procedures and delegation of responsibilities. As described below, for instance, co-operation between the Ministry of Economy and the Slovak Innovation and Energy Agency has not been as productive in the past as it could have been. For the next programming period, the intended changes of reducing co-operation with the SIEA and concentrating responsibilities and capabilities in one organisational unit may have similar positive effects in this regard.

\section{Box 2.1. Comparing the institutional framework around ESIF implementation with the Czech Republic and Estonia}

\section{Estonia}

In Estonia, there were originally eight intermediate bodies and implementing agencies. However, in an effort to optimise efficiency, the Estonian government undertook a reform in 2018 to merge several of these individual bodies. One of them, the State Shared Serviced Centre, was merged with four intermediate bodies and carries most responsibilities as managing authority now. It works under the Ministry of Finance, which is in charge of planning and monitoring activities only and which also includes the Steering Committee and the roles of the central co-ordination authority. ${ }^{*}$ 
This reform reportedly had significant positive outcomes for the European Structural and Investment Funds (ESIF) landscape in Estonia, as procedures, delegation and control of responsibilities were reduced. The involvement of fewer bodies means that the implementation of funds is now faster, because there are fewer misunderstandings regarding laws and regulations. In addition, communication with beneficiaries considerably improved, as the number of contact authorities is reduced.

\section{Czech Republic}

The overall ESIF set-up is more horizontal than vertical and merging operational programmes into a single one met active resistance, and this effectively means that ministries are in charge of the subsidies related to their designated field, i.e. subsidies for education are handled by the Ministry of Education. This offers the advantage that policy makers, who are knowledgeable in their area of expertise, are also responsible for European funds in their field, so that factual and process knowledge are combined and the overall process becomes more flexible to manage and thus more efficient. It further alleviates the duplication or fragmentation of tasks and capacities. Having the policy side and the fund working together and in close collaboration with beneficiaries allows their needs to be adequately addressed and targets to be specified.

* State Shared Service Centre, response to questionnaire, 2021.

Source: Responses to OECD questionnaire, 2021.

The Czech experience demonstrates how close collaboration with beneficiaries can pay off; however, the structural set-up is different and not necessarily comparable to that of the Slovak Republic, as each ministry is in charge of the OP related to its expertise. Nevertheless, it is important to recognise that if intermediate bodies' personnel has policy experience, in particular when they are knowledgeable about the realities of scientific research in the respective field, it is a significant advantage for the collaboration between intermediate bodies and beneficiaries.

\subsection{Regulatory framework}

Overall, ESIF administration is governed by the ESIF Management System (the latest version No. 0 issued on 18 November 2020), which sets up the specific rules applied to the implementation of ESIF-funded projects. The ESIF regulatory framework is set out by the central co-ordination authority (Ministry of Investments, Regional Development and Informatization).

Public procurement procedures under ESIF projects are governed by multiple regulations. The Public Procurement Act (Act No. 343/2015 Coll.), hereinafter referred to as the PPA, governs the public procurement system in the Slovak Republic. The latest amendment has been effective since 27 March 2020 , followed by related regulations and methodical guidance. The PPA also governs the procurement procedures carried out for the implementation of ESIF projects.

In addition to the PPA, the central co-ordination authority sets the specific rules applied to the implementation of ESIF-funded projects with the ESIF Management System mentioned above and a number of methodological guidelines (37 in total) about the ESIF Management System. These documents set the institutional and regulatory framework of ESIF projects as well as the common rules, procedures and monitoring mechanisms in a recipient country. 
Table 2.1. Methodological guidelines related to public procurement issued by the central co-ordination authority

\begin{tabular}{|c|c|c|c|}
\hline No. & Version & $\begin{array}{l}\text { Effective } \\
\text { date }\end{array}$ & Title \\
\hline 5 & 6 & $10 / 31 / 2020$ & $\begin{array}{l}\text { To determine the financial corrections applied by the managing authority in the event of non-compliance with } \\
\text { public procurement rules and procedures }\end{array}$ \\
\hline 12 & 8 & $10 / 31 / 2020$ & To award contracts falling under the Public Procurement Act \\
\hline 13 & 4 & $10 / 31 / 2018$ & To assess conflicts of interest in the public procurement process \\
\hline 14 & 8 & $10 / 31 / 2020$ & For the award of contracts with a low value above EUR 50000 \\
\hline 18 & 5 & $10 / 31 / 2019$ & To verify the cost-effectiveness of expenditure \\
\hline 35 & 2 & $4 / 30 / 2020$ & $\begin{array}{l}\text { Co-operation with the Antimonopoly Office in the field of public procurement control and the procedure of the } \\
\text { managing authority in identifying a possible violation of the rules of protection of competition or its violation within } \\
\text { the control of public procurement }\end{array}$ \\
\hline 36 & 3 & $10 / 31 / 2020$ & To control contracts awarded on the basis of a framework agreement and within a dynamic purchasing system \\
\hline
\end{tabular}

Source: Based on Central Coordination Authority (n.d.[3]).

The Ministry of Economy and the MoESRS, under the capacity of intermediate bodies, also produce their own guidelines on public procurement for their beneficiaries. These guidelines are prepared and updated in accordance with the provisions stipulated in the PPA, the ESIF Management System and the methodical guidelines on public procurement set out by the central co-ordination authority. For example, the Ministry of Economy transposed these principles and procedures into the "Guideline on the public procurement process for demand-driven projects and national projects of the Operational Programme Integrated Infrastructure under the Ministry of Economy of the SR" (the latest version effective since November 2020) (Ministry of Economy, 2016[4]]). This guideline also includes some sample forms for the benefit of beneficiaries, such as:

- calculating the estimated value of the contract, including a sample of the market research record (used in the pre-tender process)

- minutes from the evaluation of the selection criteria

- minutes from the evaluation of the tenders

- the market research record (used in the tendering process).

The guidelines of these two intermediate bodies differ only in some aspects, such as examples of good practices, a list of tips and recommendations, putting in place the requirements to beneficiaries in order to eliminate the possible occurrence of irregularities or fraud.

Figure 2.3 illustrates the regulatory frameworks that govern public procurement procedures under the ESIF-funded projects. 
Figure 2.3. Regulatory frameworks governing public procurement under ESIF projects

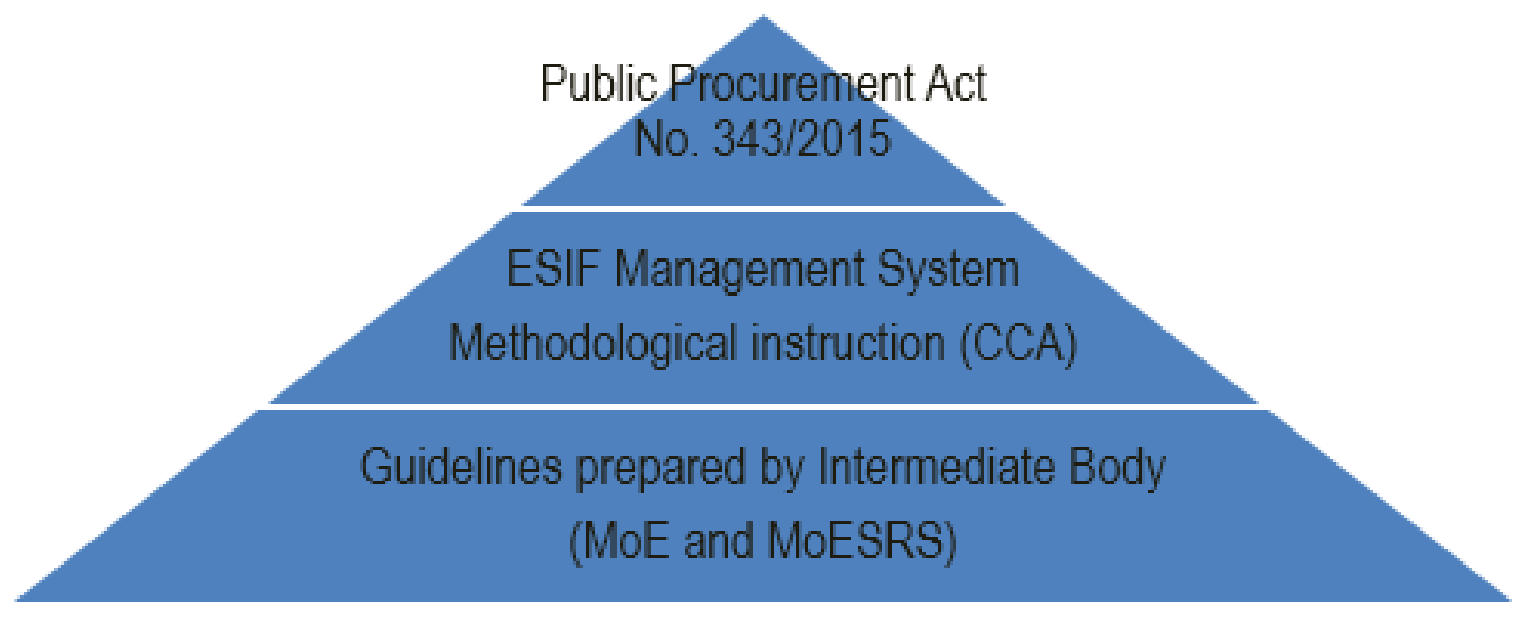

\subsection{Classification of projects}

The various types of projects can be categorised into large infrastructure projects, negotiated/national projects and smaller scale individual research projects, as illustrated in Table 2.2.

There are different types of calls in the Operational Programme Integrated Infrastructure:

- demand-oriented calls (individual research projects), based on competitive applications from relevant stakeholders interested in the topic of the call

- calls for national and large infrastructure projects, intended for one or more specific applicants/beneficiaries

- calls for proposals for the issuance of financial instruments initiated for the Slovak Investment Holding as the sole beneficiary.

There is no competition as such in the category of national and large infrastructure projects. The call is published and an applicant has to submit a project proposal, which is evaluated and subsequently contracted. However, the call is designed for a single applicant (or with a potential partner). While the Ministry of Economy mostly handles open calls for smaller individual projects with relatively few partners, the MoESRS is directly responsible for the implementation of five national projects and one large infrastructure project, all of which are implemented through calls for proposals. As national projects are pre-determined for one single applicant without competition, the implementation procedure is comparatively straightforward. Following the publication of the call, the project proposal is submitted, evaluated and contracted.

The procedures for demand-oriented calls follow more specific procedures, and are subject to several layers of control and approval, as described in Chapter 3.

Table 2.2. Classification of projects under the thematic objective research and innovation

\begin{tabular}{l|l|c}
\hline Classification & Description & Example \\
\hline
\end{tabular}




\begin{tabular}{l|l|l}
\hline $\begin{array}{l}\text { Large infrastructure } \\
\text { projects }\end{array}$ & $\begin{array}{l}\text { Flagship projects which require additional approval by the } \\
\text { European Commission } \\
\text { Notably in the areas of transport, environment and other sectors } \\
\text { such as culture, education, energy or ICT } \\
\text { Above EUR 50 million, financed through the European Regional } \\
\text { Development Fund and Cohesion Funds } \\
\text { Based on closed calls }\end{array}$ & $\begin{array}{l}\text { ACCORD project, with the objective to upgrade } \\
\text { infrastructure for universities and increase } \\
\text { research collaboration between academia and } \\
\text { industry. EU contribution amounts to } \\
\text { EUR 105.7 million. }\end{array}$ \\
\hline Negotiated projects & $\begin{array}{l}\text { Also referred to as "national" projects. } \\
\text { Medium-sized (approximately between EUR 1 million and } \\
\text { EUR 40 million) } \\
\text { Comprise excellence and competence centres, long-term research } \\
\text { projects, academia and industry co-operation projects } \\
\text { Based on closed calls }\end{array}$ & $\begin{array}{l}\text { Support for the Internationalisation of small and } \\
\text { medium-sized enterprises } \\
\text { Support for the development of creative } \\
\text { industries in the Slovak Republic } \\
\text { Science parks }\end{array}$ \\
\hline $\begin{array}{l}\text { Individual research } \\
\text { projects }\end{array}$ & $\begin{array}{l}\text { Academic research projects } \\
\text { R\&D projects in industry } \\
\text { Small-scale academia and industry co-operation projects } \\
\text { Capacity-building projects } \\
\text { Based on open and fixed deadline calls }\end{array}$ & $\begin{array}{l}\text { Increasing research in the Bratislava region by } \\
\text { improving business capacities in research } \\
\text { institutions }\end{array}$ \\
\hline $\begin{array}{l}\text { Financial instruments } \\
\text { projects* }\end{array}$ & $\begin{array}{l}\text { Slovak Investment Holding as the only beneficiary (based on } \\
\text { Government Resolution 736 of December 2013) } \\
\text { SIHAZ 1 (allocation of around EUR 180 million) } \\
\text { SIHAZ 2A (allocation of around EUR 250 million) }\end{array}$ & $\begin{array}{l}\text { Largely Anti-Corona Guarantees to support small } \\
\text { and medium-sized enterprises in the wake of the } \\
\text { COVID-19 pandemic }\end{array}$ \\
\hline
\end{tabular}

* Values and allocations as at January 2021.

Source: OECD, based on interviews. 


\section{The project life cycle}

This chapter overviews the entire life cycle of the ESIF projects in the Slovak Republic in a chronological way. The ESIF project life cycle includes the preparation and publication of calls for proposals, project evaluation, selection and contracting with beneficiaries, and public procurement. It is indispensable to understand the project life cycle to identify the bottlenecks in the implementation.

\subsection{Preparation and publication of calls for proposals}

The initial phase of the programme life cycle is the upstream process prior to the publication of the call. This process starts with collecting input about stakeholders' needs, which are directly communicated within the Monitoring Committee as well as through forums and workshops initiated by the intermediate bodies and co-operating agencies. The Government Council for STI and its adjoined RIS3 Committee set out the Smart Specialisation strategic document. This is also referred to as the RIS3 document/strategy and serves as a framework for the preparation of the call. On the basis of the strategic document, a draft aid scheme is prepared and sent for approval to the Antimonopoly Office.

If the approval is granted, the intermediate body publishes the aid scheme and simultaneously prepares the draft call. The managing authority can provide comments on the draft. The state aid test has to be elaborated prior to the submission of the state aid scheme to the Antimonopoly Office for approval. The call intent and risk analysis are sent to the Government Council for STI and the RIS3 Committee for approval. After their approval, the draft call, including the supporting documentation, is elaborated and sent to the managing authority for comment. The final version of the call, the risk analysis and supporting documentation are then sent to the central co-ordination authority (CCA) for approval. After assessment and approval by the CCA, the call is published. On the whole, the call preparation phase lasts two to six months. 
In specific cases, the intermediate bodies may launch a request to submit project strategies pursuant to the call publication. This is done to assess the compatibility of a project's core strategy with the ultimate objective of the call. Herewith, the applicant is requested to provide a summary of the project intentions and other information, which is submitted for evaluation to international expert evaluators, and for which the intermediate body in turn provides a report encompassing a criteria-based evaluation and potential recommendations, such as the involvement of particular partners. This two-stage model is mainly used by the Research Agency.

\subsection{Project evaluation, selection and contracting}

Pursuant to the publication of the call, the intermediate bodies present the call through seminars and workshops where information regarding its focus areas, eligibility conditions and recurring errors in the application is provided. Potential beneficiaries submit their application based on the required documents and fulfilment of the administrative requirements. Depending on the call, the lapse between the call announcement and the submission of the applications may be up to six months.

Upon receipt of the applications, the intermediate bodies perform the administrative verification of the documents and assess whether the predetermined criteria are fully met by the potential beneficiary. If information or documents are missing, the intermediate body may consult the beneficiary and request a follow-up with clarifications and/or additional documents.

The submission portal does not perform any automatic check of completeness nor validity of the documents, therefore manual inspection of all submissions is necessary to determine if additional information or supporting documents are necessary. Applicants are informed by mail, and have two weeks to retrieve the letter and an additional two weeks to provide the missing documents.

For efficiency purposes, it is envisioned for intermediate bodies to only grant applicants one opportunity to submit all of the missing elements and clarifications so as to prevent endless exchanges. Nevertheless, in practice, intermediate bodies allow more than one opportunity as well as for the provision of clarifications through informal channels. For the duration of the administrative verification phase, the manual allows 70 working days. However, as regards the long-term strategic research projects, the administrative assessment has been ongoing for almost two years.

The administrative verification of the eligibility conditions and project requirements is followed by an evaluation of the project. This phase entails selecting and training evaluators. The selection of evaluators encompasses the search for and contracting of experts who are required to fulfill a set of criteria and to be specialists in the field in question. The Ministry of Economy and the Research Agency set the criteria for the selection of expert evaluators. After evalutors are selected and trained, they are assigned applications for the evaluation of the project. In recent years, the evaluation phase has lasted from 3 to 18 months, with the longer time range being notably due to difficulties in finding appropriate evaluators.

Following the administrative verification and the evaluation, the intermediate bodies decide on the approval of the application by assessing whether the conditions for the award of the non-repayable financial contribution have been met. In parallel, they may request that applicants provide additional information and clarifications in case of uncertainties and/or incompleteness. The central co-ordination authority is consulted and asked for approval in cases of a special consortium agreement, whereby beneficiaries intend for all partners within a project to be included (e.g. as regards the centres for excellence call).

If the decision on the application is favourable, a contract will be signed as the beneficiaries are required to submit updated information, proof of qualification and possibly some amendments. For this reason, applicants need to provide documents which prove their eligibility for the receipt of public funds. This process lasts at least two to three months. After the contract has been signed, the implementation of the 
project commences; nonetheless, additional approval by the Public Procurement Office may be required in cases where procured items are more than EUR 600000.

\subsection{Public procurement procedures under ESIF projects}

Public procurement procedures are carried out under the same rules in accordance with the PPA, regardless of whether they are funded by the ESIF. In general, the fundamental difference lies in the specific control mechanism set out for ESIF-funded procurement. There are three types of control:

- ex ante control before the publication of the tender notice

- ex ante control before signing the contract

- ex post control immediately after signing the contract (follow-up ex post control or standard ex post control).

This implies additional procedures and documentation during the ESIF public procurement processes. The details of the current ESIF control system will be discussed in Chapter 5. In general, public procurement procedures consist of the three stages: 1) the pre-tender stage (planning and preparation); 2) the tender stage (publication and evaluation); and 3) the post-tender stage (contract management).

Figure 3.1 illustrates the basic cycle of public procurement procedures under ESIF projects.

Figure 3.1. Public procurement procedures under ESIF projects

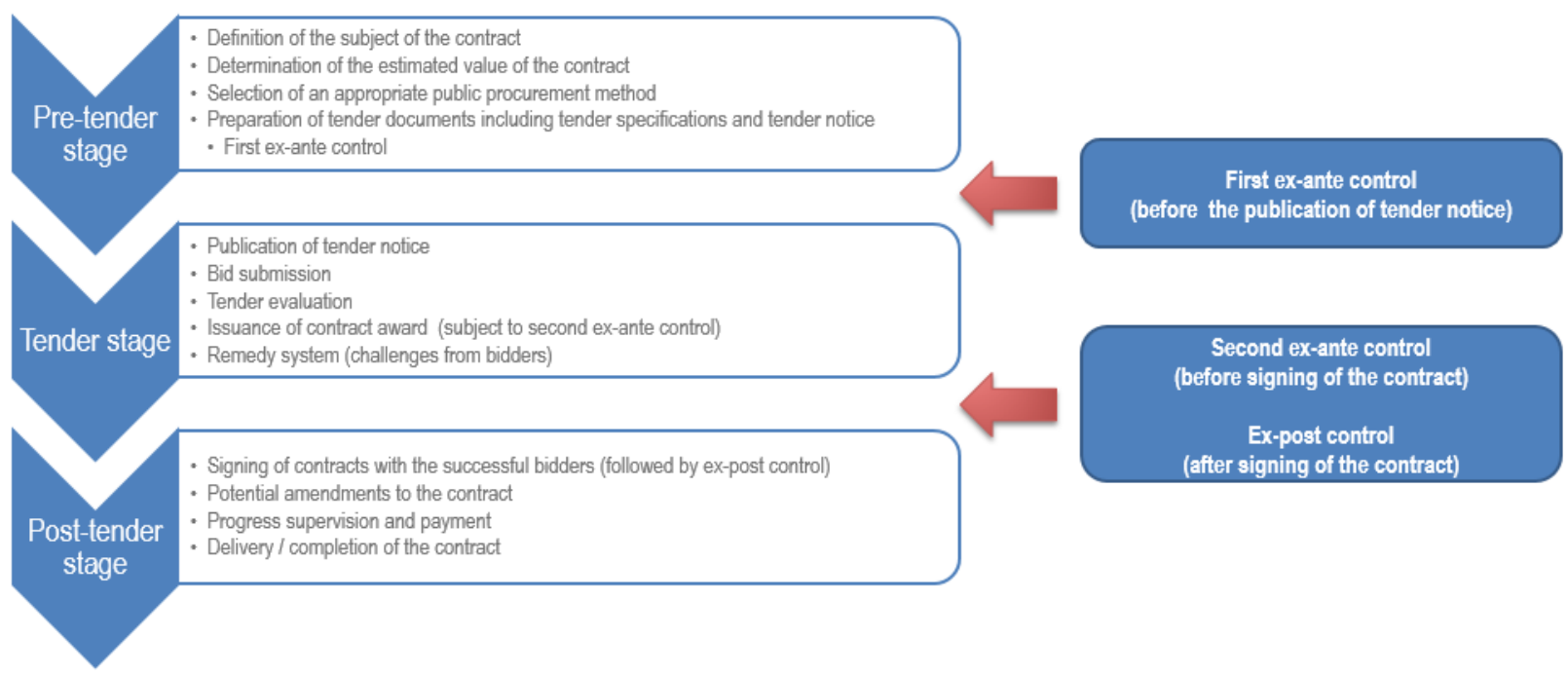

Note: It should be noted that not all public procurement processes are subject to control. It depends on various factors, such as the threshold, etc.

The pre-tender stage includes tasks ranging from needs identification and planning to the publication of tender, which include the determination of the elements such as the subject of the contract, an appropriate public procurement method, the estimated value of the contract, technical specifications and selection/contract award criteria. Market research and consultation play an important role in this stage. These elements are translated into the tender notice and tender documents. A first ex ante control by the intermediate bodies is required to complete this stage before proceeding to the next phase (not all of the public procurement processes are subject to control).

The tender phase covers the processes from the publication of tender notice up to the signing of the contract with the successful bidders. The early processes of this phase are composed of the publication of 
the tender notice, tender opening (bid submission) and tender evaluation. A second ex ante control by the intermediate body (and the PPO for some cases) is required in order to issue a contract award notice to the most successful bidder, selected as a result of a tender evaluation (not all of the public procurement processes are subject to control). As part of the remedy system, unsuccessful bidders may file challenges on the contract award decision.

The post-tender phase starts with the signing of the contract with the successful bidder. Ex post control is carried out immediately after signing the contract. After the contract enters into force, this phase consists of various contract management activities, such as the supervision and validation of progress, payments, amendments to the contract and delivery/completion of the contract. 


\section{Impediments to ESIF implementation in the preparation of calls and project selection stage}

This chapter assesses current practices of European Structural and Investment Funds (ESIF) in the Slovak Republic, focusing on the two stages: the preparation and publication of calls for proposals, and project evaluation, selection and contracting with beneficiaries. Further, it provides an overview of how past developments and situational circumstances in the main bodies and agencies involved have shaped these current practices. In particular, this chapter intends to analyse how these practices have resulted in potential bottlenecks delaying the preparation and evaluation processes under ESIF projects. These include several difficulties in call preparation, publication and execution, challenges in project evaluation arising out of past irregularities, and excessive administrative requirements and gold-plating. Apart from presenting the key findings, this chapter provides recommendations in order to increase the absorption of ESIF for research and innovation. 


\subsection{Difficulties with call preparation, publication and execution}

Chapter 1 highlighted that despite progress made in 2020, the Slovak Republic fares considerably less well off than other countries when it comes to the implementation of European Structural and Investment Funds (ESIF) in the research and innovation (R\&I) thematic area. These low numbers in the dissemination of the ESIF stem from various difficulties encountered over the past few years, which point to significant shortcomings in the set-up and execution of ESIF management in the Slovak Republic. The following drawbacks are reflective of underlying issues, which, thus far, have only been partially resolved.

The Research Agency manages the implementation of large and often quite complex calls. This may be due to the involvement of several partners, such as for the long-term strategic research projects and due to complex infrastructural investment items, i.e. complex research infrastructures with the need for significant construction works, such as for team centre projects. The implementation progress measured in the percentage of contracts signed differs substantially across calls and implementing bodies. The Research Agency has accomplished full contracting for several calls, albeit with significant delays.

In 2020, two new prioritised calls were launched to support R\&D responding to the COVID-19 pandemic and related negative impacts. This resulted in progress on two outstanding calls related to long-term strategic research being halted. Other reasons for slow progress are non-compliance with grant conditions, errors in the application and enduring administrative verification processes.

These two major calls related to long-term strategic research ${ }^{5}$ were still outstanding by end of 2020, and were cancelled by the Ministry of Education, Science, Research and Sport (MoESRs) in January $2021 .{ }^{6}$ The MoESRS took this decision because it expected beneficiaries would be unable to undertake all of the research necessary and that it would be impossible to complete all of the administrative and evaluation procedures by 2023 , in spite of claims by some beneficiaries that the research had already started and was on track. The intermediate body expressed concern that beneficiaries would overestimate their capabilities, and feared that delays would eventually lead to decommissioning of the funds. The decision to cancel these calls came as a surprise, without prior notice to beneficiaries, and caused disruption, in particular to those who had already started the research with their own financial resources in anticipation of future repayment. This move resulted in substantial disappointment, demotivation and a further loss of trust among beneficiaries in the ESIF set-up to effectively support $R \& I$ in the Slovak Republic. Following the ministries' decision not to consider the possibility of phasing funds which would remain by the end of 2023 into the next programming period, the undisbursed funds have been allocated to the Ministry of Economy. The Ministry of Economy significantly increased the use of financial instruments in early 2020, with the objective to support companies in need due to the pandemic.

The progress administered by the Ministry of Economy had been more varied; however, considerable improvements in contracting of the outstanding calls were undertaken in 2020. Although most calls have been contracted to a large extent and funds have been decided to be allocated to the corresponding projects, much of the actual spending or disbursement still remain to be enacted. There are various reasons as to why spending and contracting might have fallen short of initial planning, notably due to other forms of finance becoming available to beneficiaries, or the fact that the bulk of the cost for equipment will only incur at later stages of the projects. The following sections discuss in more detail the specificities for the intermediate body's progress.

\footnotetext{
${ }^{5}$ The calls Industry for the 21 st century and Digital Slovakia and the creative industries.

${ }^{6}$ MoESRS, 2021.
} 


\section{Ministry of Education, Science, Research and Sports/Research Agency}

\section{Symptoms}

Despite substantial progress made by the Research Agency in recent months, leading to the full contracting of all calls except the cancelled long-term research calls and the COVID-19 related calls in 2020, it must be noted that significant shortcomings had previously caused it to lag behind its implementation targets and were at the origin of frustrating delays for beneficiaries in their pursuit of progress with their projects.

The Research Agency has exhibited a lack of capacities to support beneficiaries in the process. In particular regarding smaller calls, administrative staff is often inexperienced with research matters and high staff turnover was an issue, which in recent years has, however, improved. The lack of sufficient support may in part explain why several applicants have failed to meet the ex ante conditionality, subsequently leading to the cancellation of calls prior to the audits by the audit authority.

Further, some beneficiaries have remarked that they frequently do not feel prepared enough for the application process, including what needs to be done to fulfil all of the criteria, including public procurement, and if questions arise, staff at the Research Agency are not always capable of offering informative advice or guidance, and regularly refer to the manual instead. In addition, communication between the Research Agency and beneficiaries often prolongs the process. It is therefore not uncommon for the Research Agency to send communications, expecting a response within ten working days, while it often takes much longer to answer requests or questions, in some cases up to two or three months.

Sometimes beneficiaries do not receive an answer at all, e.g. one beneficiary made several requests, including an "urgent request to obtain an environmental impact assessment, providing refreshments at events organized within the project, reimbursement for timesheet items, feasibility study and financial analysis" to the MoESRS when it was the managing authority. Several employees at the MoESRS had been contacted and at least 25 requests were left unanswered. Finally, there is not one specific contact. Some issues last for several months and it is common for beneficiaries to communicate with a different staff member from the Research Agency each time instead of having someone assigned to their case.

\section{Causes}

The MoESRS, and in particular the Research Agency, has experienced severe challenges arising from their inadequate selection of evaluators in 2016 and 2017, a number of which were found responsible for misconduct and the ensuing irregularities in the overall process. In view of these events, the European Commission has issued a warning letter followed by audits by the audit authority (Box 4.1) and certifying verification by the certifying authority. 


\section{Box 4.1. Misconduct in the evaluation process and the audit authority's findings}

In 2017, Slovak media brought attention to structural irregularities in the evaluation process of research projects applying to be (partially) financed by EU funds. These were brought to light by an incident where a project evaluator demanded a $20 \%$ bribe in order to grant a company the required evaluation points which would qualify it for a EUR 7 million EU contribution to its long-term research project.*

In response, the audit authority identified critical concerns and recommendations in its audit reports of the implementation of calls in the programming period 2014-20 II. In particular, it has found that the long-listing of evaluators is not based on a transparent selection process and the suitability of these is not assessed objectively. The database of these evaluators was under the auspices of the managing authority, back then the Ministry of Education, Science, Research and Sport (MoESRS), until 11 November 2016, when it was transferred to the Research Agency.

More specifically, the manual for evaluation leaves too much room for subjective assessment. In the call OPVal-VA / DP / 2016 / 1.2.1-02 for instance, half the questions and 31 points out of a total of 45 could be awarded based on subjective criteria. Further, very limited explanations regarding the scaling of the points fostered trust on the subjective understanding of the evaluator. This in turn exacerbates the problem that the two evaluators per project are not evaluating on a uniform basis. In addition, many of the evaluators did not fulfil the eligibility criteria. As such, they:

- did not meet the condition of at least three years of experience in research and development and/or industrial innovation

- did not possess professional experience in the relevant areas of the specific objectives of the Operational Programme Research and Innovation (OP R\&l)

- evaluated areas of specialisation in scientific areas where evaluators would be available, even though these areas were not relevant to the application

- did not demonstrate knowledge of the priority axis, specific objectives and activities of the OP $R \& I$ within the audited calls.

Pursuant to these findings, the audit authority has recommended improving the manuals and ensuring the experience and skills of evaluators so as to ensure more objective assessments and better informed and uniform evaluation as well as to enhance impartiality and transparency.

${ }^{*}$ https://e.dennikn.sk/838618/podozrenie-z-korupcie-zvlastne-firmy-a-sns-v-pozadi-o-com-je-skandal-s-eurofondmi-na-vedu. Sources: Audit Authority (2017[5]); https://e.dennikn.sk/838618/podozrenie-z-korupcie-zvlastne-firmy-a-sns-v-pozadi-o-com-je-skandal-seurofondmi-na-vedu; stakeholder interviews.

As a result of the audit findings, all calls were temporarily suspended for more than a year while changes to the process were being undertaken. For instance, following the recommendations by the certifying authority, the Research Agency has adopted new selection criteria to ensure that evaluators' experience and education correspond to the evaluation field. After this temporary halt of implementation processes, and in attempt to make up for the lost time, the Research Agency dealt with a sudden surge in workload as more than 20 calls were re-launched simultaneously in 2018; 5 of which had the same deadline. 
The significant increase in workload was accompanied by human resources departing from the Research Agency, which further exacerbated pressure on the preparation, planning and execution capacities. From a nominal capacity of 210 staff, $^{7}$ the agency was down to 122 staff at the end of April 2020.

Moreover, due to the Research Agency's fraudulent selection of evaluators prior to the amendments of the criteria, the resulting misconduct by evaluators had sparked considerable negative media coverage around expert evaluators, which resulted in additional difficulties for contracting adequate evaluators given the increased professional experience and educational requirements as well as the obligation to publish the evaluator's name, rendering many potential candidates unwilling to apply.

In addition, the Research Agency's management could have been more proactive to flexibly reallocate resources. When staff at the implementation department were unoccupied (due to the fact that very few projects were in the implementation phase), there were few (if any) transfers to tasks of application screening, where capacity was insufficient. This failed to ensure efficient operations and lengthened delays.

A change in management at the Research Agency in May 2020 was followed by additional staff turnover, with total staff further reduced to 117 in December 2020, representing a 44\% reduction from the nominal capacity of 210 . Hiring additional human resources proved challenging, mostly due to the adverse reputation of the agency, and these persisting capacity issues represent barriers to speeding up the administrative assessment and evaluation of projects.

According to initial interviews, project management tools seem to be limited to timesheets and team meetings where only the "worst cases" are discussed. The prescribed timeline in the manual (70 days for a project screening procedure) seems to be taken as an overall benchmark, but there do not seem to be any Gantt charts, retro-planning sessions, nor internal milestones to follow the progress per project, therefore management focuses its attention on issues mostly when the delays become extreme. The justification given for such a "hands off" management system is that projects are complex, and very different from one to another, and rules are thus difficult to establish.

The complexity of projects is daunting, in particular for projects with complex partnerships. In the case of project applications that involve several partners, it is necessary to verify if conditions were met for each of the partners individually. It is not sufficient that the applicant himself fulfils the general conditions, each of the partners must to do so as well. In addition, all the activities and budget lines of each partner must be consistent with the activities and budget lines of the other consortium members. Therefore, there is a need to cross-check to verify the validity of all items and at the same time to verify all the possible duplicities. There is also a need to check if the possible suppliers (providers of price offers within the market research) are not somehow related to the consortium members. All of these cross-checks cause a non-linear increase in the number of actions needed within the evaluation phase of the project application depending on the number of partners within the consortium. All purchases need to be justified by "market surveys" with at least three bids for each piece of equipment. Additionally, agency staff need to check "mathematical correctness", meaning that all items are correctly summed up in totals. Such a task is complicated by the fact that submissions are not provided in machine-readable format. In addition, the manual data input cannot be outsourced to an external service provider, since it engages the personal responsibility of the examiner. In one extreme case, a project involved 11 partners, and contained a total of 3332 pages of market research and 6443 items to be checked.

\footnotetext{
${ }^{7}$ Based on a letter sent to the Director General of the Research Agency on 21 January 2020 from the Ministry of Education, Research, Science and Sport, concerning binding indicators related to the state budget; there are 215 employees devoted to the Research Agency, including 210 administrative capacities.
} 
Not only is the breadth of the task daunting, but the depth of the checks which the Research Agency is supposed to perform, including knowledge about the availability of the goods, is also daunting. Box 4.2 shows some examples of findings of related controls.

\section{Box 4.2. Examples of findings concerning the Research Agency's performance}

1. OPVal /OC313181201/finding 11: In the project evaluation phase, the Research Agency did not sufficiently verify the availability of the procured goods and did not prove that they are commonly available goods. At the same time, there is not a sufficient mechanism in place in the relevant documentation regarding the general process of this verification. - finding by the certifying authority

2. OPVal/kontrola 1-2017/finding 9: Discrepancy in the documentation from the project evaluation. The Research Agency submitted a report after conducting market research, which contains other companies that were addressed compared to the submitted emails, by which the Research Agency addressed companies with a request for price offers submission. - control undertaken by the Ministry of Education, Science, Research and Sport

Source: Quotes provided by the Research Agency.

Many of the incurred problems originate from insufficient planning for peak load. For example, in 2018, a large number of calls were launched simultaneously, resulting in a very high number of applications arriving simultaneously for administrative screening.

For these reasons, beneficiaries have endured in part excessive delays, with some of the calls (in particular Digital Slovakia and Industry for the 21st century calls) not advancing for more than two years before being cancelled. In 2020, outstanding calls were halted once more in a bid to prioritise two calls for COVID-19 related research, which were originally foreseen to be finalised until the end of 2020 to be eligible for exceptional provisions linked to state aid during the pandemic. Nevertheless, as a general measure, the European Commission prolonged the validity of these exceptional provisions until June 2021, providing more time to finalise those projects.

In a positive development, the COVID-19 related calls are subject to simplified measures, allowing for fast preparation and execution. For instance, "mathematical correctness" checks of beneficiaries' quotations from suppliers are herein excluded. In addition, beneficiaries were asked early to provide the necessary documents that typically take time to obtain from authorities. This parallel processing of various tasks may well be an important mechanism to accelerate the other outstanding calls within this programming period, and also to adopt such good practices for the next one.

On the issue of the cancelled long-term strategic research projects (Digital Slovakia and Industry for the 21st century), the Research Agency has pointed out that projects could be "phased", and the unfinished part carried over into the next programming period. This possibility has been rejected by the intermediate bodies. Although such a possibility exists in theory according to the manual, such "phasing" may be difficult to implement in the context of the reform of the ESIF Management System, whereby in the 2021-27 programming period, there will be a single management authority (the Ministry of Investments, Regional Development and Informatization), and it may refuse to deal with parts of projects from the current programming period. It is important to stress the trust some of the beneficiaries had placed on the future receipt of the grants, thus starting research early to be able to accomplish it within the time frame. Given the decision to cancel this call, disappointment is significant and importantly, the decision was not communicated to beneficiaries in advance. The Research Agency was supposed to have sent a questionnaire to the applicants in order to investigate the feasibility of the implementation by the end of 2023. However, the OECD team was not able to determine whether this questionnaire had, in fact, been 
sent, and what the outcome was. On the other hand, beneficiaries reported various situations on those calls: while some of them are already carrying out research for these projects, and hoping to be able to be reimbursed for expenses already engaged, others reported needing to assess the risks of signing and being unable to fully implement by the end of 2023, and having to reimburse any funds engaged. Beneficiaries didn't report about any contacts with the Research Agency on this issue.

In the next programming period, the Research Agency may no longer be involved in the process and the MoESRS will act as the only intermediate body.

Box 4.3 compares project management tools and administrative capacities in benchmarking countries with the Slovak Republic. New measures and instruments to motivate employees such as home-working schemes in the Czech Republic could help, in particular at the Research Agency, to attract and retain employees to avoid the downward spiral of unqualified staff and a hevy workload leading to delays. To be able to assess progress based on the fulfilment of a clear set of targets, scoreboards, as used in Estonia, could be used to communicate expectations to all employees.

This analysis suggests that the Research Agency is not necessarily understaffed and that the abovementioned measures could help its efforts to improve the efficiency of existing staff and to attract new qualified employees.

\section{Box 4.3. Comparing project management tools and administrative capacities with the Czech Republic and Estonia}

1. Project management tools to improve efficiency in European Structural and Investment Funds (ESIF) implementation are generally limited to state administration bodies. Nevertheless, in the Czech Republic, the Ministry of Education makes use of several measures such as salary bonuses contingent on advancements in ESIF spending so as to reach compliance with the N+3 rule. Considering that its relatively young workforce comprises millennials and Generation $Y$ employees, competitions and other informal events are organised regularly between departments to enhance progress. Work-from-home options due to the COVID-19 pandemic have proved to be motivating factors for employees which had not been possible previously due to strict state administration rules. Similarly, the Operational Programme Prague - Growth Pole of the Czech Republic makes use of internal targets and milestones semi-annually, whose evaluation is based on data in the electronic monitoring system as well as estimates based on past experiences. Employees are supervised and receive a performance evaluation of their individual and team goals.

2. Similar measures are used in Estonia to boost performance. Plans for the next programming period foresee the contracting of an external partner to design new initiatives and measures for performance management. In addition, a performance management dashboard in the Grants Development Department will be introduced to effectively communicate all targets to all team members.

3. As previously mentioned, the Research Agency currently has significantly fewer staff members (120) than its nominal capacity (210). In order to analyse whether this could be the main obstacle to faster implementation, Table 4.1 illustrates the human resources capacity in the benchmarking countries for comparison.

Table 4.1. Benchmarking of administrative capacities per staff member 


\begin{tabular}{l|l|l|l|l}
\hline & \multicolumn{1}{|c|}{ Research Agency } & \multicolumn{1}{|c}{ IB 1 (Estonia) } & IB 2 (Estonia) & IB 3 (Czech Republic) \\
\hline Staff & 120 & $10-15^{1,2}$ & $10^{2}$ & 380 \\
\hline $\begin{array}{l}\text { Calls/staff member } \\
\begin{array}{l}\text { Applications/staff } \\
\text { member }\end{array}\end{array}$ & 0.175 & $2.8^{2}$ & 0.714 & 0.718 \\
\hline $\begin{array}{l}\text { Total subsidy volume } \\
\text { (EUR)/ staff member }\end{array}$ & 4.83 million & $80^{2}$ & 13.2 & 67.3 \\
\hline
\end{tabular}

1. This intermediate body also co-operates with other organisations which have additional dedicated employees.

2, Approximate values.

4. Altogether, the comparison does not suggest that the Research Agency is understaffed, even if it is working below its nominal capacity. Volume in terms of both subsidy and applications is considerably higher per individual staff member in the intermediate bodies from the Czech Republic and Estonia. However, these results should be treated with caution, as institutional differences exist across countries regarding ESIF implementation. Duties vary per individual intermediate body and some work with external partners whose headcount is not included in the table. Nevertheless, the comparison does not support the claim that too few human resources are at the origin of the Research Agency's delays.

Source: Responses to OECD questionnaires, March 2021.

\section{Way forward}

A lack of administrative staff is likely not the main reason for the slow absorption of ESIF funds, pointing to potential for efficiency gains by increasing existing staff's capabilities through training. Higher quality administrative advice to beneficiaries can only be provided by ensuring that personnel at the intermediate bodies is qualified and trained. Specific measures are needed to enhance project management skills at the Research Agency. A dedicated consulting project could be helpful to analyse and streamline internal processes and provide management with the adequate tools. Such a process could be followed by a training programme to ensure the implementation of management by objectives, and to prepare staff for the multidisciplinary nature of the work, making them proficient in the most relevant topics. Although regular training is provided at the national level, success rates and interviews with beneficiaries suggest that there is potential to restructure and propose new training initiatives.

Internal management tools and control mechanisms should be established to allow for a more efficient use of administrative capacities within the intermediate bodies.

Although the Research Agency does not face as much staff turnover as it did in previous years, long-term thinking is needed to avoid the possible negative spiral observed in the past. The loss of reputation made it unable to recruit professional staff, and the lack of staff capabilities combined with management shortcomings has led to further delays, which further damage its reputation. The availability of expert professionals in the Slovak Republic is limited and intermediate bodies often provide better work conditions, thus attracting the most qualified personnel. In addition, identifying and implementing measures to motivate employees such as teleworking opportunities, target-based salary, etc. could help the Research Agency overcome difficulties in attracting qualified staff.

Administrative capacity is clearly an issue at the Research Agency. Preliminary investigations indicate that the issue is not budgetary, since the budget foresees the nominal capacity of 215 staff, of which 210 administrative capacities. Rather, it seems that an accumulated bad will has created a negative sentiment, making it a challenge to recruit qualified staff with knowledge about the realities of scientific research. A 
human resource "shock therapy" is therefore needed to reverse this negative cycle, whereby low capacity increases pressure on the remaining staff who tend to leave, exacerbating the capacity issue even further. In the short term, management needs to:

- reallocate staff with a lighter workload to the critical tasks of administrative checks, evaluator recruitment and contracting

- adopt the simplification of tasks, such as those that have been applied in the context of the COVID calls

- explore possibilities for hiring temporary staff and/or outsourcing tasks which are less critical with respect to legal responsibility

- explore possibilities to liaise with Horizon 2020 staff regarding specific expertise on scientific equipment which may not be available within the Research Agency.

All intermediate bodies must have the financial resources to attract qualified staff. Budgetary constraints at co-operating agencies, combined with the civil service status and better work conditions in ministries, put these agencies at a disadvantage for hiring more qualified staff.

A comprehensive human resource consulting project should be undertaken, with terms of reference including (but not limited to):

- an analysis of the status of the agency's personnel (salary, benefits, career paths)

- a staff survey identifying the main areas for improving working conditions

- should the Research Agency be included within the next programming period, a human resource action plan is needed whose objective would be to create optimal working conditions for staff, and provide incentives and rewards, making the Research Agency a desirable employer.

Operationally, a thorough upskilling of the management and staff is needed to enhance project management skills and provide management and staff with the tools to enhance their performance, including, but not limited to:

- Setting agency-wide, departmental and personal performance objectives. This may be a difficult exercise due to the complexity of projects, and the lack of predictability, but it must be carried out, even if the objectives will surely need to be readjusted flexibly over time. A repetitive process of target setting and evaluation, followed by new objectives will create a learning effect over time and enable the organisation to learn.

- Creating a scorecard which gives management an overview of the implementation progress, with specific alerts being generated whenever the process shows the first symptoms of slowdown and delays.

A proactive approach in engaging beneficiaries in consultation through workshops, seminars, etc. could improve beneficiaries' success rate in the administrative verification.

Developing clear guidelines to anticipate beneficiaries' needs and challenges could be useful and reduce error rates. To accelerate the verification of formal criteria, pre-formatted documents and tools could be an effective instrument.

In addition, several of the measures proposed by the Ministry of Economy (see Box 4.4) could be relevant to the MoESRS and the Research Agency. It was communicated to the OECD team that several of the measures above have already been implemented. However, it is important to review whether the relevant measures have been implemented in all intermediate bodies and agencies, where applicable. 


\title{
Ministry of Economy/Slovak Innovation and Energy Agency
}

\author{
Symptoms
}

The Ministry of Economy has cancelled five calls and most of the launched calls have contracts signed. The outstanding calls are mostly small in scale, as the largest ones began at the beginning of the programming period to ensure compliance with the $n+3$ rule. ${ }^{8}$ See Figure 1.5 in Chapter 1.

Further, of the outstanding calls, most are pilot calls, which were not launched at the beginning of the programming period. Before being cancelled in 2020, the largest outstanding call was OPVal-MH/DP/2018/1.2.2-21: Call for proposals for a non-repayable financial contribution to support smart innovation in industry, ${ }^{9}$ with a value of EUR 140 million, and even though the call had been published two years earlier, as of November 2020, more than half the applications (169 out of 322) were still in the administrative checking procedure, and only 68 contracts had been signed, for a value of EUR 44.6 million. The implementation of this call was the responsibility of the Slovak Innovation and Energy Agency (SIEA), which had some organisational issues (some of which are similar to the ones experienced by the Research Agency). In order to address these issues, the Ministry of Economy suggested specific measures to be undertaken by the SIEA (Box 4.3).

Similar to some of the issues faced by the Research Agency, the Ministry of Economy, and in particular the SIEA, experienced hold-ups and delays, manifested in prolonged administrative verification. Some of the calls were preceded by smaller calls to assess the project intent with a short summary, which in practice may have led to long processes.

The success rate of the administrative verification phase is relatively low, with $63.3 \%$ of applications passing this stage, which is significantly lower than some of the benchmarking numbers as shown in this section. This points to potential room for improvement in beneficiaries' preparation to ensure that they fully understand all of the requirements. In addition, verification of the size of the enterprises has been an intensive undertaking, causing many delays. This has now been addressed by the Ministry of Economy, as discussed below.

The overall demand of submitted applications exceeds the call allocation, with the anticipation that not all projects will be approved and/or signed. Implementation is divided into funds for national projects, grants and financial instruments (loans, venture capital, pandemic aid loans) whereby the "over-allocation" spending is used only for grants. The amount is based on previous experience of the percentage of finalised projects. If this proves insufficient to absorb all of the savings from ongoing calls, a further reallocation of funds into financial instruments is deemed comparatively simple.

Financial instruments were initiated during the 2007-13 programming period, with the Jeremie Fund, initially managed by the European Investment Fund, then taken over by Slovak Investment Holding (SIH) under the Ministry of Finance.

In the present programming period, the SIH makes use of multiple financial instruments to disburse the funds provided from the ESIF by the Ministry of Economy under the Operational Programme Integrated Infrastructure. These comprise portfolio risk-sharing loans, through which the SIH provides zero interest rate loans alongside commercial bank loans; in the case of default, the risk is shared between the SIH and

\footnotetext{
8 The " $n+3$ rule" refers to the rule whereby all funds for a given programming period need to be fully disbursed by the end of the third year following the end of the financial framework. Specifically, for the 2014-20 programming period, all funds need to be disbursed by 31 December 2023.

${ }^{9}$ Called "Smart-Ind 1.2.2-21" in Figure 1.6.
} 
the financial intermediary. Further, first-loss portfolio guarantees are guarantees which cover loans up to a certain percentage of the whole portfolio value (typically $80 \%$ of the losses for up to $20 \%$ of the portfolio).

For the disbursement of financial instruments, the SIH collaborates with financial intermediaries who are chosen through an open and transparent process. The European Commission has required that these financial services follow public procurement procedures, even though several other member states do not apply this procedure for financial services. ${ }^{10}$ This requirement has led to a significant drop in the number of applications. For example, for the selection of one venture capital fund manager, 11 applications from 3 different EU countries were received when it was formulated as an open and transparent call (but not as public procurement); however, once the public procurement condition became known, only six applicants remained, all of whom were Slovak. For two other funds, the SIH only had two bidders, while for one fund only one bidder applied. This can be explained insofar as the Slovak procurement processes are highly complex and take on average 500 days, compared to 170 days in the Czech Republic. ${ }^{11}$

At the onset of the COVID-19 pandemic, uncertainty in the market meant that many companies had to rely on external finance to sustain their growth. The considerably large allocated amount of EUR 719 million is divided across various instruments (Table 4.2). Of these EUR 719 million, EUR 500 million were attributed to the anti-Corona instruments, notably the Anti-Corona Guarantees (SIHAZ).

\section{Table 4.2. Allocations in the National Development Fund II under the Operational Programme Integrated Infrastructure for the implementation of the Minisrty of Education, Science, Research and Sport's financial instruments}

\begin{tabular}{|c|c|}
\hline Instrument & Description \\
\hline Companies in early-stage development (start-ups) & $\begin{array}{l}\text { Under the responsibility of three fund managers } \\
\text { Agreed value: EUR } 34 \text { million with an additional option of EUR } 34 \\
\text { million } \\
\text { Ca. } 30 \text { investments with a value of EUR } 20 \text { million as of January } 2021\end{array}$ \\
\hline Direct investments in the Bratislava region & $\begin{array}{l}\text { Between EUR } 500000 \text { and EUR } 2.8 \text { million per investment } \\
\text { Includes the SIHAK CLA Scheme }\end{array}$ \\
\hline Direct investments outside the Bratislava region & $\begin{array}{l}\text { Between EUR } 1.9 \text { million and EUR } 4.6 \text { million } \\
\text { Includes SIHAK CLA Scheme }\end{array}$ \\
\hline $\begin{array}{l}\text { Portfolio risk-sharing loan (PRSL) for small and } \\
\text { medium-sized enterprises (SMEs) }\end{array}$ & 72 loans in disbursement for a total value of EUR 20 million \\
\hline First-loss portfolio guarantee (FLPG) for SMEs & 56 loans in disbursement for a total value of almost EUR 25 million \\
\hline $\begin{array}{l}\text { FLPG } 2 \text { for SMEs in the area of research, } \\
\text { development and innovation }\end{array}$ & $\begin{array}{l}\text { Ten loans in disbursement for a total value of EUR } 4.4 \text { million } \\
\text { Undisbursed funds will be allocated to SIHAZ } 1\end{array}$ \\
\hline SIHAZ 1 & $\begin{array}{l}\text { Net allocation: EUR } 180 \text { million } \\
\text { Contractual partners: various financial intermediaries } \\
\text { Targeted at companies hit by the COVID-19 pandemic } \\
\text { Entails more than } 2000 \text { loans }\end{array}$ \\
\hline SIHAZ 2A & $\begin{array}{l}\text { Net allocation: EUR } 256 \text { million } \\
\text { Contractual partners: various financial intermediaries } \\
\text { Targeted at companies hit by the COVID-19 pandemic } \\
\text { Entails more than } 3000 \text { loans }\end{array}$ \\
\hline
\end{tabular}

Notes: Contractual partner: Ministry of Transport and Construction, represented by the Ministry of Economy. Contractual allocation: nearly EUR 719 million

Source: Interviews with the Ministry of Finance and Slovak Investment Holding.

\footnotetext{
${ }^{10}$ None of the benchmarking countries (the Czech Republic, Estonia, Poland) follow public procurement procedures to contract financial intermediaries for the use of financial instruments.

11 Interview with the Ministry of Finance (2020).
} 
The SIH's Anti-Corona Guarantees (SIHAK) funds are provided to SMEs which fulfil the purposes stated in the OP Integrated Infrastructure. Together with the Ministry of Finance and the Slovak Association of Innovative Companies, this instrument was created to provide companies with convertible loans. To be eligible, companies had to submit information regarding their activities, financials and products to fulfil the innovativeness criterion. These materials were screened by Slovak innovation experts, who also acted as evaluators of the Horizon 2020 programme. Once an investment round was reached, the SIH would acquire the option to receive company shares at favourable prices.

\section{Causes}

Altogether, it is important to note that there are various reasons why absorption capacity can be low within calls, pointing to significant shortcomings in the overall process, as investigated in this report. As mentioned above, for some calls, such as support for industry for the 21 st century, there may be an over-allocation of funds, as it is expected that some projects will not be approved or signed. Apart from errors by the applicant, a potential withdrawal from the application may be due to the length of the call process and private financial resources becoming available. Further, when beneficiaries were informed that they would be subject to procurement rules committing them to enduring agreements with specific suppliers, they sometimes decided to refrain from finalising the process.

In addition, spending might appear short of the planned funds because for some projects expensive equipment will only be acquired in the late stages of the project, while the first phases mostly only entail wages for research and other work.

A key impediment to faster EISF absorption under the auspices of the Ministry of Economy were difficulties with the co-operating agency, namely the SIEA. The Ministry of Economy has submitted recommendations for structural improvements for the collaboration with SIEA (Box 4.4).

\section{Box 4.4. Measures to improve the efficiency of the Slovak Innovation and Energy Agency}

The Ministry of Economy required following measures in order to improve the efficiency of the Slovak Innovation and Energy Agency (SIEA).

1. Interim deployment of employees from the department responsible for project approval within the Operational Programme Environment, to help for the call for support of smart innovations in industry OPVAI-MH/DP/2018/1.2.2-21 until it is fully screened (the call has since been cancelled).

2. Methodological support for the SIEA from the Ministry of Economy within the approval process, in particular:

a. Establishing the management documentation for the purpose of ensuring the project approval, including the control list for administrative verification, guidelines for evaluators, evaluation sheets and decision templates.

b. Verification of the condition concerning the accordance of the application with the RIS3 Strategy.

c. Verification of the condition concerning the activity of the company applying for a grant.

d. Verification of the condition concerning the interdiction to submit more than one application for the grant under the same project objective.

e. Verification of the condition concerning the size of the enterprise.

f. Verification of the condition concerning the undertaking in difficulty. 
g. Selection of evaluators based on the knowledge areas, training for evaluators and appointment of evaluators to applications.

h. Methodological preparation within the process of projects approval.

i. Dealing with the applicants' requests for additional information (questions relating to the call and to the preparation of the applications).

3. The implementation and drawdown of funds is co-ordinated. Nevertheless, it was agreed that the Ministry of Economy establish an internal unit to be in charge of all processes, from call publication to implementation, for half the calls.

Source: Ministry of Economy.

In addition, high administrative requirements and the complexity of the process have been detrimental to the smooth implementation. In response, the Ministry of Economy has proposed a number of corrective actions and recommendations to simplify the process (Boxes 4.4 and 4.5 ).

On the matter of the use of financial instruments, it should be noted that the initial allocation was comparatively low, around EUR 30-40 million, and consisted of savings from previous instruments, reallocated by the SIH to pandemic relief, under the usual conditions of $80 \%$ of losses for $20 \%$ of the portfolio. Upon relatively quick dissemination of the funds, the Ministry of Economy has allotted larger fractions of the eventual EUR 500 million to the Anti-Corona Guarantees. The level for SIHAZ is significantly higher and disbursement comparatively simple and generous, whereby under SIHAZ 2, there is no portfolio limit and coverage extends to $90 \%$ of each loan. In addition, in line with the OP, these also allow for interest rate subsidies as long as a company does not lay off employees. Both SIHAZ schemes run simultaneously and have supported more than 5000 companies to date (as of January 2021). ${ }^{12}$

The SIH has, with the agreement of the European Commission, the possibility to reallocate funds for Specific objectives 9 and 10 towards Specific objectives 11 and 12. These, under normal circumstances, are in support of SMEs involved in R\&D and under the Smart Specialisation Strategy. However, due to the COVID crisis and its consequences for companies' liquidity, these conditions no longer hold, so these financial instruments are effectively reallocated to Specific objectives 11 and 12 without any obligation that they be targeted towards innovative companies nor entities' R\&D efforts. While the support of 5000 companies in 2020 with these funds is indicative of progress made, which is also manifested in the strong increase in the allocation rates of funds in the thematic objective of R\&l in the Slovak Republic in 2020, the use of these schemes may have come at the cost of supporting innovative companies, as there is no longer any eligibility condition in place in this regard. Altogether therefore, although fund dissemination in research and innovation has formally increased substantially under the auspices of the Ministry of Economy, this may not necessarily be indicative of actual support for innovative activities within companies.

\footnotetext{
${ }^{12}$ Interview with Slovak Investment Holding (2021).
} 


\section{Box 4.5. Benchmarking the preparation of beneficiaries and the use of financial instruments with the Czech Republic and Estonia}

\section{Benchmarking the preparation of beneficiaries}

Compared to the Slovak Republic, the Czech Republic shows a significantly higher success rate in the approval of the administrative assessments. While in the Slovak Republic about $63 \%$ (Ministry of Economy) of applications pass the administrative verification phase, this number is as high as $98 \%$ for the Ministry of Education in the Czech Republic. The Czech intermediate body engages in very close communication and collaboration with beneficiaries, including through workshops, seminars, and continuously responding to questions and using simple wording in communication materials. As such, this extensive consultation with beneficiaries prior to their submission of the application appears to have significantly helped applicants provide all of the required information and documents. Slovak beneficiaries explained to the OECD that often the exact requirements of applications are unclear, communication is difficult (in particular with the Research Agency) and that the low success rate therefore deters potential applicants from applying altogether.

\section{Benchmarking the use of financial instruments}

Although all benchmarking countries use financial instruments, they do so to a much lesser extent then in the Slovak Republic. In Estonia, around 3.5\% of the European Union's contributions to the European Structural and Investment Funds are disbursed through financial instruments; in the Czech Republic, it is 4-6\%; while in the Slovak Republic, $60 \%$ of EU contributions for research and innovation have been allocated via financial instruments. ${ }^{1}$ What is more, neither of the benchmarking countries' intermediate bodies follow public procurement procedures for contracting of financial intermediaries ${ }^{2}$ which, as previously mentioned, prolongs processes and adds to the administrative burden.

1. Responses provided by Czech and Estonian intermediate bodies to the OECD questionnaire (March 2021). For Estonia, the percentage reflects the total use of financial instruments in all thematic objectives of the ESIF. For the Czech Republic, the number is for the Operational Programme of the Prague Growth Pole. For the Slovak Republic, the percentage is the share of financial instruments used in the thematic objective of research and innovation.

2. One respondent explained to the OECD: Entrustment of the management of financial instruments by the managing authority to the bank was carried out without public procurement on the basis of Article 38, §4b (iii) Regulation (EU, Euratom) 2018/1046 of the European Parliament and of the Council of 18 July 2018, the so-called Omnibus Regulation, which corrects in particular Regulation (EU) No $1303 / 2013$ of the European Parliament and of the Council of 17 December 2013. The Omnibus Regulation takes precedence over national legal standards and therefore also over the application of Czech Act No. 134/2016 Coll., on public procurement.

Source: Responses to OECD questionnaires, March 2021.

\section{Way forward}

Close collaboration with beneficiaries and increased clarity in the relevant materials could significantly reduce the error rate. Feedback to consultation services provided by beneficiaries should be incorporated into guidelines and an FAQ.

In 2020, significant progress was achieved due to simplifications made possible by the COVID pandemic. Possibilities with respect to the continuation of those measures which have proven effective, e.g. simplified communication and expanding the electronic submission of documents, should be considered. These simplifications could also apply for the intermediate bodies and agencies as well.

In the call preparation phase, the cost and benefits of using multi-stage approvals should be evaluated and the phases of administrative verification and scientific evaluation should run in parallel where feasible. 
Streamlining the views of all governance bodies involved in the ESIF is crucial to avoid misunderstandings and false rejections of applications and reduce delays. As such, a common methodology should be developed at the national level for the assessment of the size category, cumulation of de minimis aid and determining the undertaking in difficulty. A specific department has been established at the Ministry of Economy to handle these issues. The notion of the common methodology regarding the assessment of the size of enterprises was proposed in reference to the simplification adopted by the Ministry of Economy as regards the verification of the SME status, which now only has to formally be true on the date of the signing of the contract. As previous multiple undertakings of the verification of the size of the enterprise have prolonged the process, the applicability of this change in methodology for other intermediate bodies should be analysed.

As a very large share of ESIF resources have been allocated through financial instruments and, in particular, via other specific objectives than previously foreseen, an analysis of the outcome of the spent funds in terms of achieved contribution towards R\&I purposes should be undertaken.

Confronted with difficulties disbursing funds, which would lead to decommittment, and the need for funds for SMEs during the pandemic, a large share of ESIF resources has been transferred from Thematic objectives 1 and 2 towards Thematic objective 3, and finally disbursed through financial instruments for a total amount of EUR 694.5 million. In crisis situations, governments often reallocate funding foreseen for research and innovation, which is not seen as urgent. Nevertheless, experience from OECD countries shows that retaining constant funding for R\&l over the long term is essential for sustainable development of knowledge-based economies.

As part of the envisioned ex post evaluations of the specific objectives, an impact analysis into the outcome of the financial instruments is foreseen. Such an analysis should reflect on the impact achieved on the economy in the short term (crisis relief) versus reduced funding available for R\&l in the medium and long term. The result should inform policy action in future crisis situations.

\section{Box 4.6. List of corrective actions and simplifications implemented by the Slovak Ministry of Economy along the process (improvements introduced in 2020 vs. issues identified in 2017/18)}

\section{Minimising the formal shortcomings in the documents submitted by applicants/beneficiaries through the introduction of predefined forms and tools for applicants/beneficiaries}

- For example, publication of an automated form for the SME Qualification Declaration (that includes all of the relevant instructions) to simplify its completion and reduce the error rate associated with completing it.

\section{Establishing an internal control body to ensure correct and effective verification of the size category of the undertaking/SME status, undertaking in difficulty and of de minimis aid accumulation}

\section{Minimising shortcomings in public procurement implemented by beneficiaries*}

- Elaboration and publication of a comprehensive and summary handbook on the public procurement process, including standardised predefined/model forms and documents on the public procurement process (such as model minutes of tender evaluation, model market research record, model of the beneficiary's solemn declaration of exclusion of conflicts of interest in the public procurement process, model minutes of the evaluation of the conditions of participation, the requisites of tender documents for individual types of contracts, as well as the draft contracts that are part of them), the most common mistakes in various stages of the public procurement process, and checklists for beneficiaries on the completeness of public procurement documentation submitted for control.

- Elaboration and publication of:

○ answers to frequently asked questions (FAQ) 
- guidelines for the process of awarding in-house and horizontal co-operation contracts

- guidelines for the application of the principles of social public procurement

- guidelines for the application of the principles of green public procurement.

- Training and personal, telephone and written consultations for beneficiaries.

Establishing the possibility of ongoing reimbursement of expenditure related to the purchase of tangible and intangible assets

- The possibility for beneficiaries to submit interim payment requests related to the purchase of tangible and intangible assets without these expenditures being included in the beneficiary's assets.

Introducing temporary measures to speed up the drawing of funds and to meet the annual financial commitments under the $n+3$ rule

- Establishing the possibility of applying advance payments.

- Establishing the possibility of safeguarding the claims (funds provided) after the related request for payment is paid to the beneficiary.

- Applying the principles of crisis management for the implementation of projects that have the potential to contribute to the annual financial commitments under the $n+3$ rule, involving:

- shortening the set procedural deadlines of the Slovak Ministry of Economy (especially regarding contract preparation, approval of public procurements, approval of applications for payment, approval of change requests, verification of cost effectiveness)

- improving communication with beneficiaries in order to reduce the error rate of their outputs and to accelerate the implementation of actions aimed at submitting requests for payment

- optimising co-operation with the Public Procurement Office by prioritising the control of the over-limit public procurements that could contribute to the fulfilment of the set financial goals/commitments

- flexible personnel management in order to optimise the workload of administrative capacities.

\section{Introducing new forms of granting to reach the widest possible target group with a minimum administrative burden}

- In order to create an effective form of providing support for SME projects with a low amount of financial support (up to EUR 10000 ), the Ministry of Economy has introduced a so-called voucher system, which was applied within the national project "Support for the development of creative industries in Slovakia" aimed at stimulating the demand of SMEs for creative industry services and thus contributing to the development of creative industries in the Slovak Republic. The aim of this mechanism was to set the simplest possible conditions for the preparation and implementation of SME projects corresponding to the low amount of support provided (EUR 5000-10 000).

\section{Measures adopted in response to COVID-19}

- In response to the spread of COVID-19 and its negative impact on the implementation of projects, the Ministry of Economy has introduced several measures to reduce the administrative burden on beneficiaries and ensure the smoothest possible implementation of projects and their cash-flows during this period. The measures include simplification in the field of communication, signing and submission of documents with maximum use of electronic submission, extension of the set procedural time limits for beneficiaries, non-penalising of beneficiaries in case of non-compliance with set procedural deadlines, creation of conditions for documentary (administrative) verification of project implementation, which used to be verified on the spot, simplification of the rules for safeguarding of the claims (funds provided), etc. 
* Some of these measures were already developed or are in use in other public procurement procedures; some of them will require close collaboration with the Public Procurement Office. Chapter 5 provides a comprehensive view and elaborates on specific recommendations for improving the public procurement process for research and innovation ESIF projects.

Source: Ministry of Economy.

The financial instruments have proven to be relatively easily disbursed, in particular for SIHAZ 2, with the generous conditions of $90 \%$ of loss guaranteed for the full portfolio. The downside is of course the very low leverage factor achieved, barely 1.1, whereas the norm is 6 or more. This can be justified by the pandemic; however, the success of the first such instrument under standard conditions $(80 \%$ of loss for $20 \%$ of the portfolio) would suggest that such conditions would also have been acceptable.

A comparison of the experiences of the pandemic response should be made between the Research Agency's approach, which prepared a specific call for grants, and the Ministry of Economy's approach of generous credit guarantees. It would be important to assess the value for money achieved through the financial instruments, given the very low leverage factor.

\subsection{Difficulties concerning project evaluation}

\section{Symptoms}

The insufficient availability and contracting of evaluators to assess applicants' projects has been a major reason that intermediate bodies and co-operating agencies have been unable to achieve progress in a timely manner. In particular, after 2018, the search for evaluators was a major concern and caused major delays. Since then, progress has been made in establishing databases of expert evaluators, at both the Ministry of Economy and the Research Agency.

Use of foreign evaluators has been limited since applications are submitted in Slovak only and overall incentives for foreign experts are low considering the compensation and the amount of work involved.

In addition, the evaluations themselves have been criticised for being too subjective and often not rewarding the true innovativeness of a project. Beneficiaries have voiced concern that some of the evaluations were very questionable, in particular when the two (or three) evaluators reached opposing conclusions.

Irregularities in 2016 and 2017 with some selected evaluators resulted in audits, which in turn prompted the adoption of new evaluator selection criteria.

\section{Causes}

After the aforementioned implementation of new criteria for the evaluator selection in response to the irregularities involving an expert evaluator in 2017, intermediate bodies and co-operating agencies have faced difficulties finding evaluators. As the irregularities were accompanied by negative media, the reputation of evaluators has suffered dramatically. This has left many potential evaluators unwilling to perform evaluations, as the new requirements stipulate that the evaluator's name must be made public. In addition, incentives for evaluators are low, as pre-tax remuneration amounts to around EUR 200 per project. This is even more so as the demanded requirements regarding the qualification of evaluators are very high. As such, potential evaluators are required to have the following qualifications:

- a PhD in the relevant field

- an $\mathrm{H}$-factor of at least 11 (i.e. 11 scientific publications with 11 citations each)

- experience with projects in the relevant field. 
Moreover, evaluators are required to have a very extensive array of expertise to assess the various parts of the project, ranging from the science, project management, software development and public procurement to global market trends and prices. Finding evaluators who are knowledgeable in all of these areas is unlikely, as such experts typically work full-time.

Considering the reputation concerns, the low compensation and the high requirements, the low availability of willing evaluators is unsurprising. If a project is undertaken within a specific research area, it proves particularly problematic if not impossible to find adequate evaluators. This problem is exacerbated by the fact that the Slovak Republic has a relatively small population, which makes it inherently difficult for intermediate bodies to find evaluators who also fulfil the requirements of no conflict of interest, i.e. not being acquainted with the beneficiaries. This poses a significant additional barrier, in particular as beneficiaries and evaluators often come from the academic sector, where the likelihood of affiliation is high.

This issue has been partially addressed through reliance on international evaluators. One advantage of including international evaluators is that they are often more aware of global developments and if a proposed innovation project already exists in another country. Greater reliance on international evaluators can guarantee a better quality assessment, as they tend to be more knowledgeable about global trends in science and markets. Another advantage is avoiding conflict of interest, since international evaluators usually do not have links with local applicants. Therefore, the inclusion of international evaluators could help alleviate the problem of finding sufficient, capable and independent experts.

In this endeavour, the language barrier is a major consideration:

- For proposals written in Slovak, the only evaluators outside of the Slovak Republic which could evaluate them are Czechs (since the two languages are sufficiently similar to allow good understanding without translation), or researchers from the Slovak and Czech diaspora living and working abroad.

- Another solution is to translate the proposals into English to allow the participation of a broad international scientific community in the evaluation process. It must be noted that submissions in English are already a prerequisite for national calls for grants administered by the Slovak Research and Development Agency's long-term strategic research, but this was not the case in ESIF submissions.

In an initial effort to overcome the limitations of the available pool of evaluators in the Slovak Republic, the intermediate bodies and co-operating agencies, most notably the Research Agency, used evaluators from the Czech Republic. However, the efficiency of this initiative was limited by two factors:

- Originally, the evaluators were required to be present on the intermediate bodies' premises, and this created difficulties in finding Czech evaluators willing to go to Bratislava.

- In addition, evaluators were sought through open calls rather than proactively contacted or targeted through campaigns, which might prove an effective solution for finding evaluators, in particular among the Slovak diaspora. The proactive element is crucial in this regard, as otherwise awareness about the search for expert evaluators remains low. The Research Agency has compiled a database of more than 100 potential evaluators, also from the Czech Republic, in an effort to avoid conflicts of interests.

In some cases, notably the long-term research projects, the Research Agency made use of a two-stage call preparation and submission process with international evaluators evaluating the project idea and strategy in the first phase, while Slovak evaluators perform the more in-depth criteria-based evaluation. For the first phase, the short outlines of projects in English were sent to international evaluators. However, the evaluation outcome by those evaluators was returned to the Slovak Republic six to eight months later. Pursuant to this initial evaluation of the project strategy, the applicants had another three to four months 
available to incorporate suggestions and amendments before the second phase was initiated, this time with the full project proposals in Slovak, evaluated by Slovak (and sometimes Czech) evaluators.

There are several additional issues concerning the contracting of adequate evaluators. One is the workload required for the evaluation of a project with regards to the fee, which corresponds to a remuneration for about ten working hours. Due to the fact that manuals used for the evaluation comprise 160 pages of rules, the ten hours are barely sufficient for the full understanding of the manual, much less for the evaluation of the project proposal itself. What is more, until a recent change in the regulations, the evaluator had to be physically present on the premises of the intermediate body for the time of the evaluation. A new computer system has since been established to allow for remote evaluations aiming at simultaneously ensuring an independent evaluation. Altogether, however, finding an expert in a given field who fulfils all of the aforementioned criteria and is not only willing, but also available, to commit a significant amount of time to undertake the evaluation at the intermediate body's premises for low pay has thus proven to be a crucial impediment to implementing the ESIF.

\section{Box 4.7. Comparing challenges in finding evaluators with the Czech Republic and Estonia}

\section{Estonia}

HavWithing a smaller population than the Slovak Republic, Estonia is confronted with similar challenges when it comes to finding evaluators that are independent to avoid a conflict of interest. Foreign evaluators are used as much as possible by some agencies, albeit not all, and overall experience with them has been described as positive for both the intermediate bodies and the beneficiaries. Although most potential foreign evaluators decline, it is generally possible to find two to three evaluators per application. If it is determined to use foreign evaluators for a given call, the applications are made available in English. Moreover, it is common for intermediate body/agency employees to evaluate the project in-house at no extra cost; however, this is dependent on the project. When external expertise is required, compensation typically ranges from EUR 150 to EUR 500 per project. The time per evaluation is very project-dependent, from 1 to 16 hours or more. Compared to the Slovak Republic, Estonia thus pays slightly more per project, makes intensive use of foreign evaluators and has notably much shorter evaluation manuals, around 2-5 pages compared to 160 pages in the Slovak Republic.

\section{Czech Republic}

In the Czech Republic, the evaluation process is dependent on the intermediate body. The Prague Growth Pole, for instance, contracts companies through open calls in accordance with the Public Procurement Act to perform the evaluation which is part of the company's employees' duties. Other intermediate bodies use their own databases, which classify evaluators according to their scientific field. Qualification requirements vary depending on the intermediate body, with some demanding a minimum of a $\mathrm{PhD}$ and several years of experience for the scientific evaluation while for others, a high school degree can be enough if compensated by 15 years of relevant experience. Evaluators themselves are regularly assessed according to the validity of their evaluation results. The monitoring system automatically assigns evaluators in the relevant field to the project; however, it is common that in some areas, there is a shortage of evaluators. In this case, the intermediate body will contact Czech bodies such as the Council of Universities or the Czech Academy of Sciences to ask if they can motivate their employees. Otherwise, foreign evaluators may be used by contacting foreign institutions, not individuals, to publish a corresponding advertisement.

In general, however, using foreign evaluators in the Czech Republic is rather complicated due to national law stipulating that these processes need to be conducted in Czech. Further, past experiences had shown it was only feasible to use foreign evaluators for select prestigious calls and only for the scientific part as they reached very different conclusions on the economic part. As such, foreign 
evaluators would determine the wages as insufficient while those wages would be deemed excessive in the Czech Republic. Thus, foreign evaluators might only be tasked to assess the feasibility study, which is then provided in English, and whether the project is deemed cutting-edge internationally. For this matter, applicants are asked to provide relevant parts of the application in both Czech and English.

The remuneration is comparable to that in the Slovak Republic, and even though it is deemed too low, it is bound by law to be indexed to Czech salaries. The length of the evaluations is very projectdependent, but can be as much as 60 hours for the most complex projects, while evaluation manuals are 25-70 pages long and thus significantly shorter than in the Slovak Republic.

Overall, it is common in the benchmarking countries to make use of all external expert panels/companies, own full-time employees and foreign evaluators depending on the intermediate body. Remuneration is low in all countries, with Estonia being able to pay slightly above average as it is not held back by national legislation, as is the case for English language applications, which allows Estonian intermediate bodies to use foreign evaluators as much as possible if they want to. Evaluation time per project appears to vary per project in all countries, although the Slovak Republic has by far the longest manuals. Evaluators in the Slovak Republic have complained that the allotted time for the evaluation, e.g. 10 hours, is not even enough to read all 160 pages of the manual. Requirements for evaluators are high in both benchmarking countries, although they appear to be lower than in the Slovak Republic and generally more flexible.

Source: Responses to OECD questionnaires, March 2021.

\section{Way forward}

The OECD recommends using English language applications for at least the science parts of research projects so as to allow for evaluation by international experts. Including international experts in the evaluation process would significantly help reduce delays by expanding the choice of available evaluators. As these evaluators tend to be knowledgeable about global markets and developments, it is likely that the quality of the assessments will increase. In addition, making use of foreign evaluators ensures independence and avoids conflicts of interest. For the Slovak Research and Development Agency's projects, applications are to be submitted in English regardless, which showcases that it is feasible to request applicants to provide translations and that it should not constitute a significant barrier. As in the benchmarking countries, applications could be submitted in English, if it is known beforehand that international evaluators will be used.

The search for evaluators should include different channels if possible. Ideally, databases should be established, as is already the case for some fields of expertise in the intermediate bodies. If foreign evaluators are to be used, heads of foreign institutions should be proactively contacted and asked to advertise the roles among their staff rather than contacting individuals separately.

Higher remuneration could incentivise more professionals to perform ESIF project evaluations. All intermediate bodies must therefore have the financial means to contract evaluators.

In particular, in niche expertise areas, some flexibility from the intermediate bodies regarding the criteria for the selection of evaluators is advisable if evaluators do not fulfil all of the criteria but compensate for the missing diploma (e.g. Ph.D) with a Master's degree combined with extensive professional experience and a track record in the field.

Evaluation manuals should be reduced significantly in length and the allocated time frame for performing the evaluation should realistically reflect the amount of time necessary for the evaluator to study the rules and definitions. Criteria for evaluation should be as objective as possible to streamline results across evaluators. Particular prominence and more emphasis for innovativeness criteria are warranted to ensure 
that the most innovative projects are supported. It may be useful to regularly evaluate the performance of the evaluators themselves to ensure quality evaluation and accountability.

In contrast to the ESIF calls, the evaluation process with regard to Horizon 2020 projects is considerably shorter and the response by evaluators is straightforward according to beneficiaries. The Horizon 2020 expert evaluator database could serve as a best practice, because a pool of international evaluators who are experienced in their field could provide an effective means for more efficient evaluation of ESIF projects. The Horizon 2020 process, therefore, could serve as a role model to enhance efficiency. In particular, the relevant Horizon 2020 evaluators in Brussels could provide support if needed.

Training for Slovak evaluators by Horizon 2020 staff may be an effective mechanism for developing the needed skills.

\subsection{Excessive administrative requirements and gold-plating}

\section{Symptoms}

With regard to call preparation, some calls have been published in multiple stages, which have seen procedures take considerably longer. Amendments to calls as well as grant agreements later on are difficult to implement, meaning that if a change becomes necessary, it can prolong procedures quite severely.

In the administrative verification and evaluation phases, applicants provide several documents to be assessed by the intermediate bodies and evaluators. Many of these, including timesheet requirements, procurement items and the status of the size of enterprises, only have a validity of up to three months, and since it is not uncommon for the entire implementation process to last several years, these documents need to be submitted multiple times.

Similarly, some of the same documents are required at various stages by different controlling bodies. This situation is exacerbated by the IMTS online submission portal, which requires the same documents to be uploaded several times and does not provide any possibility to cross-check whether all of the required information and documents have been uploaded.

For SME projects, the verification of the status of the beneficiary is a complex and time-consuming task. Namely, the criteria for determining whether the company qualifies as an SME can be complex, in particular when the company has corporate shareholding and could potentially be seen as a subsidiary of a large company rather than an SME. For this purpose, all other companies with which the potential beneficiary maintains relations need to be evaluated against these criteria. This represents one of the most cumbersome and lengthy tasks.

The use of both ex ante and ex post controls in the administrative verification means that beneficiaries commit significant resources and time to the formal fulfilment of all criteria for the ex ante controls. However, as mentioned previously, about a third of applications do not pass this first phase and an additional share will get rejected during the scientific evaluation. The trade-off of invested work to pass all ex ante checks and the relatively low chances of eventually receiving funding act as a major deterrent in companies applying for the ESIF.

For all projects, the verification of the market research justifying the expected costs is a long and overly extensive task. This is particularly true for the procurement of very specific scientific equipment. On the one hand, applicants encounter major difficulties in providing the required three bids (for some equipment there are very few suppliers); on the other, the intermediate body has to determine the mathematical correctness, i.e. go into the sub-items of the bids and verify all of the sums for all of the items. In some cases there are 1000 or more pages of such bids to cross-check.

Timesheet requirements set by the intermediate bodies require beneficiaries to submit the hourly wages of all employees, outlining activities to the minute (including lunch breaks) and updating them regularly. 
This is particularly problematic for long-term strategic research projects, as employees and wages change. Beneficiaries are obliged to request approval for each change in the budget. As the timesheet information has to be provided within the budget as well, each change in either wage or staff translates into a change in the budget, which implies another approval. Individual beneficiaries have accumulated thousands of pages of timesheets, with three to four employees being occupied with collecting the timesheets for all personnel. Together with the other required documents (including tender documents, publications, activity reports), at one university with 80 staff members, these timesheets which need to be submitted in hard copies via mail amount to $7-10 \mathrm{~kg}$ of paper per month. These extensive requirements on reporting pose the greatest burden for many beneficiaries and shift the focus from research activities to administration.

In the budget, a separate column with explanatory information is required for each budget line. This in turn creates problems in the implementation, as the comments in the budget are required to correspond to the needs in the implementation phase. If the information needs to be amended, this constitutes a change to the contract and thus requires formal approval by the Research Agency.

Due to documents only being valid for three months and the administrative assessment often taking significantly longer, these documents need to be submitted multiple times. In particular, regarding the market research process, suppliers have become unwilling to provide bids, as no purchases have been made and they do not want to commit to a certain price.

\section{Causes}

In response to the aforementioned warning letter by the European Commission concerning the irregularities involving expert evaluators in 2017, ${ }^{13}$ several anti-corruption measures have been implemented in an attempt to prevent further decommissioning of ESI funds. The audit authority has introduced these measures to improve transparency, which has, however, inadvertently contributed to a complex administrative set-up as well as processes. These measures include repetitive, multi-layer and sometimes excessive controls, for instance as regards the verification of procured items, timesheets for beneficiaries' employees, de minimis schemes and the size of enterprises. Consequently, these added layers of checks turned the controls into the most time-consuming tasks in the administrative verification phase.

Further, the Ministry of Economy has developed a specific competence in the domain of determining the status of a business and is assisting the SIEA with this extensive task. Assessment methodologies are very complex since all relations with other companies have to be evaluated. At the Ministry of Economy, a department has been established to focus on these kinds of controls as well as on an accumulation of de minimis aid and undertaking the difficulty issue. These controls took several months, as in some cases, beneficiaries are asked to provide more information about relations with other companies, to see whether they can be considered for single unit status. The Ministry of Economy made a recommendation to assess a company's size only on the day of the agreement comes into force. Previously, the condition was required to hold and be controlled during the entire administrative verification process. This new rule is applicable to all calls since 2020 and within the next programming period, and is expected to simplify the process significantly.

Furthermore, the MoESRS and the Research Agency tend to be responsible for research-intensive projects which often involve many partners. As the verification of the size of enterprises has to be undertaken for all partners in a project as well, this partially explains the extensive delays encountered by the MoESRS and the Research Agency.

Some employees in the intermediate bodies exhibit risk-averse attitudes, such that in case of uncertainty, they require excessive and unnecessary documentation so that the intermediate body cannot be held

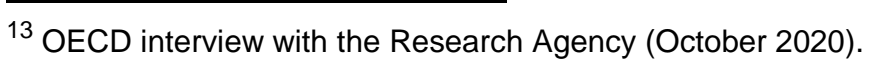


accountable for errors. This uncertainty arises in particular when human resources are not well-qualified and when there is a lack of administrative and technical competences around research projects.

Compared to the previous programming period 2007-13, the electronic submission of applications has proven to be cumbersome, as it is not user-friendly, in particular regarding submission of annexes, and also because there is no mechanism to check whether the right documents have been submitted. In addition, in many cases, documents have to be uploaded several times in different places on the ITMS interface (ITMS2014+ is the central IT monitoring system for ESIF-funded projects, further detailed in Chapter 5). These can also be provided at later requests by the agencies, which might mean further delays.

However, the templates are complicating the process, because some information cannot be retrieved automatically and needs to be input several times. For instance, budget items need to be put in with a description in the budget as well as in the description of the project, providing reasons with all of the technical parameters. In addition, this has to be provided again when writing about activities and how the item is used in this exact activity. Further, the electronic submission has raised beneficiaries' concerns about the General Data Protection Regulation and intellectual property protection, as the project strategies are openly visible.

\section{Box 4.8. Comparing administrative requirements in the Czech Republic and Estonia}

Overall administrative requirements surrounding the European structural and investment funds (ESIF) system are universally perceived as high in the benchmarking countries of the Czech Republic and Estonia, in particular with regard to verification of the small and medium-sized enterprise status and timesheet and wage requirements. Further, tenders constitute a significant bottleneck leading to the prolongation of public procurement procedures.

Estonia has adopted several simplification measures through a special task force for simplification under the managing authority. For instance, regarding timesheet requirements, the intermediate bodies rely on proportion estimates per month rather than specific numbers. Similarly, they make use of simplified cost options and lump sums as well as risk assessments to determine the extent of controls necessary. As such, in some cases, only $25 \%$ of supporting documents may be required. If the error rate increases, then controls are intensified accordingly. Finally, the threshold for requiring public procurement procedures has been increased from EUR 5000 to EUR 20000 . Multiple controls of documents on several levels lead to a high administrative burden, similar to that in the Slovak Republic. However, Estonia benefits from a sophisticated e-government system and the Structural Funds Operation System has interfaces with other IT systems. Further, it captures all communication with intermediate bodies and includes a project evaluation system which ensures transparent evaluation. Estonia undertakes large-scale investments into the IT infrastructure on the administrative side at the beginning of each programming period, which provides significant returns in terms of gained efficiency.

On the whole, intermediate bodies in Estonia demonstrate flexibility in the intensity of checks, depending on the instrument in question and the associated level of financial support, with the overall objective to reduce the administrative burden for beneficiaries. Relevant ministries and intermediate bodies from both the Czech Republic and Estonia confirmed to the OECD what had been voiced by Slovak parties, namely that the ESIF system is generally not well adapted to research and many of the requirements are not only unnecessary, but practically unfeasible in scientific research. Finally, it was mentioned that possibilities to give feedback to the European Commission as regards the practicality of the ESIF processes are very limited.

Source: Responses to OECD questionnaires, March 2021. 


\section{Way forward}

Significantly reduce the overall administrative burdens:

- Simplify timesheet requirements and only key personnel involved in the project should be included.

- Avoid the use of multi-stage calls.

- Simplify call as well as grant agreement amending procedures, i.e. through so-called technical amendments.

- Keep the budget column of additional comments for each budget line in a separate document outside the contract. This would allow changes in comments in the implementation phase without the need to request approval, as is the case with changes to information provided within the contract.

- Administrative verification and scientific evaluation should run in parallel as much as possible.

- The selection of evaluators, for instance, could occur while the administrative verification is still ongoing.

The OECD views the Dutch "justified trust" approach as a promising best practice example. Herein, public procurement controls are undertaken on a random basis and only expost. This approach has the significant advantage that it circumvents situations in which applicants invest time and resources into providing all of the necessary documents for ex ante controls without eventually having their project proposal approved in the scientific evaluation afterwards. This uncertainty in combination with the vast administrative requirements very likely deters potential applicants from applying for the ESIF altogether. In an analysis of the Dutch approach regarding the misuse of funds, it was found that misuse did not increase. Nevertheless, an analysis should be made in order to guarantee the integrity and adherence to the rule of law of the process so that ex post controls should be made the norm rather than only in occasional cases.

The benefits from a functioning and effective electronic portal which avoids duplication of efforts are particularly visible in Estonia. In the Slovak Republic, the ITMS portal should be improved or replaced by a more user-friendly system, like, for instance, a system similar to the H2020 portal. Overall, the Horizon 2020 process could serve as a guide, as it is considerably more efficient in spite of the high requirements in terms of information and documents that are required. As such, proposals include:

- Training for Slovak evaluators by Horizon 2020 staff.

- Try to establish exchange ("twinning") programmes, whereby a Horizon 2020 staff would come to the Slovak Republic to work on calls and share experience, and perhaps a Slovak staff member could go to Brussels.

- Establish contacts with Horizon 2020 teams to seek information, for example about costs and availability of equipment.

- Explore possibilities to liaise with Horizon 2020 staff regarding specific expertise on scientific equipment which may not be available within the Research Agency.

A large-scale investment into restructuring and updating an IT system fit for purpose at the beginning will pay off in the medium term.

This portal could be used for further simplification of application forms (e.g. through a grant application generator) and their instructions (pre-formatting, segmentation of fields, auto-validation of fields, use of prompts, default filling in of fields based on earlier information, print preview, tracking contract status, alerts on achieved milestones, etc.).

The Online Portal should enable:

1. providing forms for machine readable applications, and making this mandatory (if at all possible);

2. checking whether all documents are submitted; 
3. making simple checks of validity, such as checks of electronic signatures on documents, dates of issuance, etc.;

4. performing "mathematical correctness" or similar tests automatically, on machine readable data (perhaps controlled ex post by a human);

5. potential use of artificial intelligence tools for more sophisticated checks (for example, tax authorities develop such tools to check for fraud, perhaps some of them can be applicable here as well).

Human interaction needs to proceed via digital exchanges and paper mail should be avoided. E-mail, or messaging on specific secure platforms, should be the norm. Delays for response by the beneficiaries should be adapted to the digital age as well.

Ensure the audit authority and the Public Procurement Office have unified views regarding public procurement procedures and on the requirements for the audit trail to reduce the scope of checklists. 


\title{
Impediments to ESIF
} implementation in the public procurement procedures

\author{
This chapter assesses current practices of European Structural and \\ Investment Funds (ESIF) public procurement processes in the Slovak \\ Republic in order to identify key findings and recommendations to increase \\ the absorption of ESIF for the research and innovation (R\&I) sector. In \\ particular, this chapter intends to identify potential bottlenecks that could \\ delay the public procurement processes under ESIF projects, and thus \\ hinder the absorption capacity of ESIF funding for R\&I.
}

This chapter assesses current practices of European Structural and Investment Funds (ESIF) public procurement processes in the Slovak Republic in order to identify key findings and recommendations to increase the absorption of ESIF for the research and innovation (R\&I) sector. In particular, this chapter intends to identify potential bottlenecks that could delay the public procurement processes under ESIF projects, and thus hinder the absorption capacity of ESIF funding for R\&I. High administrative burdens could even result in mistrust in the ESIF system, and disincentives among beneficiaries to use the ESIF.

The following methods were used to analyse current practices of ESIF public procurement processes in the Slovak Republic:

- questionnaire on the general concepts and frameworks of ESIF public procurement sent to stakeholders, including the intermediate bodies (the Ministry of Economy and the Ministry of Education, Science, Research and Sport) and beneficiaries 
- feedback from participants during a virtual workshop held on 3 November 2020 to share the initial findings with stakeholders

- short questionnaire sent to eight beneficiaries to identify the potential bottlenecks of ESIF public procurement procedures

- a series of fact-finding video interviews with stakeholders.

During the virtual fact-finding meetings, the OECD met various stakeholders involved in ESIF R\&I projects: the Ministry of Transport and Construction, intermediate bodies (the Ministry of Economy and the Ministry of Education, Science, Research and Sport), the Research Agency, the Public Procurement Office, the certifying authority/audit authority at the Ministry of Finance, the Supreme Audit Office, and a number of beneficiaries.

In addition to the fact-finding meetings with Slovak stakeholders, the OECD requested public authorities of relevant EU member states (Estonia, Lithuania, Poland and Slovenia) to collaborate on the survey, providing examples and good practices of ESIF implementation in their national context, namely related to public procurement procedures. These entities are responsible for public procurement under ESIF projects, in particular, for carrying out controls. The objective of this short survey was to allow additional benchmarking of Slovak practices in order to strengthen the recommendations for solving the key bottlenecks in ESIF public procurement procedures.

Table 5.1. Entities of EU countries that responded to the short questionnaire on good practices of ESIF public procurement procedures

\begin{tabular}{c|l|c}
\hline Country & \multicolumn{1}{|c}{ Entity } & \multicolumn{1}{c}{ Role } \\
\hline Estonia & State Shared Service Centre & Managing authority \\
\hline \multirow{2}{*}{ Lithuania } & Public Procurement Office & Public procurement authority \\
\cline { 2 - 3 } & European Social Fund Agency & Intermediate body \\
\cline { 2 - 3 } & Central Project Management Agency & Intermediate body \\
\cline { 2 - 3 } & Environmental Projects Management Agency & Intermediate body \\
\cline { 2 - 3 } & Lithuanian Business Support Agency & Intermediate body \\
\hline \multirow{2}{*}{ Poland } & Public Procurement Office & Public procurement authority \\
\cline { 2 - 3 } & Ministry of Development Funds and Regional Policy & Managing authority \\
\hline Slovenia & Public Procurement Directorate, Ministry of Public Administration & Public procurement authority \\
\hline
\end{tabular}

\subsection{The complex and multi-layered control system lacks legal certainty and creates delays}

Public procurement procedures under ESIF-funded projects are carried out in accordance with the same rules stipulated in the Public Procurement Act (PPA). The fundamental difference lies in the specific controls required by the intermediate body and the Public Procurement Office (PPO) at each procurement stage of ESIF projects. This section starts with an overview of the control system of ESIF public procurement, then identifies bottlenecks and challenges.

\section{Overview of the control system of public procurement under ESIF projects in the Slovak Republic: Ex ante and ex post controls are both carried out intensely}

Two types of controls are carried out under the procurement of ESIF projects: ex ante and ex post. Ex ante controls are carried out at two stages: 1) before the publication of the tender notice; and 2) before the signing of the contract. The first ex ante control is carried out before the publication of the tender publication by the intermediate body for above-threshold procurement (Table 5.2) and the PPO (optional). In 
accordance with Article 168 of the PPA, the first ex ante control by the PPO is limited to legal compliance checks. In other words, it does not apply to the assessment of the technical/functional requirements, such as technical specifications, which is the responsibility of the intermediate body. The second ex ante control is carried out before the signing of the contract by the intermediate body for above-threshold procurement (Table 5.2), and by the PPO for the procurement of the goods and services whose estimated value is above EUR 600 000, as well as for construction works whose estimated value exceeds the above-threshold amount (EUR 5350000 in 2020).

Ex post control is carried out by the intermediate body immediately after the signing of the contract. The follow-up ex post control is applicable to the procurement procedures that were subject to the second ex ante control, while the standard ex post control is carried out for those without the second ex ante control and with a contract value more than EUR 5000 . Amendments to the contract after the signing of the contract are also subject to the second ex ante control and/or ex post control by the intermediate body.

\section{Table 5.2. Thresholds for public procurement control under ESIF projects}

\section{EUR}

\begin{tabular}{|c|c|c|c|c|c|c|}
\hline \multirow[b]{2}{*}{$\begin{array}{l}\text { Subject of } \\
\text { procurement }\end{array}$} & \multicolumn{3}{|c|}{$\begin{array}{l}\text { First/second ex ante controls } \\
\text { Follow-up ex post control }\end{array}$} & \multicolumn{3}{|c|}{ Standard ex post control } \\
\hline & $\begin{array}{l}\text { Contracting } \\
\text { authorities }\end{array}$ & $\begin{array}{l}\text { Subnational } \\
\text { governments } \\
\text { and public } \\
\text { entities } \\
\text { governed by } \\
\text { public law }\end{array}$ & $\begin{array}{l}\text { Subsidised } \\
\text { contracts by } \\
\text { more than } \\
50 \%\end{array}$ & $\begin{array}{l}\text { Contracting } \\
\text { authorities }\end{array}$ & $\begin{array}{l}\text { Subnational } \\
\text { governments } \\
\text { and public } \\
\text { entities } \\
\text { governed by } \\
\text { public law }\end{array}$ & $\begin{array}{c}\text { Subsidised } \\
\text { contracts by } \\
\text { more than } \\
50 \%\end{array}$ \\
\hline $\begin{array}{l}\text { Goods and } \\
\text { services }\end{array}$ & $\geq 139000$ & $\geq 214000$ & $\geq 139000$ & $\begin{array}{c}\geq 5000 \\
<139000\end{array}$ & $\begin{array}{c}\geq 5000 \\
<214000\end{array}$ & $\begin{array}{c}\geq 5000 \\
<139000\end{array}$ \\
\hline Works & \multicolumn{3}{|c|}{$\geq 5350000$} & \multicolumn{3}{|c|}{$\begin{aligned} & \geq 5000 \\
&<5350000\end{aligned}$} \\
\hline $\begin{array}{l}\text { Social services } \\
\text { or other specific } \\
\text { services listed } \\
\text { in the Public } \\
\text { Procurement } \\
\text { Act, Annex } 1\end{array}$ & \multicolumn{3}{|c|}{$\geq 750000$} & \multicolumn{3}{|c|}{$\geq 5000<750000$} \\
\hline
\end{tabular}

Source: Information provided by the implementing bodies.

Each type of control is carried out in accordance with the methodology set out in the regulatory frameworks prepared by the central co-ordination authority, such as the ESIF Management System and the methodical guidelines on public procurement, as well as the guidelines elaborated by the intermediate bodies, including specific checklists for each type of control. Checklists include a set of questions to be dealt with during the control. Beneficiaries are required to answer each question of the relevant checklist and provide references to the supporting documents which were subjected to the control. Beneficiaries are not allowed to move forward until the control procedures are completed.

Tabnle 5.3 summarises the control system of public procurement under ESIF projects.

Table 5.3. Control system of public procurement under ESIF projects in the Slovak Republic

\begin{tabular}{c|c|c|c|c}
\hline & Stages & Timing & Who controls & $\begin{array}{c}\text { Duration of approval process specified in } \\
\text { the legal framework }\end{array}$ \\
\hline
\end{tabular}




\begin{tabular}{l|l|l|l|l}
\hline $\begin{array}{l}\text { Ex ante } \\
\text { control }\end{array}$ & $\begin{array}{l}\text { First } \\
\text { ex ante } \\
\text { control }\end{array}$ & $\begin{array}{l}\text { Before } \\
\text { publication of } \\
\text { tender notice }\end{array}$ & $\begin{array}{l}\text { Intermediate body (only for above-threshold, which } \\
\text { differs for each subject of contract, etc.) } \\
\text { Public Procurement Office (optional, not mandatory) }\end{array}$ & $\begin{array}{l}\text { Intermediate body: 15 working days (ESIF } \\
\text { Management System) } \\
\text { Public Procurement Office: } 30 \text { working days } \\
\text { (Article 168 of the Public Procurement Act) }\end{array}$ \\
\hline $\begin{array}{l}\text { Ex ante } \\
\text { control }\end{array}$ & $\begin{array}{l}\text { Second } \\
\text { ex ante } \\
\text { control }\end{array}$ & $\begin{array}{l}\text { Before signing } \\
\text { the contract }\end{array}$ & $\begin{array}{l}\text { Intermediate body (only for above-threshold, which } \\
\text { differs for each subject of contract, etc.) } \\
\text { Public Procurement Office (mandatory for the } \\
\text { procurement of: goods and services with a value } \\
\text { above EUR 600 000; and construction works whose } \\
\text { estimated value is more than an above-threshold } \\
\text { contract (EUR 5 350 000 in 2020) }\end{array}$ & $\begin{array}{l}\text { Intermediate body: 20 working days (ESIF } \\
\text { Management System ) } \\
\text { Public Procurement Office: } 30 \text { working days } \\
\text { (Article 169 2-b of the Public Procurement } \\
\text { Act) }\end{array}$ \\
\hline $\begin{array}{l}\text { Ex post } \\
\text { control }\end{array}$ & $\begin{array}{l}\text { Follow-up } \\
\text { ex post } \\
\text { control }\end{array}$ & $\begin{array}{l}\text { After the } \\
\text { signing of the } \\
\text { contract }\end{array}$ & $\begin{array}{l}\text { Intermediate body (only for the tender subject to a } \\
\text { second ex ante control) }\end{array}$ & $\begin{array}{l}\text { Intermediate body: 7 working days (ESIF } \\
\text { Management System) }\end{array}$ \\
\hline $\begin{array}{l}\text { Ex post } \\
\text { control }\end{array}$ & $\begin{array}{l}\text { Standard } \\
\text { ex post } \\
\text { control }\end{array}$ & $\begin{array}{l}\text { After the } \\
\text { signing of } \\
\text { contracts }\end{array}$ & $\begin{array}{l}\text { Intermediate body (contract value above } \\
\text { EUR 5 000) }\end{array}$ & $\begin{array}{l}\text { Intermediate body: 20 working days (ESIF } \\
\text { Management System) }\end{array}$ \\
\hline
\end{tabular}

Source: Prepared in accordance with the Central Coordination Authority (2014[6]) and the Public Procurement Office (2015[7]).

Currently, intermediate bodies are the main actors that implement public procurement control under the ESIF programming period 2014-20. However, it is expected that the PPO will take over this role under the next programming period (2021-27), and will be responsible for carrying out both ex ante and ex post controls. Control officers of public procurement currently working at intermediate bodies are expected to move to the PPO to assume the control tasks. Although the details for the programming period 2021-27 have not yet been finalised, the Slovak Republic will benefit from reviewing the control system of ESIF public procurement, while balancing the administrative burdens (time and cost) related to the control with transparency and effectiveness, in comparison to practices in EU other countries.

It should be noted that EU countries like Estonia, Lithuania and Poland focus more on ex post control than on ex ante control. Table 5.4 benchmarks the Slovak Republic against other EU countries in terms of the control system of ESIF public procurement.

\section{Table 5.4. Overview of the public procurement control system under ESIF projects in elect EU} countries

\begin{tabular}{l|c|c|c|c}
\hline \multicolumn{1}{c|}{ Control stages } & Slovak Republic & Estonia & Lithuania & Poland \\
\hline $\begin{array}{l}\text { Ex ante control before the } \\
\text { publication of the tender notice }\end{array}$ & $\begin{array}{c}\text { Yes (above- } \\
\text { threshold) }\end{array}$ & $\begin{array}{c}\text { No (no obligation but } \\
\text { right/option of } \\
\text { beneficiary) }\end{array}$ & $\begin{array}{c}\text { No (no obligation but } \\
\text { right/option of beneficiary) }\end{array}$ & $\begin{array}{c}\text { No (no obligation but } \\
\text { right/option of } \\
\text { beneficiary) }\end{array}$ \\
\hline $\begin{array}{l}\text { Ex ante control before signing } \\
\text { the contract with successful } \\
\text { bidders }\end{array}$ & $\begin{array}{c}\text { Yes (above- } \\
\text { threshold) }\end{array}$ & $\begin{array}{c}\text { No obligation but } \\
\text { right/option of } \\
\text { beneficiary) }\end{array}$ & $\begin{array}{c}\text { Yes/no (depends on each } \\
\text { intermediate body) }\end{array}$ & Yes (above-threshold) \\
\hline $\begin{array}{l}\text { Ex post control after signing the } \\
\text { contract }\end{array}$ & Yes & Yes & Yes & Yes (but not for all) \\
\hline
\end{tabular}

Notes: This table summarises and simplifies the control system of each country for the purpose of demonstrating the overall general tendency. There are more operational details in each country.

Source: Responses to OECD short questionnaires from Estonia, Lithuania and Poland, March 2021.

In general, these countries focus on ex post control; ex ante control is optional. In contrast, both ex ante and ex post controls are carried out intensely in the Slovak Republic. In Estonia, the procurement procedure as a whole is checked after the award of the contract (ex post control). Ex ante control is not mandatory, but optional at the request of beneficiaries. For some measures, however, ex ante control is mandatory if the managing authority/intermediate body considers the risks to be high; for example, in the 
case of large-scale investments like road construction, building health care institutions or the risks associated with the beneficiary's profile. However, the basic concept is to minimise ex ante control.

In Poland, the ex ante control before the public of tender notice is not mandatory, but optional. The ex ante control before signing the contract is performed by the PPO only for above-threshold procurement (EUR 10 million for goods and services and EUR 20 million for public works). At the request of the managing authority, the Polish PPO may refrain from carrying out this ex ante control if it deesm that the procedure was conducted in a manner consistent with the provisions of the Public Procurement Law. In Poland, ex post control is not carried out for all procurement procedures under ESIF projects. As a general rule, all contracts exceeding the EU thresholds and a sample of other contracts are verified by either the managing authority or the intermediate body that directly supervises the ESIF-funded contract. The sample is selected by taking into account risk factors and complemented by a random sample to ensure that all items have the probability of being selected. The PPO also carries out ex post control called an ad hoc control at the request of the managing authority or of the paying agency, if there is a reasonable suspicion that the provisions of the Public Procurement Law were violated.

In Lithuania, the control system differs among each intermediate body. However, in most cases, it is similar to Estonia's and Poland's in the sense that the ex ante control is not mandatory but optional, and shall be carried out only under certain circumstances, such as above-threshold procedures, past breach of beneficiaries in complying with the Public Procurement Law and other risk factors such as public attention (Box 5.1). 


\section{Box 5.1. Control system of the Environmental Projects Management Agency of Lithuania}

The Environmental Projects Management Agency (APVA) under the Ministry of Environment of Lithuania acts as an intermediate body which is in charge of carrying out public procurement control for the European Structural and Investment Funds projects related to the environment. The APVA implements a two-stage ex ante control before the publication of the tender notice and before/after signing the contract with successful bidders, but only for the public procurement procedures that meet the criteria, such as:

- the estimated value of procurement is more than EUR 134000 for the purchases of goods/services and more than EUR 5186000 for the procurement of public works

- for the procurement of a contracting authority (beneficiary) which has been found to be in breach of the requirements for procurement procedures in the programming period $2014-20$

- the existence of certain risk factors, such as public interest/attention, negative information broadcast in the media, etc.

The procurement procedures that do not meet the criteria of the two-stage ex ante control are subject to the one-stage control before signing the contract with successful bidders.

Follow-up control is carried out after the contracts are signed until the confirmation of the eligibility of expenditure, but it is applied only to $5 \%$ of procurement procedures, selected at random, considering that controls have been implemented before signing of contracts.

The APVA's procedural manuals stipulate that each control shall be carried out within 30 days. Sometimes, the time frame exceeds 30 days if additional information is required. However, this does not occur often, and the control for $95 \%$ of public procurement procedures is completed on time.

Source: Information provided by the APVA and the Public Procurement Office of Lithuania.

There is always a trade-off in any control system between the administrative burdens (cost and time) and transparency/effectiveness in preventing errors in public procurement procedures. Countries recognise that irregularities are found sometimes due to the limited ex ante control. However, the percentage of irregularities is not high enough to require significant ex ante control, considering the administrative burdens required for such control and their impact on cost and time. In addition, countries regularly provide consultations and trainings on public procurement, such as the most common mistakes, in order to prevent errors in public procurement procedures, especially for EU-funded projects.

\section{Way forward}

Review the overall control system of ESIF public procurement by carrying out an evidence-based analysis of the trade-off between administrative burdens (cost and time) and transparency/effectiveness in preventing errors in public procurement.

\section{Control procedures of ESIF public procurement delay project implementation, putting high administrative and bureaucratic burdens on beneficiaries}

The control part of the public procurement process is identified as one of the main factors contributing to the delay of the implementation of ESIF-funded projects. Beneficiaries describe the control system of ESIF 
public procurement as long and inefficient, which causes unnecessary administrative burdens and delays in ESIF project implementation with repetitive checks. Some beneficiaries even described it as a principal example of the systematic failure of the ESIF Management System.

The regulatory frameworks such as the ESIF Management System specify the deadline for the approval of each control performed by the intermediate bodies. Beneficiaries stated that these processes add approximately half a year to the ESIF procurement process, even if they are completed on time. However, interviews with various stakeholders, including the intermediate bodies and beneficiaries, demonstrate that the actual approval for each control takes more time than the approval duration specified in the ESIF regulatory framework.

Beneficiaries shared their views that it takes twice the amount of time foreseen in the regulatory framework. According to the intermediate bodies, for example, it takes a few months to complete the second ex ante control; the regulatory requirement states 20 working days by the intermediate body and 30 working days by the PPO. It should be noted that the PPO can not start its ex ante control processes before the intermediate body finishes them. Standard ex post control, which shall be performed within 20 working days, often takes one month for contracts above EUR 50 000, and up to a few months for low-value contracts up to EUR 50000 , due to the large quantity of procurement procedures which fall into this category. Follow-up ex post control should be completed within seven working days, because a similar control is carried out during the second ex ante control before signing the contract. However, beneficiaries stated that even the follow-up expost control does not comply with the specified deadline, because controllers tend to reflect recent audit practices.

Intermediate bodies state that it takes a long time to complete the control processes due to the incomplete documentation of public procurement procedures as well as incorrect filling in of checklists that beneficiaries are required to submit with the control documents. For example, they listed the absence of documentation such as affidavits of the beneficiary on the completeness of the documentation and its compliance with the original, affidavits on conflicts of interest, documents to determine the estimated value of the contract, in which the not-allowed reserve amount is sometimes included by mistake.

Table 5.5 lists the typical documents that beneficiaries are requested to submit in order to request the control of public procurement.

\section{Table 5.5. Documents required for public procurement control under the ESIF}

\begin{tabular}{l|l}
\hline \multicolumn{1}{c|}{ Types of control } & \multicolumn{1}{c}{ Required documents } \\
\hline $\begin{array}{l}\text { First ex ante control } \\
\text { (before publication of the tender } \\
\text { and contract notice) }\end{array}$ & 1) Calculation of the estimated value of the contract including relevant source \\
documents & 2) Draft tender notice (call for tender) \\
& 3) Draft tender documents (instructions to tenderers + technical specifications + \\
description of the contract) & 4) Draft contract \\
& 5) Authorisation to carry out public procurement by a body other than the \\
& beneficiary (if applicable) \\
& 6) Justification for not dividing the contract into lots \\
& 7) Declaration of honour on absence of conflict of interest \\
& 8) Declaration of honour on complete documentation \\
\hline second ex ante control (before & Documents submitted in the first ex ante control plus: \\
& 1) Published tender notice \\
& 2) Published tender documents (instructions to tenderers + technical specifications \\
& + description of the contract) \\
& 3) List of potential bidders who obtained tender documents, and its proof of \\
& reception \\
& 4) Draft contract (annexes) \\
& 5) Appointment of the members of the evaluation committee (declaration of honour \\
& on absence of conflict of interest) \\
& 6) List of bidders and minutes of tender opening \\
\hline
\end{tabular}




\begin{tabular}{l|l}
\hline & 7) Assessment of exclusion grounds \\
& 8) Assessment of selection criteria \\
9) Evaluation of tenders & 10) Clarifications (if applicable) \\
11) Successful candidate(s) or tenderer(s) (including subcontractors and their \\
corresponding shares, if any) and justification \\
12) Justification for not cancelling public procurement if only one bid was submitted \\
13) Unsuccessful candidate(s) or tenderer(s) and justification \\
14) Rejection of abnormally low tenders and justification \\
15) Evaluation matrix(es) \\
16) List(s) of attendance at evaluation meeting(s) \\
17) Draft notification to unsuccessful bidders \\
18) Contract award notice \\
19) Declaration of honour on absence of conflict of interest \\
20) Declaration of honour on complete documentation \\
\hline Ex post control \\
(after signing the contract) \\
1) All the documents submitted in the first and second ex ante control \\
2) Signed contract (annexes) \\
of Public Sector Partners (if relevant) \\
\hline
\end{tabular}

Notes: These are typical documents for control. The document requirements slightly differ among intermediate bodies.

Source: Information provided by the Ministry of Economy; the Ministry of Education, Science, Research and Sport; and the Research Agency.

The documents requested by the control bodies sound reasonable. However, there are two points to consider in order to decrease the administrative burdens of beneficiaries for the submission of control documents. First, beneficiaries should be exempted from submitting documents that have already been submitted in previous steps. For example, all the documents submitted in the first ex ante control must be submitted again for the second ex ante control. Ex post control demands all the documentation submitted for the first and second ex ante controls. Therefore, these duplicate and redundant tasks should be avoided. Furthermore, beneficiaries must submit the documents necessary for control procedures through the ESIF Management System, ITMS2014+, which is not a user-friendly system, in addition to submitting original hard copies. This places high administrative burdens on beneficiaries. Furthermore, regardless of the electronic (and hard copy) document submission by beneficiaries, the intermediate body sends the result of the control to the beneficiaries only by mail, which takes time (e.g. a few weeks according to a beneficiary) for the reception of written approval by beneficiaries. These administrative burdens and inefficiencies should be relieved to facilitate and speed up the control processes. The details of administrative burdens arising from the ITMS2014+ will be discussed in Section 5.2.

Contrary to intermediate bodies, beneficiaries mentioned that the delay of control approval processes could be attributed to the capability of control officers. This point was echoed by some audit institutions that shared their views that control officers in the intermediate bodies did not always know how to perform control processes properly. Control officers often resort to rule-oriented processes (e.g. ensuring that forms are filled out correctly) rather than substance and understanding (e.g. ensuring that the content of the forms makes sense). Therefore, they often check the items in the control list, or provide only very short remarks without detailed reasons behind their observations.

Table 5.6 lists the training courses taken by control officers at the Ministry of Economy; the Ministry of Education, Science, Research and Sport; and the Research Agency.

Table 5.6. Training courses taken by control officers in the intermediate bodies (2016-19)

\begin{tabular}{l|c|l}
\hline \multicolumn{1}{c|}{ Course name } & Year & Provider \\
\hline Public Procurement Act (PPA) & $2016-19$ & Government Office of the Slovak Republic \\
\hline Amendments of the PPA and its application in the ESIF & $2016-19$ & Government Office of the Slovak Republic \\
\hline The most common breaches of the PPA & $2016-19$ & Government Office of the Slovak Republic \\
\hline
\end{tabular}




\begin{tabular}{l|c|l}
\hline $\begin{array}{l}\text { Public Procurement Act (case studies/findings of the Public } \\
\text { Procurement Office on controls) }\end{array}$ & 2016 & Government Office of the Slovak Republic \\
\hline Introduction to public procurement control & 2017 & Government Office of the Slovak Republic \\
\hline Public procurement within EU funds from A to Z & 2019 & Private company \\
\hline $\begin{array}{l}\text { ESIF Management System concerning public procurement } \\
\text { control and conflict of interests in public procurement }\end{array}$ & 2016 & Government Office of the Slovak Republic \\
\hline Public procurement control in ESIF financed projects (two parts) & $2016-19$ & Government Office of the Slovak Republic \\
\hline Decisions of the PPO and their impact on public procurement & 2018 & Private company \\
\hline New rules and control of the EU funds contracts & 2019 & Private company \\
\hline $\begin{array}{l}\text { First steps to full electronisation of the public procurement } \\
\text { process }\end{array}$ & $2017-18$ & Private company \\
\hline Transition to full electronic public procurement & 2017 & Private company \\
\hline $\begin{array}{l}\text { Introduction to protecting competition - anticompetitive } \\
\text { practices in public procurement }\end{array}$ & $2017-19$ & Government Office of the Slovak Republic \\
\hline Most economically advantageous tender (MEAT) & 2017 & Private company \\
\hline Register of Public Sector Partners & 2017 & Private company \\
\hline Specification of purchase of IT & 2017 & Private company \\
\hline Contract for construction work & 2017 & Private company \\
\hline Contracts in public procurement & 2018 & Private company \\
\hline $\begin{array}{l}\text { FIDIC through the eyes of lawyers and from the point of view of } \\
\text { a civil engineer }\end{array}$ & 2018 & Private company \\
\hline
\end{tabular}

Note: Courses taken by control officers working at the Ministry of Economy; the Ministry of Education, Science, Research and Sport; and the Research Agency. FIDIC referes to International Federation of Consulting Engineers.

Source: Information provided by the Ministry of Economy; the Ministry of Education, Science, Research and Sport; and the Research Agency.

The impact or effectiveness of these trainings, or how they are applied in practice, are not known or assessed adequately. It is not certain whether these trainings are perceived among control officers as something that added significant value to their daily work and longer term skill development. Some audit institutions stated that these trainings were not sufficient because participants are not properly tested on what they have learnt.

Some beneficiaries also argued that the processes are delayed due to the time for a number of approvers to sign the approval within the intermediate bodies, even if control officers complete their tasks quickly. Beneficiaries also coincided in the high level of administrative burdens related to the use of the ITMS2014+ (see Section 5.2).

\section{Way forward}

Alleviate the high administrative burdens related to public procurement control procedures by eliminating the duplicate submission of the control documents and introducing electronic procedures (document submission and notification of the result through ITMS2014+ or an eventual replacement system without mail transactions, unless necessary).

Provide more high-quality training opportunities to the intermediate bodies' control officers and beneficiaries. A standardised evaluation of the training should be implemented, including its objectives and expected impact.

Independently verify the control flow and approval processes inside the intermediate bodies to allow for further improvements in terms of reducing the overall timeline and avoiding redundancy and duplication of tasks. 


\section{Conflicting opinions among different stakeholders brings legal uncertainty on the control system of ESIF public procurement}

Another issue on the control system of ESIF-funded public procurement procedures is related to the conflicting opinions among various control and audit actors, such as the intermediate bodies, the PPO, the certifying authority and the audit authority. In other words, each controller interprets the same case in a different way by expressing different perspectives. From the beneficiaries' viewpoint, this implies that the decisions issued by the intermediate bodies after the long control processes are not regarded as final, legitimate, nor legally binding, which places legal uncertainty on the decisions. Procurement procedures approved by the controls of the intermediate body might be subject to financial correction due to the irregularities identified by the audits that are performed during the implementation stage after signing of contracts with the successful bidders.

One beneficiary stated that it received the three control reports (first ex ante, second ex ante and ex post) from the intermediate body, stating that every procurement procedure was carried out in accordance with the ESIF regulatory requirement, but later the very same intermediate body ended up filing a beneficiary with irregularities and financial correction identified by the audits. Therefore, beneficiaries feel that they are "hostages" of the ESIF control system: they have many obligations but basically no rights and no protection, because control bodies do not take any responsibility for their decisions. Ultimately, inconsistency and lack of legal certainty in control processes can lead to delays, affect absorption and limit the attractiveness of ESIF-funded projects for beneficiaries. Beneficiaries have a strong desire to have one single control authority responsible by assuring legal consistency, certainty and a predictable control system that provide beneficiaries with decent protection of their rights.

This challenge is recognised among the control and audit institutions. Recently, the PPO signed a memorandum with audit institutions on collaboration to minimise the conflict of opinions.

In fact, the Slovak Repubic is not the only country facing this challenge. EU countries like Estonia, Lithuania and Poland state that such situations inevitably occur among intermediate bodies, managing authorities, auditors and ESIF beneficiaries: for example, between beneficiaries and ESIF administration, between audit bodies, the public procurement authority and intermediate bodies. This is attributable to the different specialisations of each institution and their established practices. Countries are taking various initiatives to mitigate the occurrence of conflicting opinions. For example, Poland established a Committee for Control in Public Procurement to serve as a forum for co-operation between all procurement control institutions that address both national and ESIF funds (Box 5.2). 


\section{Box 5.2. Committee for Control in Public Procurement in Poland}

Poland established a Public Procurement Control Committee to mitigate the conflict of opinions in public procurement. The committee is a forum for co-operation between all procurement control institutions that address both national and EU funds. As a rationale for introducing this new institution, it was emphasised that the committee's activities are not aimed at limiting the competences of individual institutions, but at creating a space for the exchange of experiences, co-operation and pointing to problems of individual institutions, by using the knowledge shared by each of them. In addition, the President of the Public Procurement Office is mandated to express its view in the event of any doubts regarding interpretation among inspection bodies at their request.

Source: Information provided by Public Procurement Office of Poland.

It is highly recommended to further reinforce the collaboration mechanism by sharing different views to avoid any discrepancy in the opinions of different authorities.

\section{Way forward}

Further reinforce the collaboration mechanism among control and audit authorities to share different views to avoid any discrepancy in the opinions of different authorities

Create a database with a typology of control decisions to allow for further standardisation and harmonisation of the control process. It could also support the newly established governance mechanism for the next programming period by preserving institutional memory.

Provide the PPO with adequate financial and human resources to carry out control processes under the programming period 2021-27.

\subsection{ITMS2014+ creates additional administrative burdens and does not facilitate performance measurement}

ITMS2014+ is a central IT monitoring system used for submitting the necessary documents under the ESIF-funded projects and monitoring data for the financial management, control and audit for the ESIF programming period 2014-20 (Computer Security Incident Response Team Slovakia, $\left.2014{ }_{[8]}\right]$ ). It is not an e-procurement system to carry out public procurement procedures under ESIF projects. The system is administered by the Ministry of Investments, Regional Development and Informatization as the central co-ordination authority.

\section{ITMS2014+ is not user-friendly and intuitive, bringing excessive administrative burdens to beneficiaries}

Beneficiaries are required to use ITMS2014+ to submit the necessary documents for the following procedures under the ESIF-funded projects.

- grant application

- control of public procurement

- first ex ante control

- second ex ante control

- ex post control (follow up/standard). 
- payment requests.

Stakeholders agreed that ITMS2014+ is not user-friendly and intuitive, and that it brings high administrative and bureaucratic burdens to stakeholders, including intermediate bodies and beneficiaries, during the procedures of ESIF-funded projects.

Transactions between the intermediate bodies and the beneficiaries through ITMS2014+ are not electronic. Beneficiaries are required to submit the original documents to the intermediate body even after updating the documents in ITMS2014+. In addition, the beneficiaries are notified of the result of the control only by regular mail, not via ITMS2014+.

The submission of documents for control is more streamlined in comparable EU member states like Estonia, Lithuania and Poland. As Table 5.7 shows, none of these EU countries require beneficiaries to submit the same documents in multiple ways (i.e. electronically and hard copies). In Estonia, in general, beneficiaries are not required to submit documents for control due to the interconnection of the e-procurement system with the ESIF system. Control officers can access the systems to obtain the necessary documents.

\section{Table 5.7. Conditions for submitting documents for control}

\begin{tabular}{|c|c|}
\hline Country & Requirement of submission \\
\hline Slovak Republic & Beneficiaries need to submit documents in two ways: ITMS2014+ and hard copies. \\
\hline Estonia & $\begin{array}{l}\text { In general, beneficiaries do not need to submit documents, due to the interconnection of the ESIF } \\
\text { system with the e-procurement system. The beneficiary, if it is a contracting authority, is obliged to } \\
\text { carry out the procurement in an e-procurement (i.e the public procurement register RHR). All } \\
\text { documents related to the procurement procedure must be uploaded to this system. The ESIF } \\
\text { electronic system used in Estonia (i.e. SFOS) is interfaced with the RHR. Therefore, the beneficiary } \\
\text { does not have to submit the procurement documents to the intermediate body/managing authority } \\
\text { separately for verification. The officials responsible for procurement control can obtain the } \\
\text { necessary documents from the RHR. }\end{array}$ \\
\hline Lithuania & $\begin{array}{l}\text { For ex ante control, beneficiaries submit documents through the ESIF electronic system. They can } \\
\text { submit documents by e-mail if it is not possible to submit documents through the data exchange } \\
\text { site. For ex post control, beneficiaries do not need to submit the documents. Access to the central } \\
\text { public procurement IS allows control officers to consult all procurement and procedure documents. }\end{array}$ \\
\hline Poland & $\begin{array}{l}\text { Beneficiaries can submit documents in one way (electronic or hard copies) The documents can be } \\
\text { submitted on the ESIF electronic system (SL2014), unless the amount of data to transfer is too big. }\end{array}$ \\
\hline
\end{tabular}

Source: Responses to OECD short questionnaires from Estonia, Lithuania and Poland, March 2021.

For grant applications, beneficiaries have difficulty understanding where to upload each attachment to the grant proposal (for example, market research documents). The same document could be uploaded to two or three different places on the platform because each call for proposal has different rules for uploading. Intermediate bodies also have an issue downloading and sorting out the attachment. In addition, the project budget must be prepared twice for projects of the Research Agency, first in the system called ISVA, then in ITMS2014+. This is a duplicate task.

Furthermore, in order to input all the data required to the ITMS2014+ and the SFC2014 (electronic data exchange system of information between member states and the European Commission), beneficiaries of financial instruments are required to prepare two different reports: the monitoring report exclusively for the ITMS2014+ and a detailed report on the implementation of financial instruments for the SFC2014. The current function of ITMS2014+ is not set up for reporting financial instruments, so the data must be input manually into the SFC2014 by the intermediate body. If the two systems (ITMS2014+ and the SFC2014) were integrated, relevant data could be downloaded from the ITMS2014+ into SFC2014. This would decrease the administrative burdens for both the intermediate bodies and the beneficiaries. 
As mentioned above, public procurement control processes performed on the system bear the same characteristics and are considered to be very redundant and repetitive. Additional improvements can be introduced once repetition and redundancies are eliminated, especially if the system allowed the user to retrieve information submitted for prior controls when following up the multi-step control process.

The methodological assistance available on ITMS2014+ is not sufficient to beneficiaries. Guidelines exist on how to use the system, but they do not seem to be widely known among beneficiaries, and/or the quality needs to be improved due to different rules for uploading documents. Training on the use of ITMS2014+ is only available to public officials in charge of ESIF-funded projects, such as the managing authorities and intermediate bodies, but not to beneficiaries.

Table 5.8 summarises challenges and possible suggestions for improving ITMS2014+.

\section{Table 5.8. Challenges of ITMS2014+ and suggestions for improvement}

\begin{tabular}{|c|c|c|}
\hline $\begin{array}{l}\text { Processes under } \\
\text { ESIF projects }\end{array}$ & Challenge & Suggestion for improvement \\
\hline \multirow[t]{2}{*}{ Grant application } & $\begin{array}{l}\text { It is hard to understand where to upload each attachment to the } \\
\text { grant proposal (for example, market research documents). The } \\
\text { same document could be uploaded to two or three different } \\
\text { places on the platform because each call for proposal has } \\
\text { different rules for uploading. Intermediate bodies also have } \\
\text { problems downloading and sorting out the attachments. }\end{array}$ & $\begin{array}{l}\text { Unification of rules } \\
\text { Automatically assign where documents should be } \\
\text { uploaded. } \\
\text { Create a clear list of required attachments to allow } \\
\text { applicants to check whether they have been properly } \\
\text { uploaded. }\end{array}$ \\
\hline & $\begin{array}{l}\text { The project budget must be prepared twice for projects of the } \\
\text { Research Agency, first in the system called ISVA, then in } \\
\text { ITMS2014+. }\end{array}$ & $\begin{array}{l}\text { It would be ideal to be able to export data to the } \\
\text { ITMS } 2014+\text { system from the ISVA system, and import } \\
\text { the budget in Excel so that beneficiaries do not have to } \\
\text { print data twice. }\end{array}$ \\
\hline \multirow[t]{2}{*}{$\begin{array}{l}\text { Control of public } \\
\text { procurement }\end{array}$} & $\begin{array}{l}\text { Beneficiaries are required to submit the original documents to } \\
\text { the intermediate body even after updating the documents in } \\
\text { ITMS2014+. In addition, the result of the control is notified only } \\
\text { by mail. }\end{array}$ & $\begin{array}{l}\text { It is necessary to have complete electronic submission } \\
\text { without submitting the same documents in hard copies } \\
\text { by mail (all in one place and communicated through one } \\
\text { channel). }\end{array}$ \\
\hline & $\begin{array}{l}\text { Each set of documents needs to be allocated to a project. } \\
\text { Despite the fact that the actual public procurement is already } \\
\text { included in the project, each set of documents needs to be } \\
\text { allocated to the project again. This takes } 40 \text { minutes of clicking } \\
\text { because beneficiaries always have to allocate documents not } \\
\text { only to the project, but also to the specific activity, even to the } \\
\text { application and its activity. This is repeated every time } \\
\text { beneficiaries need to provide supplementary documents. }\end{array}$ & $\begin{array}{l}\text { Restructure the ITMS2014+ database and submission } \\
\text { process to allow documents uploaded in previous steps } \\
\text { of the control process to be retrieved. }\end{array}$ \\
\hline $\begin{array}{l}\text { Methodological } \\
\text { assistance }\end{array}$ & $\begin{array}{l}\text { Guidelines on how to use ITMS2014+ are available, but are not } \\
\text { widely known among beneficiaries. In addition, training on } \\
\text { ITMS2014+ is open only to government officers, such as the } \\
\text { intermediate bodies, not to beneficiaries. }\end{array}$ & $\begin{array}{l}\text { Improve and disseminate the guidelines. Provide } \\
\text { training to beneficiaries. }\end{array}$ \\
\hline $\begin{array}{l}\text { Creation of } \\
\text { ITMS2014+ account }\end{array}$ & $\begin{array}{l}\text { Each user has to be added by creating their own account and } \\
\text { submitting a paper application that should be signed by the } \\
\text { representative of the beneficiaries and a public notary. }\end{array}$ & $\begin{array}{l}\text { To avoid administrative burdens by creating an account } \\
\text { for each user of the beneficiary, create only one } \\
\text { account for one staff appointed "officially" by the } \\
\text { representative who can act on behalf of the beneficiary. } \\
\text { Then that authorised staff can electronically appoint } \\
\text { other users within the beneficiary. }\end{array}$ \\
\hline $\begin{array}{l}\text { Integration of } \\
\text { ITMS2014+ with the } \\
\text { SFC2014 }\end{array}$ & $\begin{array}{l}\text { Beneficiaries of financial instruments are required to prepare } \\
\text { two different reports: the monitoring report exclusively for } \\
\text { ITMS2014+ and a detailed report on implementation of financial } \\
\text { instruments for the SFC2014. The current function of } \\
\text { ITMS2014+ is not set up for reporting financial instruments, so } \\
\text { the intermediate body must input the data manually into the } \\
\text { SFC2014. }\end{array}$ & $\begin{array}{l}\text { Both systems (ITMS2014+ and the SFC2014) could be } \\
\text { integrated, so that the relevant data could be } \\
\text { downloaded from the ITMS2014+ into SFC2014. }\end{array}$ \\
\hline $\begin{array}{l}\text { Lack of more useful } \\
\text { functions }\end{array}$ & $\begin{array}{l}\text { The system does not provide any useful functions for } \\
\text { beneficiaries, such as a list of submitted grant proposals or a } \\
\text { list of active projects. }\end{array}$ & Add these types of functions. \\
\hline
\end{tabular}


Source: Based on interviews with the intermediate bodies and beneficiaries.

The Slovak government plans to update ITMS2014+ for the next programming period 2021-27. It will benefit from the challenges identified by stakeholders (actual users of the system), and reflect them to improve the system. It is highly recommended that the government organise a series of meetings to discuss how to make the system user-friendly by inviting all users, such as intermediary bodies' control officers and beneficiaries. The timeline and the objectives for the revision should be as clear as possible and its implementation as quick as possible, since the system is the backbone of an adequate and proper ESIF management. It is widely recognised by different stakeholders that an updated version, or even the deployment of a new system, would allow for significant gains in terms of efficiency and economies of scale in the management of EU-funded projects.

\section{Way forward}

Improve the ITMS2014+ in order to make it user-friendly and intuitive.

Organise a series of meetings to discuss how to make the system user-friendly by inviting relevant users such as intermediate bodies' control officers and beneficiaries. Appoint a task force and co-ordinator to facilitate this process, as it involves different stakeholders with distinct priorities and objectives.

\section{ITMS2014+ does not function as an effective data collection system to measure the performance of the ESIF public procurement procedures}

Availability and clarity of data are essential elements to calculate performance indicators, not only for monitoring the progress of procurement processes, but also for making better policy in general. Indeed, the OECD Recommendation of the Council on Public Procurement (hereafter referred to as the "Recommendation") calls upon countries to collect consistent, up-to-date and reliable information on public procurement, and to develop indicators to measure performance, effectiveness and savings of the public procurement system to support strategic policy making on public procurement. (OECD, 2015[9]) (Box 5.3). Electronic platforms allow governments to collect information related to public procurement in open and machine-readable formats with friendly search functions.

\section{Box 5.3. OECD Recommendation of the Council on Public Procurement: Evaluation}

X. RECOMMENDS that Adherents drive performance improvements through evaluation of the effectiveness of the public procurement system from individual procurements to the system as a whole, at all levels of government where feasible and appropriate.

To this end, Adherents should:

i) Assess periodically and consistently the results of the procurement process. Public procurement systems should collect consistent, up-to-date and reliable information and use data on prior procurements, particularly regarding price and overall costs, in structuring new needs assessments, as they provide a valuable source of insight and could guide future procurement decisions.

ii) Develop indicators to measure performance, effectiveness and savings of the public procurement system for benchmarking and to support strategic policy making on public procurement.

Source: OECD (2015[9]). 
Measuring and analysing performance indicators contributes to identifying potential bottlenecks in public procurement processes which might hinder the smooth implementation of public procurement procedures, and thus the absorption of the ESIF.

The OECD verified that there is a significant challenge in collecting data on ESIF public procurement. In fact, ITMS2014+ is not functioning properly as an effective data collection system to measure indicators related to ESIF public procurement processes in the Slovak Republic. The system stores PDF documents which were submitted for certain procedures, such as public procurement control, but does not provide a search function to download in an efficient way the necessary information into readable formats such as Excel. For example, when policy makers would like to know the basic information of each individual procurement, such as contract amount and the number of bids submitted, they need to check the documents of each individual procurement to obtain the information (for example, contract documents for contract amount, tender evaluation report for the number of bids submitted). In addition, the current system does not allow policy makers to calculate even the aggregate contract amount or the payment amount of each priority axis and intermediate body. As discussed in Section 5.1, when ESIF policy makers carry out evidence-based analyses on the trade-off between administrative burdens (cost and time) and transparency/effectiveness in preventing errors in public procurement, they need to obtain the data of every ESIF individual procurement procedure on the cost and time spent carrying out control as well as information on irregularities (errors identified as a result of ex ante control, etc.). The current situation makes it difficult for stakeholders such as ESIF policy makers and auditors to collect the information they need in an efficient way to analyse the data as well as to further improve ESIF public procurement policy and practices. Some audit institutions even mentioned that they need to check with the managing authority and intermediate bodies to collect the information they are looking for.

It is essential to improve the function of ITMS2014+ as a data collection system, or develop a new electronic platform to collect data related to ESIF public procurement. Table 5.9 lists examples of potential performance indicators and necessary information to calculate those indicators for monitoring the performance of public procurement as well as for making better policy in ESIF public procurement.

\section{Table 5.9. Potential performance indicators for European Structural and Investment Funds public} procurement

\begin{tabular}{l|l}
\hline \multicolumn{1}{c|}{ Indicators } & \multicolumn{1}{c}{ Data requirement } \\
\hline $\begin{array}{l}\text { 1. Days spent for each step of public procurement } \\
\begin{array}{l}\text { From approval of the grant proposal to a request for the } \\
\text { first ex ante control }\end{array}\end{array}$ & Date of grant proposal approval, request date of first ex ante control \\
\hline $\begin{array}{l}\text { From request for first ex ante control to approval of first } \\
\text { ex ante control }\end{array}$ & Request date of first ex ante control, approval date of first ex ante control \\
\hline From approval of first ex ante control to call for tender & Approval date of first ex ante control, date of call for tender \\
\hline From call for tender to the bid submission deadline & Date of call for tender, bid submission deadline \\
\hline $\begin{array}{l}\text { Difference between the original and actual bid } \\
\text { submission deadline }\end{array}$ & $\begin{array}{l}\text { Original submission deadline, actual submission deadline } \\
\text { * Were there any challenges from bidders? }\end{array}$ \\
\hline $\begin{array}{l}\text { From bid submission deadline to submission of tender } \\
\text { evaluation report (second ex ante control) }\end{array}$ & $\begin{array}{l}\text { Bid submission deadline, submission date of tender evaluation report (second ex ante } \\
\text { control) }\end{array}$ \\
\hline $\begin{array}{l}\text { From submission of tender evaluation report (second } \\
\text { ex ante control) to approval of second ex ante control }\end{array}$ & $\begin{array}{l}\text { Submission date of tender evaluation report (second ex ante control), approval date of } \\
\text { second ex ante control }\end{array}$ \\
\hline $\begin{array}{l}\text { From approval of second ex ante control to issuance of } \\
\text { contract award }\end{array}$ & Approval date of second ex ante control, issuance date of contract award \\
\hline From issuance of contract award to signing of contracts & $\begin{array}{l}\text { Issuance date of contract award, date of signing of contracts } \\
\text { * Were there any challenges from bidders? }\end{array}$ \\
\hline From signing of contracts to approval of ex post control & Date of signing of contracts, approval date of ex post control \\
\hline $\begin{array}{l}\text { From approval of ex post control to completion of } \\
\text { contracts }\end{array}$ & Approval date of ex post control, completion date of contracts \\
\hline 2. Period spent on procedures of amendments to & Request date of amendments, approval date of amendments \\
\hline
\end{tabular}




\begin{tabular}{l|l}
\hline contracts & \\
\hline $\begin{array}{l}\text { 3. Period spent on payment procedures (from the } \\
\text { submission of payment request to the actual payment) }\end{array}$ & Submission date of payment request, payment date \\
\hline $\begin{array}{l}\text { 4. Difference between the estimated value of the } \\
\text { contract (budget) and the actual contract amount }\end{array}$ & Estimated value of contract, actual contract amount \\
\hline $\begin{array}{l}\text { 5. Share of small and medium-sized enterprises (SMEs) } \\
\text { that submitted bids/awarded contracts }\end{array}$ & $\begin{array}{l}\text { Number of SMEs that submitted bids/awarded contracts, total number of procurement } \\
\text { procedures and values }\end{array}$ \\
\hline $\begin{array}{l}\text { 6. Share of foreign suppliers that submitted } \\
\text { bids/awarded contracts }\end{array}$ & $\begin{array}{l}\text { Number of foreign bidders that submitted bids/awarded contracts, total number of } \\
\text { procurement procedures and values }\end{array}$ \\
\hline $\begin{array}{l}\text { 7. Share of single bid } \\
\text { 8. Share of the use of public procurement for innovation }\end{array}$ & Number of bids (single bid) submitted per tender \\
\hline $\begin{array}{l}\text { 9. Share of most economically advantageous tender } \\
\text { (MEAT) criteria }\end{array}$ & Number and values of public procurement for innovation \\
\hline $\begin{array}{l}\text { 10. Share of irregularities and financial correction } \\
\text { 11. Share of cancelled bids }\end{array}$ & Causes, amounts, name of beneficiary, intermediate body in charge \\
\hline $\begin{array}{l}\text { 12. Difference between the planned (physical and } \\
\text { financial) progress and actual progress }\end{array}$ & Number of cancelled bids, total number of procurement procedures and values \\
\hline 13. Use of e-procurement system & Planned and actual progress (financial and physical) \\
\hline 14. Use of framework agreements & Number and values of the use of the e-procurement system \\
\hline
\end{tabular}

In the short term, the Slovak Republic could consider preparing an Excel database, like the case of the federal government of Mexico, to register the data for the data analysis (Box 5.4). Each intermediate body could be in charge of registering the information, and ensuring that the data are correct and accurate.

\section{Box 5.4. Excel spreadsheet of individual public procurement procedures in Mexico}

The federal government of Mexico provides Excel sheets that include the public procurement data each fiscal year since 2002 through CompraNet, the federal government of Mexico's e-procurement system. These Excel sheets include the basic information related to public procurement, including contract amounts for all of the public procurement procedures (goods; services and public works; tender methods such as open tender; and modalities such as paper-based, electronic and mixed) for one fiscal year. This allows users to easily calculate the aggregated contract amount of one fiscal year with various customised options, for example, calculating the total contract amounts of open tender procedures for the procurement of public works which used electronic modalities.

Source: CompraNet (2019[10]).

\section{Way forward}

Develop indicators on public procurement in order to measure the performance of ESIF public procurement procedures, not only for monitoring the progress of procurement processes, but also for better policy making.

Develop an effective data collection system to calculate the indicators; access to the results should be provided to the relevant users. In the short term, the Slovak Republic could consider preparing an Excel database. 


\subsection{Reinforcing the competitiveness of the market and the attractiveness of participating in ESIF projects}

\section{Market research requirements for low-value contracts are one of the highest administrative burdens under the ESIF administration}

The legal framework of public procurement foresees a simplified procurement procedure for a procurement whose estimated value of the contract is considered low.

Article 5 of the PPA defines three types of financial thresholds to determine the procurement procedures: 1) above-threshold; 2) below-threshold; and 3) threshold for a low-value contract. Contracting authorities are allowed to use more simplified procurement procedures for a low-value contract than for abovethreshold and below-threshold procedures.

Table 5.10Table 5.10 presents the financial thresholds applicable to a low-value contract updated by the PPO, and valid since 1 January 2020.

Table 5.10. Threshold for a low-value contract (effective since 1 January 2020)

\begin{tabular}{l|c}
\hline \multicolumn{1}{c|}{ Subject of procurement } & Threshold for low-value contract (EUR) \\
\hline Goods and services & $\geq 5000<70000$ \\
\hline Works & $\geq 5000<180000$ \\
\hline Social services or other specific services listed in the PPA Annex 1 & $\geq 5000<260000$ \\
\hline
\end{tabular}

Source: Public Procurement Office (2020[11]).

Beneficiaries point out that a specific rule set for a low-value contract procedure under ESIF projects represents one of the highest administrative burdens under the ESIF administration. This specific rule is defined by Methodological Guideline No. 14 issued by the central co-ordination authority for the award of contracts with a low-value contract above EUR 50000 (latest version 8, issued on 31 October 2020), and is considered much stricter than what is required for a low-value procurement under the PPA.

This guideline applies to low-value contracts under ESIF projects whose estimated value is equal to or exceeds EUR 50000 (excluding value-added tax). The contract may include goods, services, construction works, social services or other special services. Table 5.11 summarises the threshold of a low-value contract which is subject to Methodological Guideline No. 14. It is worth mentioning that the latest version 8 issued on 31 October 2020 raises the threshold from version 7 from EUR 30000 to EUR 50000.

Table 5.11. Threshold of a low-value contract applicable to Methodological Guideline No. 14

EUR

\begin{tabular}{l|c|c|c}
\hline & $\begin{array}{c}\text { Threshold for low-value } \\
\text { contract under the PPA }\end{array}$ & $\begin{array}{c}\text { Non-application Guideline } \\
\text { No. 14 }\end{array}$ & $\begin{array}{c}\text { Application of Guideline } \\
\text { No. 14 }\end{array}$ \\
\hline Goods and services & $5000-70000$ & $5000-499999.99$ & $50000^{*}-70000$ \\
\hline Works & $5000-180000$ & $5000-499999.99$ & $50000^{*}-180000$ \\
\hline $\begin{array}{l}\text { Social services or other specific services listed in } \\
\text { the PPA Annex 1 }\end{array}$ & $5000-260000$ & $5000-499999.99$ & $50000^{*}-260000$ \\
\hline
\end{tabular}

* This threshold was EUR 30000 until 31 October 2020.

Sources: Based on Central Coordination Authority (n.d. $\left.{ }_{[3]}\right)$ and Public Procurement Office (2020[11]). 
In short, there are two extra administrative burdens required for low-value contracts above EUR 50000 but below the regular thresholds of the ESIF Methodological Guideline No. 14, compared with that of the PPA: a mandatory requirement for publishing the tender as well as obtaining three price quotations through the market research.

First, publishing the tender is mandatory for a low-value procurement above EUR 50000 under the ESIF public procurement, while it is not required by the PPA. Indeed, Article 65 (2) of the PPA stipulates that the contracting authority shall publish a tender notice if it intends to award a contract by open tender, restricted procedure, negotiated procedure with publication, competitive dialogue or innovation partnership, to conclude a framework agreement or to set up a dynamic purchasing system. This implies that carrying out a low-value procurement does not require the publication of a tender notice under the PPA. However, Methodological Guideline No. 14 makes it mandatory for beneficiaries to publish tender for a low-value contract above EUR 50000.

Second, obtaining three price quotations (up until October 2020, two in the revised version 8) is mandatory to determine the estimated value of the contract for a low-value procurement above EUR 500000 under the ESIF public procurement, while it is not required by the PPA. Article 6 (1) of the PPA defines the estimated value of the contract. According to this article, the contracting authority calculates the estimated value of the contract on the grounds of data and information about contracts of the same or comparable subject matter. If the contracting authority does not have such data, it shall determine the estimated value based on data obtained from market research for the required performance, preparatory market consultation or other data obtained by other appropriate means. Therefore, the market research, including obtaining the price quotation, is laid down as one of the optional tools for calculating the estimated value of the contract in pre-tender stage of the public procurement process: it is not necessarily mandatory as long as the information is available from other sources (e.g. similar products). Article 25 of the PPA defines a preparatory market consultation, but it can be interpreted not as an obligation, but as the right of the contracting authority. Article 117 of the PPA on the low-value contract stipulates that the contracting authority shall observe the principles of equal treatment and non-discrimination, but does not specify the mandatory requirement of obtaining the price quotation. This implies that obtaining three price quotations is not mandatory under the PPA, whether it is a low-value procurement or above- and below-threshold procurement.

On the other hand, obtaining the three price quotations is mandatory for awarding a low-value contract above EUR 50 000. The intention of this specific ESIF requirement is to ensure that the most efficient, transparent and cost-effective offers are selected. However, this excessive measure, which tends to place an unbalanced focus on price rather than the quality of the proposals, brings high administrative and bureaucratic burdens to beneficiaries of ESIF projects.

First, obtaining the price quotation itself is a challenging and painstaking task. Beneficiaries stated that it requires high administrative demand (e.g. ten documents for each budget item), and one beneficiary stated that it needs a few full-time staff to work on this administrative requirement. They find it difficult to gain collaboration from suppliers because suppliers do not want to collaborate unless the request is directly connected with an order. Indeed, the quotation request involves mountains of items (very often hundreds), and companies are not interested in providing beneficiaries with the price quotation. Suppliers know that the price quotation is used only for the purposes of determining the estimated value of the contract to prepare a grant proposal, not for the actual procurement process, and thus think that the collaboration is a waste of time. During the fact-finding workshop held on 3 November 2020, one beneficiary stated that it could not obtain the 3 price quotations even after requesting it from 19 potential suppliers.

Second, it is very challenging to obtain the price quotation for the innovative goods and services required for R\&I activities. Beneficiaries mentioned that the goods and services required by their scientists and researchers are not widely offered in the market, and it is quite difficult to obtain three price quotations. If the subject of the procurement is a part of a prototype device, which is subject to additional developments, 
it is basically impossible to define the technical parameters and obtain the price quotation. Methodological Guideline No. 14 stipulates that the price available on the Internet or the past price in the database can be used without requesting a price quotation. However, this is not an effective measure for innovative goods and services, because they are not commonly available on the market due to the specific requirements to meet the needs of R\&I activities. Therefore, they usually end up addressing economic operators to obtain their price quotation. It could be assumed that the strict requirement of price quotation is even an obstacle to procuring innovative services and goods under ESIF R\&I projects. In fact, this can explain, at least partially, the lack of actual cases in the past ESIF R\&I projects of using public procurement for innovation (PPI) to procure innovative solutions. The topic of PPI will be discussed later in Section 5.6.

Third, obtaining the price quotation is a repetitive procedure throughout the ESIF project cycle. The price quotation needs to be obtained several times to determine and update the estimated value of the contract, during the preparation of the grant proposal, even during the evaluation of the grant proposal and before starting the procurement procedures. It should be noted that there can be up to a few years' time between submitting a grant proposal application and actually starting the procurement processes (after the proposal is selected), because the evaluation of the grant proposal takes so long, as discussed above. Therefore, the price quotation obtained for the grant proposal preparation a few years earlier will be out of date when the procurement procedures start.

Beneficiaries pointed out that there was no point in obtaining a price quote for items whose price fluctuates over time, such as travel costs, accommodation costs, conference services, etc. In addition, part of the items proposed in the grant proposal might no longer be available on the market a few years later. Taking these situations into account, beneficiaries consider that obtaining the price quotation itself is unnecessary, and nothing more than a meaningless administrative procedure.

Beneficiaries suggested that the market research requirement for a low-value procurement under the ESIF public procurement should be simplified like in the case of Horizon 2020, in which only the short description of each budget item is required without additional documents related to market research.

This strict requirement of obtaining three price quotations is unique, compared with $\mathrm{EU}$ and international practices. Table 5.12 benchmarks the Slovak Republic against other EU member states in terms of the requirements in obtaining the price quotation. Indeed, none of the EU countries that responded to the short questionnaire foresee such strict regulations.

Table 5.12. Regulations on obtaining price quotations

\begin{tabular}{r|c|c|c|c|c}
\hline Regulations & Slovak Republic & Estonia & Lithuania & Poland & Slovenia \\
\hline $\begin{array}{r}\text { Regulatory framework of public } \\
\text { procurement }\end{array}$ & Not mandatory & $\begin{array}{c}\text { Not } \\
\text { mandatory }\end{array}$ & $\begin{array}{c}\text { Not } \\
\text { mandatory }\end{array}$ & $\begin{array}{c}\text { Not mandatory (depends } \\
\text { on on the CA) }\end{array}$ & Not mandatory \\
\hline $\begin{array}{r}\text { Specific regulations of ESIF } \\
\text { public procurement }\end{array}$ & $\begin{array}{c}\text { Mandatory }(3 \text { price } \\
\text { quotations) }\end{array}$ & $\begin{array}{c}\text { Not } \\
\text { mandatory }\end{array}$ & $\begin{array}{c}\text { Not } \\
\text { mandatory }\end{array}$ & Not mandatory ${ }^{1}$ & $\begin{array}{c}\text { Information not } \\
\text { available }\end{array}$ \\
\hline
\end{tabular}

1. Until October 2020. The revised version 8 requires two price quotations.

2. Not mandatory for a value from PLN 20000 to PLN 50000 (excluding VAT). For contracts above PLN 50 000, beneficiaries need to place an inquiry in the Competitiveness Database (a website prepared by the Ministry of Development Funds and Regional Policy) or the beneficiary is obliged to send a request for proposal to three potential bidders, minimum. However, the number of offers to be obtained by the beneficiary as a result of the published inquiry is not specified.

3. One intermediary body specified the requirement of obtaining one price quotation under certain conditions.

Source: Responses to OECD short questionnaires from Estonia, Lithuania, Poland and Slovenia, March 2021.

Several countries have carried out initiatives in order to decrease the administrative burdens of ESIF beneficiaries related to market research. In Poland, the ESIF guidelines on the eligibility of expenditures foresee the possibility to waive the market research for orders of services provided as part of R\&D. In Lithuania, the European Social Fund Agency (ESFA) conducted its own research and prepared an Excel 
spreadsheet that lists the average market prices of the common goods and services which are relevant to its projects, so that beneficiaries can use these market prices when submitting their grant proposals for the ESIF projects in order to justify the cost. This initiative has greatly helped to decrease administrative burdens related to market research (Box 5.5). The Slovak Republic could benefit from preparing price lists for common goods and services related to R\&I activities, such as travel costs, accommodation costs, conference services, etc.

\section{Box 5.5. Market price list of the Lithuanian European Social Fund Agency}

The Public Procurement Act of Lithuania does not specify the obligation of obtaining price quotations. Such requirements are usually under the control of each intermediate body.

The European Social Fund Agency (ESFA) acts as an intermediate body and is in charge of carrying out public procurement control for European Structural and Investment Funds (ESIF) projects in Lithuania, in particular, projects financed by the European Social Fund. In general, the ESFA does not specify the minimum number of price quotations to be obtained by its beneficiaries. Only the beneficiaries that do not fall into the category of contracting authorities defined in the Public Procurement Act are required to obtain a price quotation from one potential supplier.

The ESFA recognises the administrative burdens on its beneficiaries related to market research. Therefore, in order to reduce these administrative burdens, the ESFA conducted its own research and prepared an Excel spreadsheet that lists the average market prices of the following common goods and services which are relevant to its projects:

- rent for hall and equipment (microphone, laptop and video projector)

- coffee breaks, lunch and dinner

- primary legal consultation (30-60 minute consultation)

- psychologist services (45-60 minute consultation)

- website development and administration

- publishing articles in the press

- average market prices of printing and publishing services

- translations from/into foreign languages

- general skills training services

- event moderator services.

Beneficiaries can use these market prices when submitting their grant proposals for ESIF projects in order to justify their calculation of the cost. This list of market prices offered by the ESFA greatly contributes to reducing the administrative burdens of beneficiaries for obtaining a price quotation.

Sources: ESFA (2017[12]) and information provided by the Public Procurement Office of Lithuania.

\section{Way forward}

Consider streamlining the market research requirement, in particular for low-value contracts, in order to decrease high administrative burdens for beneficiaries.

Prepare price lists for common goods and services related to R\&I activities, such as travel costs, accommodation costs, conference services, etc. 
Develop detailed guidelines on how to simplify and justify limited market research when procuring innovative goods or services (not previously available) to allow beneficiaries to reduce this step of the process.

\section{Unreasonable cancellation of tenders due to single bids}

Article 57 (2) of the PPA stipulates the grounds for the cancellation of tenders. Contracting authorities may cancel a tender if only one bid is submitted. If they decide not to cancel the tender, they are required to justify their decision. This article also applies to public procurement under ESIF-funded projects.

Regardless of this regulation, however, some beneficiaries expressed concern that the public procurement processes with only one bid always had to be cancelled in practice under the ESIF procurement. They were advised to cancel the tender during the second ex ante control by the intermediate bodies, who are afraid of any potential problems in future audits. Procurement processes with a single bid were cancelled even when the bid was within the estimated values of contract. There are no compelling reasons for cancelling a tender with a single bid when it satisfies the selection and contract award criteria stipulated in the tender documents with a lower price than the estimated values of contract.

In fact, this practice in the Slovak Republic is not aligned with that of other EU member states. Table 5.13 benchmarks the Slovak Republic against other EU countries in terms of the cancellation of procurement procedures when only one bid is submitted. Indeed, none of the EU countries that responded to the short questionnaire foresee such regulations, and the cancellation of tenders with a single bid does not happen in practice.

\section{Table 5.13. Cancellation of procurement procedures with a single bid}

\begin{tabular}{l|c|c|c|c|c}
\hline \multicolumn{1}{c|}{ Regulations } & Slovak Republic & Estonia & Lithuania & Poland & Slovenia \\
\hline $\begin{array}{l}\text { Regulatory framework of public procurement/specific } \\
\text { regulations of ESIF public procurement }\end{array}$ & $\begin{array}{c}\text { Not mandatory with } \\
\text { justification }\end{array}$ & $\begin{array}{c}\text { Not } \\
\text { mandatory }\end{array}$ & $\begin{array}{c}\text { Not } \\
\text { mandatory }\end{array}$ & $\begin{array}{c}\text { Not } \\
\text { mandatory }\end{array}$ & $\begin{array}{c}\text { Not } \\
\text { mandatory }\end{array}$ \\
\hline In practice & Yes, it happens & No & No & No & No \\
\hline
\end{tabular}

Source: Responses to OECD short questionnaires from Estonia, Lithuania, Poland and Slovenia, March 2021.

In Poland, ESIF beneficiaries can proceed with awarding a bidder even if they have only received one bid, as long as the bid meets all of the requirements specified in the tender documents. Slovenia also states that a single bid does not constitute grounds for cancellation.

Previously, the Public Procurement Act of Lithuania had an article on cancelling a tender with a single bid, but that was more than ten years ago. This article was abolished because Lithuania recognised that there was no justification for cancelling a tender process only because only one bid was submitted.

\section{Way forward}

Make sure that beneficiaries are not obliged to cancel a tender due to a low number of bids (in particular, only one), as long as the situation is justified and follows the PPA (e.g. it satisfies the selection and contract award criteria stipulated in the tender documents with a price that is less than the estimated value of the contract). 


\subsection{Procedures related to contracts add significant administrative burdens}

\section{Register of Public Sector Partners}

The Register of Public Sector Partners (RPVS) is a public sector information system that contains the data on public sector partners. It is governed by the Law on the Register of Public Sector Partners and on Amendments to Certain Acts (Act No. 315/2016 Coll.), as amended by Act No. 38/2017 Coll. and Act No. $241 / 2019$ Coll. The system is administered by the Ministry of Justice and the registering authority is the District Court of Žilina. The main purpose of this law is to assist the government in tackling illegal activities of ghost companies that receive public funds for money laundering and terrorism financing.

A public sector partner is defined as a natural person and/or a legal entity that receives payments (public recourses) from the state and local government as well as from other public sector entities. Therefore, those who conclude a contract pursuant to public procurement regulations as well as their subcontractors are required to register in the RPVS, in accordance with the financial thresholds: more than EUR 100000 for a single payment of public funds or more than EUR 250000 per year in case of multiple payments. The obligation to register arises before the signing of the contract.

Article 11 of the PPA also stipulates that the contracting authority may not enter into a contract, concession contract or framework agreement with a tenderer or tenderers who are required to register in the RPVS but have not yet been registered, in accordance with the Law on the Register of Public Sector. The government is not allowed to transfer public funds to those who are not registered in the RPVS. The RPVS also applies to all European funds since 1 September 2019, with the only exception being the European Agricultural Guarantee Fund.

Article 5 of the Law on the Register of Public Sector Partners stipulates that the register of public sector partners needs to be carried out only through an authorised person on behalf of the public sector partner. An authorised person needs to verify the identification of a potential public sector partner through the verification documents, such as the ownership structure and management structure of the public sector partner. The potential public sector partner itself cannot apply for the registration, and such a proposal would be rejected. Therefore, potential public sector partners who have the obligation to register in the RPVS must sign the agreement with an authorised person, which is limited to a lawyer, notary, bank, foreign bank branch, auditor or tax advisor with a registered office or place of business in the territory of the Slovak Republic. This implies that an authorised person could also be foreign as long as s/he has a registered office in the Slovak Republic. The registration procedure itself is free of charge. However, the fee for an authorised person is not regulated by the Law on the Register of Public Sector Partners because it depends on the workload of the authorised person, which is determined by the characteristics of each potential public sector partner.

Article 7 of the Law on the Register of Public Sector Partners stipulates that the registration shall be completed within five working days after receipt of the application from the potential public sector partners.

Some intermediate bodies and beneficiaries shared their views that the registration requirement of the RPVS hinders a smooth start of the contract under ESIF-funded public procurement, because beneficiaries are not allowed to enter into a contract with a successful bidder who is subject to the RPVS but has not yet been registered.

In particular, this registration system is an obstacle to foreign bidders who intend to participate in public procurement in the Slovak Republic, because they find difficulties in the registration procedure itself, and/or are not willing to register. However, detailed information is not available to identify specific factors that cause such difficulties during the registration procedure. The potential factors could be a language barrier, possible additional requirement for foreign companies, a lack of an international authorised person with a registered office in the Slovak Republic, the requirement of having an office in the Slovak Republic, etc. Therefore, the Slovak Republic should analyse the elements that might lead to bottlenecks in the 
registration (including the impact on foreign bidders) as well as the actual practices, including the actual time spent to complete the registration in comparison with the regulatory requirement (five working days after receipt of the application from the potential public sector partners).

\section{Way forward}

Analyse the elements that may lead to bottlenecks in the registration in the RPVS (including the impact on foreign bidders) as well as the actual practices, including the actual time spent to complete the registration.

\section{Payment procedures}

Beneficiaries consider payment procedures to be one of the highest administrative and bureaucratic burdens in ESIF projects. As discussed above, they have to submit a lot of documents to request a payment. This process should be streamlined, especially when considering the additional features to be included in the IT management system.

\subsection{Additional support could be provided to reinforce capacities and capabilities of the public procurement workforce of ESIF projects}

Adequate capacity of the public procurement workforce is a key element to ensure a sound procurement system in order to deliver efficiency and value for money in the use of public funds. The aforementioned OECD Recommendation has a principle related to the capacity of the public procurement workforce. It calls upon countries to develop a procurement workforce with the capacity to continually deliver value for money efficiently and effectively (OECD, 2015[9]) (Box 5.6).

\section{Box 5.6. OECD Recommendation of the Council on Public Procurement: Capacity}

IX. Recommends countries to develop a procurement workforce with the capacity to continually deliver value for money efficiently and effectively.

i) Ensure that procurement officials meet high professional standards for knowledge, practical implementation and integrity by providing a dedicated and regularly updated set of tools, for example, sufficient staff in terms of numbers and skills, recognition of public procurement as a specific profession, certification and regular trainings, integrity standards for public procurement officials, and the existence of a unit or team analysing public procurement information and monitoring the performance of the public procurement system.

ii) Provide attractive, competitive and merit-based career options for procurement officials, through the provision of clear means of advancement, protection from political interference in the procurement process, and the promotion of national and international good practices in career development to enhance the performance of the procurement workforce.

iii) Promote collaborative approaches with knowledge centres such as universities, think tanks or policy centres to improve skills and competences of the procurement workforce. The expertise and pedagogical experience of knowledge centres should be enlisted as a valuable means of expanding procurement knowledge and upholding a two-way channel between theory and practice, capable of boosting application of innovation to public procurement systems.

Source: OECD (2015[9]).

Under the context of ESIF-funded projects, the capability of the public procurement is considered critical not only for speeding up the absorption of the ESIF funds through the smooth implementation of public 
procurement processes, but also for avoiding any mistakes which might lead to irregularities and cancellation of the tender. Indeed, the investment in capacity and capability helps improve the ESIF Management System, which eventually contributes to optimising the absorption rate (spending available funds fully); to minimising irregularities (spending funds correctly); and most importantly, to maximising impact and sustainability (spending them strategically) (European Commission, 2017 [13]).

ESIF-funded procurement involves many actors, including public procurement control officers at the intermediate bodies, the PPO, audit institutions, as well as beneficiaries from the public and private sectors. In particular, beneficiaries from the private sector face additional challenges in carrying out public procurement processes, as most of the time they are not familiar with regulations and implications for the overall project implementation.

Beneficiaries are key stakeholders in the whole ESIF project cycle, not only as essential presenters of the investment needs through the grant proposal application, but also as project implementers by carrying out public procurement procedures. A lack of adequate capability, or skills, is a key barrier to effective implementation of public procurement procedures.

All of the beneficiaries who answered the OECD survey stated that they had a specialised unit and staff for public procurement, including that for ESIF-funded projects. However, some beneficiaries rely occasionally on external resources to implement public procurement procedures under ESIF-funded projects. One beneficiary from the public sector mostly subcontracts to an external company/consultant because it considers that the capacity and capability of its procurement staff are not sufficient to perform complicated public procurement procedures. Another beneficiary's public procurement staff carry out the majority of ESIF procurement. However, it sometimes hires external experts, and in the case of large projects, creates a separate part-time position to work as an internal expert that works exclusively on ESIF public procurement.

Figure 5.1 shows the most challenging procurement areas in terms of capacity building which were identified by the ESIF beneficiaries surveyed by the OECD. 
Figure 5.1. Challenging procurement areas for beneficiaries in terms of strengthening capacity building

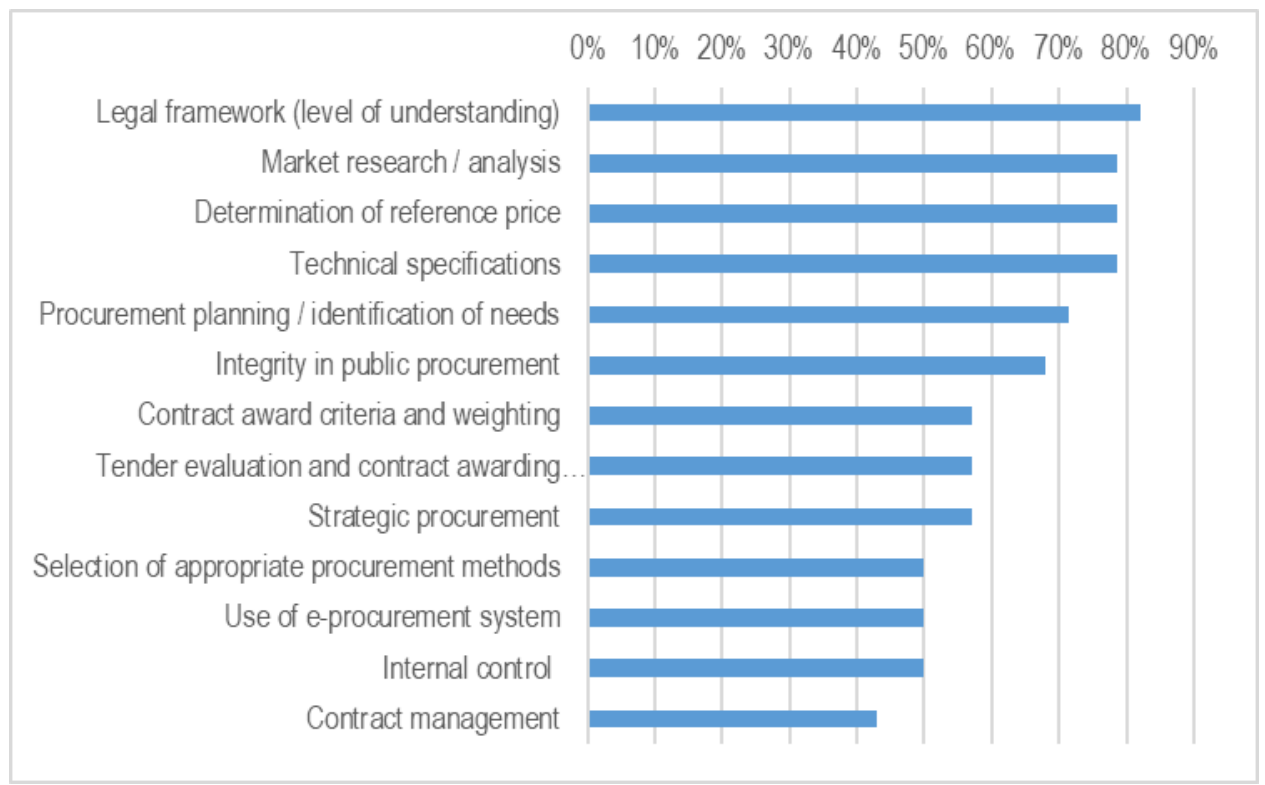

Notes: Seven beneficiaries answered this survey question. Each beneficiary was requested to rate each of the procurement topics in terms of challenges in strengthening the capability of its procurement staff. The result was then summed up for each topic after the conversion in accordance with the following scoring rule: first challenge (greatest challenge) $=4$ points, second challenge $=3$ points, third challenge $=2$ points, fourth challenge (least challenging topic) $=1$ point. Finally, the accumulated number of points obtained by each topic was divided by the total possible maximum number of points (in this case, 28: 4 points $x 7$ beneficiaries) in order to calculate the percentage.

Source: Responses to the short OECD questionnaire sent to beneficiaries on public procurement.

Legal framework (level of understanding and interpretation) was identified as the most challenging area of public procurement under ESIF-funded projects. Many beneficiaries shared their views that the PPA is very difficult and complicated to interpret, not only for non-public procurement experts, but also for public procurement professionals who actually work on the public procurement procedures. Furthermore, the PPA has been amended frequently (about 15 times since its entry into force in 2015), which makes it even more difficult to interpret in a timely and correct manner.

Market research/analysis, determination of reference price and technical specifications were mixed with the administrative burdens concerning the requirement for price quotations under the ESIF procurement, because most of the beneficiaries commented on its bureaucratic and time-consuming aspects rather than their capability to perform it.

Contract award criteria and weighting and strategic procurement are mostly related to the implementation of public procurement for innovation (PPI), which will be discussed in Section 5.6. It should be noted that strategic procurement (in particular, green public procurement and PPI) was identified as the most challenging topic for two large beneficiaries that have relatively sufficient capability, although its overall ranking is not so high in Figure 5.1 partially because some beneficiaries are not familiar with the concept of strategic procurement.

Beneficiaries stated that the methodological assistance system such as trainings and manuals is not sufficient. Training on public procurement is not provided to beneficiaries, while control officers at the intermediate bodies have greater access to training opportunities (see Table 5.6).

One beneficiary from the private sector stated that its procurement staff regularly attended public procurement courses provided by private companies, such as public procurement under the ESIF, in order to remain up to date on the concept of public procurement as well as the changes in the PPA. This case 
implies that there might be other training opportunities besides the government that can be used to strengthen the capabilities of beneficiaries if properly identified.

Beneficiaries also need more methodological training and guidelines/manuals. For example, clear and reader-friendly guidelines on the PPA are critical, because proper understanding and interpretation of the PPA has been identified as the biggest challenge. Beneficiaries need a simple manual that describes the flow of public procurement procedures and the main steps to follow, rather than a long list of legislative provisions. Common mistakes in public procurement that might lead to financial correction could be included in these guidelines by listing actual cases against each article. Beneficiaries also need guidelines and training related to strategic procurement, such as green public procurement and PPI, as well as contract award criteria. Public procurement officials have different options available - lowest price criteria, the most economically advantageous tender (MEAT) criteria including the life cycle costing option - where they would need additional support to achieve better value for money through public procurement. In Croatia, for example, the Agency for SMEs, Innovation and Investments, as an intermediate body of the ESIF programme, conducted a very fruitful workshop that focuses on helping beneficiaries identify the most common errors leading to irregularities (OECD, 2020[14]).

Currently, no comprehensive capacity-building system has been developed for the beneficiaries of ESIF projects. The Slovak Republic should consider developing induction sessions for beneficiaries. They could include the topics discussed above such as an introduction to public procurement, regulatory frameworks (the PPA and the ESIF Administration System), contract award criteria focusing on the MEAT criteria, strategic procurement such as PPI and green public procurement, common mistakes with actual examples and case studies, etc. This could be accomplished through collaboration among various stakeholders, including the intermediate bodies, the PPO and audit institutions. Beneficiaries also pointed out the need for more involvement of the PPO, because they currently can not rely on the PPO to receive practical advice on public procurement matters. The Audit Authority of the Ministry of Finance provides training on common mistakes on public procurement to subnational governments and is also willing to provide this training to other types of beneficiaries. Regular training opportunities after the induction sessions as well as setting up a help desk to answer questions on public procurement would reinforce the methodological assistance system for ESIF public procurement.

Raising awareness on the methodological assistance tools such as training and manuals is also critical, so that these tools reach stakeholders working on ESIF-funded public procurement procedures. Currently, the information related to ESIF public procurement is fragmented. International good practices include the development of a one-stop shop procurement portal. This consists of a single and comprehensive web platform which offers a range of public procurement information and support services. Its rationale lies in the efficiency gained without the need to navigate multiple websites and formats to get assistance. Having everything on one site also makes it easier for users to access the right source of information. Ideally, the following content should be available on the one-stop shop procurement portal for ESIF public procurement in the Slovak Republic:

- schedule of face-to-face training courses

- regulatory framework (ESIF Management System, the PPA, intermediate body guidelines) and its update

- e-learning modules (video, training materials such as PowerPoint slides), if available

- guidelines and manuals, FAQs and best practice sheets

- standardised templates

- help desk, if available.

Signing up to a periodic newsletter would keep practitioners informed on recent updates such as legal changes, newly developed guidelines, events, etc. 
Developing the solid capacity-building system discussed above will help speed up the absorption of the ESIF funds and as well as avoid mistakes leading to irregularities and cancellation of the tender under the ESIF public procurement.

\section{Way forward}

Develop structured capacity-building mechanisms for ESIF beneficiaries, including targeted training, guidelines, manuals, a help desk, etc., with the collaboration of various stakeholders, including the CCA, the managing authority, the intermediate bodies, the PPO and audit institutions.

Provide induction sessions for beneficiaries, including topics such as an introduction to public procurement, regulatory frameworks (the PPA and the ESIF Administration System), contract award criteria focusing on the MEAT criteria, strategic procurement such as PPI and green public procurement, and common mistakes with actual examples and case studies.

Develop a one-stop shop procurement portal to provide a single and comprehensive web platform with a range of public procurement information and support services.

\subsection{Strategies for using public procurement to foster innovation are underused}

All OECD countries are using public procurement in order to pursue complementary policy objectives that are aligned with the Sustainable Development Goals. Indeed, public procurement is increasingly recognised as a strategic tool to achieve broader government outcomes, such as stimulating innovation, promoting the circular economy, supporting SMEs, and promoting ethical behaviour and responsible business conduct. In 2018 , about $72 \%$ of OECD countries $(83 \%$, if the initiatives at some contracting authorities are taken into account) had developed policies or strategies related to public procurement for innovation (OECD, 2019 $\left.9_{[15]}\right)$.

\section{Figure 5.2. Evolution of the strategic use of public procurement in OECD countries}

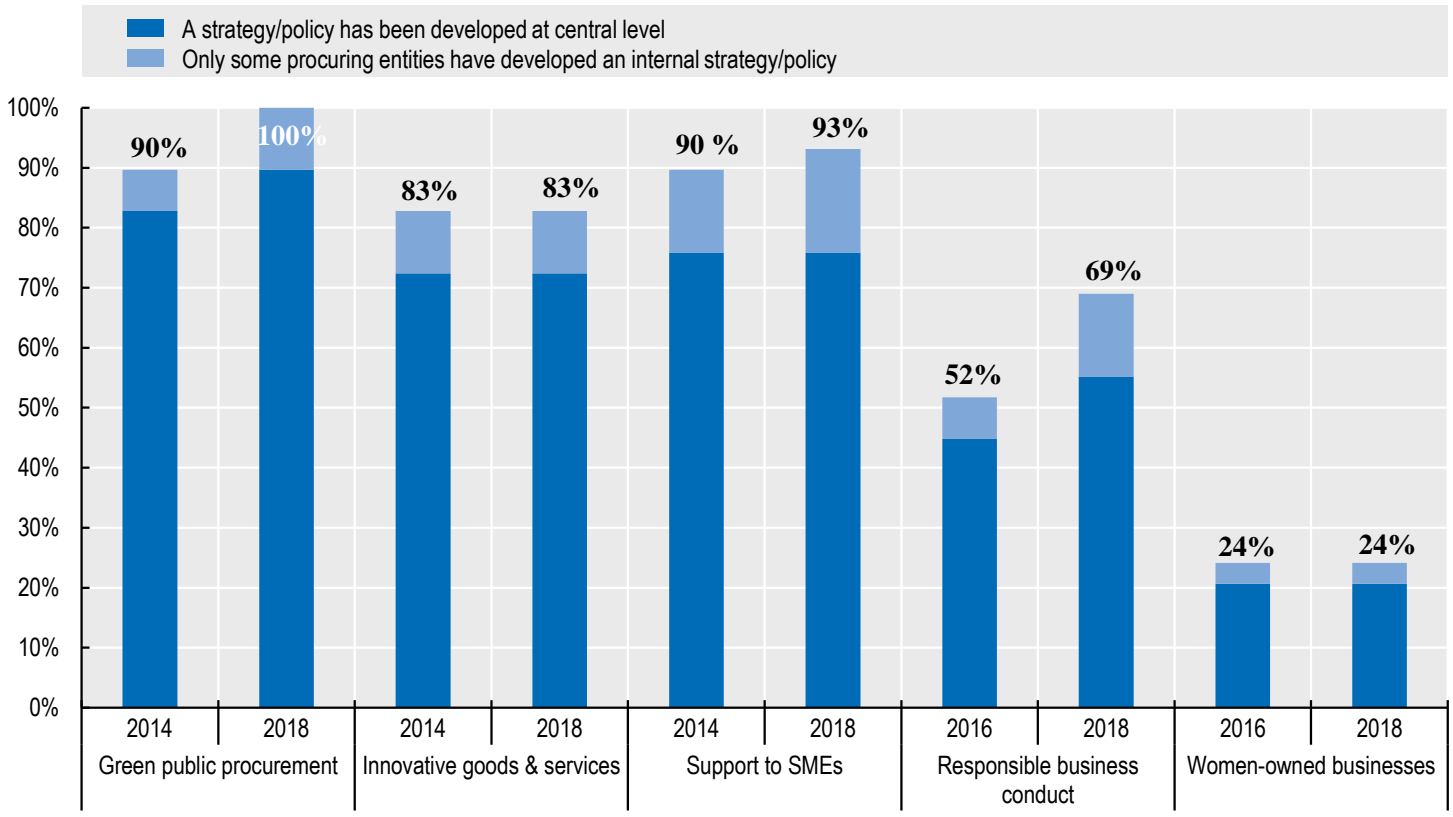

Notes: Based on data from 29 OECD countries that answered both the 2018 and one of the 2016/14 Surveys on Public Procurement. Percentages give the sum of both categories. Countries indicating that some procuring entities developed an internal strategy/policy and that a strategy/policy has been developed at central level are included in the second category (i.e. a strategy/policy has been developed at central level).

Source: OECD (2019[15]). 
Used strategically, public procurement can help governments boost innovation at both the national and the local level. Strategic use of PPI is defined as "any kind of public procurement practice (pre-commercial or commercial) that is intended to stimulate innovation through research and development and the market uptake of innovative products and services" (OECD, 2017 $\left.7_{[16]}\right)$.

The Slovak Republic introduced the concept of PPI by transposing the EU Public Procurement Directives (Directive 2014/24/EU) into the PPA. The PPA foresees the procurement mechanisms that can be used to stimulate innovations, such as competitive dialogue (Articles 74-77) and Innovation Partnership (Articles 78-90) (Office, Public Procurement, 2015[7]).

PPI is currently not a common practice in the Slovak Republic. There are few actual examples of using PPI under ESIF-funded R\&I projects. Even the largest beneficiaries related to R\&I have never carried out PPI under ESIF projects.

The role of public procurement as an instrument for stimulating innovation has been increasingly emphasised in the Slovak Republic, but it has not yet been fully recognised by stakeholders, such as the managing authority, the intermediate bodies, audit institutions or beneficiaries. One beneficiary mentioned that public procurement was meaningless for R\&I projects, because what is not developed yet cannot be procured. This remark implies that PPI might not be a concept with which public procurement practitioners in the Slovak Republic are familiar. Some beneficiaries even stated that the grant application proposal would be negatively evaluated by the intermediate bodies if they propose the use of public PPI.

In addition, there is no target set for PPI in terms of percentage of total public procurement (number of procedures and/or amounts), and no systematic monitoring of the data on PPI. This leads to fewer incentives for the government to promote the application of PPI under ESIF R\&I projects. Poland has proven experience in using PPI schemes such as pre-commercial procurement (PCP) and Innovation Partnership (IP) under ESIF R\&I projects. Poland's National Centre for Research and Development, the agency in charge of ESIF R\&I projects, initiated an e-Pioneer project financed under the ESIF Operational Programme "Digital Poland 2014-2020", under which the PCP scheme was used by beneficiaries to procure innovative solutions. This initiative contributed to encouraging a larger pool of interested contractors to participate in ESIF R\&I projects by using PCP (Box 5.7). The Slovak Republic could benefit from considering the pilot initiative of this good practice in order to increase the use of PPI under ESIF R\&I projects.

\section{Box 5.7. Promotion of public procurement for innovation by the National Centre for Research and Development of Poland under the ESIF R\&I programme}

In Poland, the new Public Procurement Law of 11 September 2019, which entered into force on 1 January 2021, further supports public procurement of innovation (PPI) by implementing new solutions in this area. The law directly links the procurement of innovation with a broader perspective of national policy.

The National Centre for Research and Development (NCRD) has experience in using public procurement for innovation in ESIF-funded research and innovation (R\&I) projects. The NCRD is in charge of carrying out tasks in the area of scientific, technical and innovation policy, including financing innovative solutions through R\&D programmes. The NCRD decided to launch pilot research programmes based on both procurement models: pre-commercial procurement (PCP) and innovation partnership, both of which are adapted to procuring innovative solutions that cannot be specified at the beginning of the procedure, i.e. those that require research and development.

The NCRD's first experience related to PCP dates back to 2013. It was further developed in 2016 owning to the implementation of the e-Pioneer project, which aims to support talented programmers in solving identified social or economic problems with information and communication technologies. This 
is a joint project of the NCRD and the accelerators selected by the NCRD, which uses the PCP model. The NCRD does not directly use PCP, but it is an obligatory project implementation tool for the accelerators selected by the NCRD. The e-Pioneer project is financed under the ESIF Operational Programme "Digital Poland 2014-2020".

For example, Akcelerator Accelpoint Sp. z o. o., one of the selected accelerators in the e-Pioneer project, developed a Cleanbox to fight against COVID-19 using the PCP model. Cleanbox is an easyto-use, modern device with antibacterial and antifungal properties, which eliminates $99.99 \%$ of microbes and bacteria, ensuring an additional antibacterial effect for up to 30 days. With its functionalities, the project helps to prevent common infections and answers the growing need for surface disinfection, contributing to the fight against the spread of coronavirus. The MVP (a minimum viable product or, to put it simply, a demo version of the target product) was created and tests were successfully carried out using the public partner's (Municipal Sport and Recreation Centre in Lublin) infrastructure.

The NCRD promoted itself as an agency which not only finances innovation, but which also carries out innovative activities. It presented new forms of research programme implementation to the market and the potential contractors to encourage a larger pool of interested contractors to participate in ESIF R\&I projects.

With the experience gained so far and the competences built within the organisation, the NCRD has been working since 2020 to launch further initiatives based on PCP. By doing so, it aims to ensure that this instrument is permanently included in its portfolio of support instruments.

Source: Polish Public Procurement Office (2020[17]).

OECD research shows that one of the biggest obstacles to overcome when aiming to increase innovation through public procurement is the tendency to use the award criterion of lowest price, rather than MEAT, which consists of elements including price, cost and/or quality (OECD, 2017 $[16])$. MEAT criteria are not deeply rooted in public procurement in the Slovak Republic, including for ESIF-funded projects.

Recognising the relevance of PPI, many ESIF beneficiaries have a strong appetite for using this scheme to procure innovative solutions. They stated that they sometimes had to cancel a tender because they realised that the market can not live up to their expectation to supply what they need since their needs for R\&I activities change day by day. The use of PPI will respond very flexibly to the changing demands for their R\&I activities. However, beneficiaries are concerned that they do not have enough capabilities to carry out PPI, because PPI is an emerging public procurement topic.

The government has recently has been taking initiatives to promote the use of PPI. For example, the PPO issued a methodological document Innovation in Public Procurement in 2017 (Public Procurement Office, $2017_{[18]}$ ). In addition, a working group has been established by the PPO to analyse the possibility of using public procurement as a tool to achieve complementary policy objectives, including stimulating innovation (also green public procurement, social procurement, etc.), as part of the long-term PPO strategy (Public Procurement Office, n.d.[19]). These topics are currently being further developed by the PPO under separate projects, some with OECD support, with the aim of preparing a solid base of conceptual materials.

In addition to the initiative taken by the PPO, the Ministry of Economy prepared a Methodological Document for Beneficiaries on the Application of the Principles of the Public Procurement for Innovation within the Tenders Co-financed from the Operational Programme Integrated Infrastructure under the Ministry of Economy (Ministry of Economy, 2020[20]) (Box 5.8). 


\section{Box 5.8. Methodological document for public procurement for innovation prepared by the Ministry of Economy}

The methodological instrument for public procurement for innovation prepared by the Ministry of Economy provides a basic framework for understanding innovation-oriented public procurement.

This document introduces innovative tools that can be incorporated into public procurement for innovation, including widely used open, restricted procurement procedures as well as alternative public procurement procedures such as negotiated procedure with competition, competitive dialogue, design contest, innovation partnership or the pre-commercial procurement approach. It also provides a list of award criteria (other than criteria commonly used in the standard public procurement) such as price, cost and quality (MEAT criteria). These criteria represent an important potential for innovation procurement.

It also provides instructions on how the contract management phase should be carried out, including the contract clauses that should include:

- contract performance criteria, measurable quality indicators and performance objectives

- provisions on how to stop contract performance in case of insufficient performance or if the market offers a more suitable solution than the one currently being developed (bearing in mind fair conditions for the suppliers)

- provisions on how to amend the contract in case of wide variations or high potential of other innovations identified during the contract performance.

Source: Ministry of Economy (2020[20]).

These guidelines could be a first important step for promoting PPI, as well as for enhancing the capability of beneficiaries to use public procurement to stimulate innovation. However, beneficiaries expressed their strong desire for more methodological assistance. The initiatives should be positively evaluated, but the guidelines mentioned above lack comprehensiveness (13 pages by the PPO and 15 pages by the Ministry of Economy) and need to be further revised to improve the overall quality and increase their coverage. In addition, no practical training is available to beneficiaries on the use of PPI and MEAT criteria. Even the control officers at the intermediate body took a training course on the MEAT criteria only in 2017, and this course was provided by a private company. This stresses the importance of developing training on PPI and MEAT criteria for all the stakeholders involved in ESIF-funded public procurement, including intermediate bodies, audit institutions and beneficiaries. The PPO is addressing the issues related to the strategic use of public procurement in the Slovak Republic through different and complementary projects, so the next programming period could benefit from these additional efforts, when available.

The PPO provides methodological assistance to support contracting authorities to implement PPI, this includes consultation with the optional ex ante control as well as the issuance of the best practice book on PPI in Poland (Box 5.9). The Slovak Republic could benefit from learning from this initiative in the methodological assistance for PPI. 


\section{Box 5.9. Methodological assistance provided by the Public Procurement Office of Poland for public procurement for innovation}

The Public Procurement Office of Poland (PPO) provides methodological assistance to promote the use of public procurement in stimulating innovation in Poland.

Article 614 of the new Public Procurement Law (PPL) of 11 September 2019, which entered into force on 1 January 2021, refers to the possibility of the PPO to carry out an ex ante control of the procurement documents at the request of the contracting authority. This option is applied to the public procurement procedures on procuring innovative products and solutions with a contract value equal to or exceeding the EU thresholds (Article 614 of the PPL). This ex ante control is supervised by the President of the Public Procurement Office. It does not cover the technical part of the contract documents, but it may cover the entire procedure or the stage of the call for proposals or tenders, the negotiation stage, or the tender evaluation stage.

In addition, the PPO published a book: Public Procurement of Innovation. This publication describes the concept of public procurement for innovation, and demonstrates actual good practices from a wide range of contracting authorities in Poland:

- the central government administration: the National Center for Research and Development, GovTech Poland, the National Center for Agricultural Support

- the local government entity: Regional Water and Sewage Management Center S.A. in Tychy

- the academic sector: SOLARIS National Synchrotron Radiation Center of the Jagiellonian University.

Source: Information provided by Public Procurement Office of Poland.

Knowledge sharing will also facilitate the exchange of concrete experiences of PPI. PPI is a relatively new public procurement scheme, and it is necessary to learn from good and bad practices through repetitive trials and errors.

\section{Way forward}

Consider the possibility of setting up a target for PPI implementation for the ESIF R\&I projects in terms of percentage of total public procurement (number of procedures and/or amounts), as well as of collecting the systematic monitoring of the data on PPI.

Consider the possibility of carrying out ESIF pilot projects that require the use of PPI schemes, such as PCP and IP.

Provide more capacity-building opportunities to stakeholders (beneficiaries, intermediate bodies and audit institutions) in order to raise awareness of PPI and promote its use in ESIF R\&I projects.

Organise regular seminars to exchange practices of PPI by the PPO and other relevant stakeholders. 


\title{
6. Moving forward: Implementing the action plan to reform ESIF administration for research and innovation
}

\author{
This chapter presents an action plan for implementing the \\ recommendations identified in the previous chapters, which the government \\ of the Slovak Republic could consider in order to reform the European \\ Structural and Investment Funds (ESIF) administration in the \\ Slovak Republic for better implementation of ESIF projects related to \\ research and innovation $(\mathrm{R} \& \mathrm{l})$.
}

This chapter presents an action plan for implementing the recommendations. The draft action plan with concrete and targeted recommendations was prepared in accordance with the RACl methodology (Box 6.1). In order to allow for a more precise definition of the actions and identification of the right actors to implement them, the recommendations detailed in the previous chapters were integrated into 15 key initiatives according to their similarity, importance and possibility of execution. The draft action plan as initially prepared by the OECD was presented to the relevant Slovak stakeholders during a workshop organised on 22 April 2021. This event was organised to stimulate the discussion and exchange of opinions among the different counterparts and to agree on the way forward. As agreed, after the workshop, the Ministry of Transport and Construction, as the managing authority, took the initiative to facilitate internal discussion among Slovak stakeholders to agree on the main elements for each action, such as the priority, implementation time frame and division of tasks. After several interactions, the government of the Slovak Republic and the OECD finalised the action plan in June 2021. 


\section{Box 6.1. RACl methodology}

The RACI methodology was used to identify the actors for the implementation of the proposals. RACl enables the understanding of the roles and responsibilities required for various tasks, processes and assignments. The following criteria were used:

- $R=$ Responsible - the individual who carries out the work.

- $\mathrm{A}=$ Accountable - the individual who holds the ultimate accountability for the work being carried out and/or decision making.

- $\quad \mathrm{C}=$ Consulted - individuals who should be informed and referred to prior to decision making or task completion.

- $I$ = Informed - individuals who should be informed once decisions are taken or upon work completion.

Source: Delos Santos (2018[21]).

Table 6.1 shows the final action plan with its 15 initiatives, their priority, the division of tasks for each entity and the estimated implementation time frame. 
Table 6.1. Action plan to reform the administration of the European Structural and Investment Funds in the Slovak Republic

\begin{tabular}{|c|c|c|c|c|c|c|c|c|}
\hline Initiative & Context & Recommendation & Priority & Responsible & Accountable & Consulted & Informed & $\begin{array}{l}\text { Estimated } \\
\text { time frame }\end{array}$ \\
\hline \multirow[t]{2}{*}{ Human resources } & $\begin{array}{l}\text { Project management tools } \\
\text { - Overall project management seems to } \\
\text { be deficient. } \\
\text { - Some benchmarking countries use } \\
\text { tools to measure progress to ensure } \\
\text { monitoring of achieved milestones. } \\
\text { Yearly targets are defined and } \\
\text { outcomes discussed through at least } \\
\text { semi-annual seminars with all agencies } \\
\text { in the ESIF system. } \\
\text { - Some benchmark countries use } \\
\text { perfomance dashboards and progress } \\
\text { measured through traffic light systems. } \\
\text { - In Estonia, milestones and their } \\
\text { achievement are measured } \\
\text { automatically on the online portal } \\
\text { through provision of data and } \\
\text { documents. }\end{array}$ & $\begin{array}{l}\text { - Establish internal management tools } \\
\text { and control mechanisms for better } \\
\text { monitoring progress achieved by staff } \\
\text { members and enable more efficient use } \\
\text { of administrative capacities within the } \\
\text { intermediate bodies. } \\
\text { - Create a scorecard to give } \\
\text { management an overview of the } \\
\text { implementation progress, with specific } \\
\text { alerts at the first signs of slowdown and } \\
\text { delays. } \\
\text { - Flexibly reallocate staff who have a } \\
\text { lighter workload to the critical tasks of } \\
\text { administrative checks, evaluator } \\
\text { recruitment and contracting. } \\
\text { - Explore possibilities for hiring } \\
\text { temporary staff, and/or outsourcing } \\
\text { tasks which are less critical with respect } \\
\text { to legal responsibility. } \\
\text { - Adopt simplification of tasks such as } \\
\text { the ones which have been applied in } \\
\text { the context of the COVID calls. }\end{array}$ & High & $\begin{array}{c}\text { Research } \\
\text { Agency }\end{array}$ & $\begin{array}{c}\text { Ministry of } \\
\text { Education, } \\
\text { Science, Research } \\
\text { and Sport } \\
\text { Ministry of } \\
\text { Economy }\end{array}$ & $\begin{array}{c}\text { Central } \\
\text { co-ordination } \\
\text { body } \\
\text { Audit authority } \\
\text { Certifying } \\
\text { authority }\end{array}$ & $\begin{array}{l}\text { Ministry of } \\
\text { Investments, } \\
\text { Regional } \\
\text { Development } \\
\text { and } \\
\text { Informatization } \\
\text { (managing } \\
\text { authority for } \\
\text { 2021-27) }\end{array}$ & Short \\
\hline & $\begin{array}{l}\text { Incentives } \\
\text { - Even though the lack of administrative } \\
\text { staff is likely not the main reason for } \\
\text { slow absorption of ESIF funds } \\
\text { according to the benchmarking, the } \\
\text { Research Agency is affected by a } \\
\text { vicious circle whereby the loss of } \\
\text { reputation makes it unable to recruit } \\
\text { professional staff, and the lack of staff } \\
\text { capabilities combined with management }\end{array}$ & $\begin{array}{l}\text { - A comprehensive human resource } \\
\text { consulting project should be } \\
\text { undertaken, with terms of reference } \\
\text { including (but not limited to): } \\
\text { - An analysis of the status of the } \\
\text { Research Agency's personnel (salary, } \\
\text { benefits, career paths) } \\
\text { - A staff survey identifying the main } \\
\text { areas for improving working conditions } \\
\text { (teleworking opportunities, target-based }\end{array}$ & High & $\begin{array}{l}\text { Research } \\
\text { Agency }\end{array}$ & $\begin{array}{l}\text { Managing authority } \\
\text { Ministry of } \\
\text { Education, } \\
\text { Science, Research } \\
\text { and Sport }\end{array}$ & $\begin{array}{l}\text { Ministry of } \\
\text { Education, } \\
\text { Science, } \\
\text { Research and } \\
\text { Sport } \\
\text { Research } \\
\text { Agency }\end{array}$ & $\begin{array}{l}\text { Ministry of } \\
\text { Investments, } \\
\text { Regional } \\
\text { Development } \\
\text { and } \\
\text { Informatization } \\
\text { (managing } \\
\text { authority for } \\
\text { 2021-27) }\end{array}$ & Short \\
\hline
\end{tabular}




\begin{tabular}{|c|c|c|c|c|c|c|c|c|}
\hline \multirow[t]{2}{*}{ Initiative } & Context & Recommendation & Priority & Responsible & Accountable & Consulted & Informed & $\begin{array}{l}\text { Estimated } \\
\text { time frame }\end{array}$ \\
\hline & $\begin{array}{l}\text { shortcomings leads to aggravated } \\
\text { workload and further delays, which } \\
\text { further damage its reputation. } \\
\text { - High staff turnover in the past has } \\
\text { contributed to difficulties and delays. } \\
\text { - Incentives to attract and keep staff } \\
\text { members are crucial. } \\
\text { - Availability of expert professionals in } \\
\text { the Slovak Republic is limited and often } \\
\text { intermediate bodies provide better } \\
\text { working conditions, thus attracting the } \\
\text { most qualified personnel. }\end{array}$ & $\begin{array}{l}\text { salary, bonuses, etc.) } \\
\text { - A human resources action plan is } \\
\text { needed with the objective to create } \\
\text { optimal working conditions for the } \\
\text { agency's staff, and provide incentives } \\
\text { and rewards, making the agency a } \\
\text { desirable employer. }\end{array}$ & & & & & & \\
\hline \multirow[t]{2}{*}{ Capabilities } & $\begin{array}{l}\text { Training for intermediate bodies and } \\
\text { agencies } \\
\text { - Higher quality administrative advice to } \\
\text { the beneficiaries can only be provided } \\
\text { by sufficiently qualified and trained staff } \\
\text { in the intermediate bodies. Specific } \\
\text { measures are needed to enhance } \\
\text { project management skills. } \\
\text { - Beneficiaries in the sciences often } \\
\text { face particular limits and other realities } \\
\text { than other businesses and intermediate } \\
\text { body staff need to be adequately } \\
\text { trained to respond to these needs. }\end{array}$ & $\begin{array}{l}\text { - Efficiency in management in } \\
\text { intermediate bodies could be improved } \\
\text { through training focusing on project } \\
\text { management skills. } \\
\text { - A training programme to ensure the } \\
\text { implementation of objectives by } \\
\text { management, and to prepare staff for } \\
\text { the multidisciplinary nature of the work, } \\
\text { making them proficient in the most } \\
\text { relevant topics and sensitising them for } \\
\text { the realities of scientific research. } \\
\text { - Provide more high-quality training } \\
\text { opportunities to the intermediate bodies' } \\
\text { control officers and beneficiaries. } \\
\text { Implement a standardised evaluation of } \\
\text { the training with objectives and } \\
\text { expected impact. }\end{array}$ & High & $\begin{array}{c}\text { Ministry of } \\
\text { Education, } \\
\text { Science, } \\
\text { Research and } \\
\text { Sport } \\
\text { Ministry of } \\
\text { Economy } \\
\text { Research } \\
\text { Agency }\end{array}$ & $\begin{array}{c}\text { Ministry of } \\
\text { Education, } \\
\text { Science, Research } \\
\text { and Sport } \\
\text { Ministry of } \\
\text { Economy }\end{array}$ & $\begin{array}{l}\text { Ministry of } \\
\text { Investments, } \\
\text { Regional } \\
\text { Development } \\
\text { and } \\
\text { Informatization } \\
\text { (managing } \\
\text { authority/central } \\
\text { co-ordination } \\
\text { authority for } \\
\text { 2021-27) } \\
\text { Research } \\
\text { Agency } \\
\text { Beneficiaries }\end{array}$ & $\begin{array}{l}\text { Ministry of } \\
\text { Investments, } \\
\text { Regional } \\
\text { Development } \\
\text { and } \\
\text { Informatization } \\
\text { (managing } \\
\text { authority/ } \\
\text { central } \\
\text { co-ordination } \\
\text { authority for } \\
2021-27 \text { ) }\end{array}$ & Medium \\
\hline & $\begin{array}{l}\text { Training for beneficiaries } \\
\text { - Most training opportunities are } \\
\text { provided to intermediate body control } \\
\text { officers, not to beneficiaries. } \\
\text {-The usefulness or effectiveness of } \\
\text { these trainings, or how they are applied }\end{array}$ & $\begin{array}{l}\text { - A proactive approach in engaging } \\
\text { beneficiaries in consultation through } \\
\text { workshops, seminars, etc. could } \\
\text { improve beneficiaries' success rate in } \\
\text { the administrative verification. } \\
\text { - Develop structured capacity-building }\end{array}$ & High & $\begin{array}{l}\text { Research } \\
\text { Agency } \\
\text { Ministry of } \\
\text { Education, } \\
\text { Science, } \\
\text { Research and } \\
\text { Sport }\end{array}$ & $\begin{array}{l}\text { Ministry of } \\
\text { Investments, } \\
\text { Regional } \\
\text { Development and } \\
\text { Informatization } \\
\text { (central } \\
\text { co-ordination body) }\end{array}$ & $\begin{array}{l}\text { Ministry of } \\
\text { Investments, } \\
\text { Regional } \\
\text { Development } \\
\text { and } \\
\text { Informatization } \\
\text { (managing }\end{array}$ & $\begin{array}{l}\text { Beneficiaries } \\
\text { Research } \\
\text { Agency }\end{array}$ & Medium \\
\hline
\end{tabular}




\begin{tabular}{|c|c|c|c|c|c|c|c|c|}
\hline Initiative & Context & Recommendation & Priority & Responsible & Accountable & Consulted & Informed & $\begin{array}{l}\text { Estimated } \\
\text { time frame }\end{array}$ \\
\hline & $\begin{array}{l}\text { in practice, are not known or assessed } \\
\text { adequately. } \\
\text {-Beneficiaries face challenges in } \\
\text { capability in fields such as } \\
\text { understandging the complicated legal } \\
\text { framework and setting contract award } \\
\text { criteria, implementing strategic } \\
\text { procurement, etc. } \\
\text { - No comprehensive capacity-building } \\
\text { system has been developed for the } \\
\text { moment for the beneficiaries of ESIF } \\
\text { projects. } \\
\text { - Information related to ESIF public } \\
\text { procurement is fragmented. }\end{array}$ & $\begin{array}{l}\text { mechanisms for ESIF beneficiaries, } \\
\text { including targeted training, guidelines, } \\
\text { manuals, help desk, etc., with the } \\
\text { collaboration of various stakeholders, } \\
\text { including the central co-ordination } \\
\text { authority, managing authority, } \\
\text { intermediate bodies, the Public } \\
\text { Procurement Office, audit institutions. } \\
\text { - Provide induction sessions for } \\
\text { beneficiaries, including topics such as } \\
\text { an introduction to public procurement, } \\
\text { regulatory frameworks (PPA and ESIF } \\
\text { Administration System), contract award } \\
\text { criteria focusing on the MEAT criteria, } \\
\text { strategic procurement such as public } \\
\text { procurement for innovation and green } \\
\text { public procurement, common mistakes } \\
\text { with actual examples and case studies. } \\
\text { - Develop a one-stop shop procurement } \\
\text { portal to provide a single and } \\
\text { comprehensive web platform to group } \\
\text { public procurement information and } \\
\text { support services. }\end{array}$ & & $\begin{array}{l}\text { Ministry of } \\
\text { Economy }\end{array}$ & $\begin{array}{c}\text { Ministry of } \\
\text { Education, } \\
\text { Science, Research } \\
\text { and Sport } \\
\text { Ministry of } \\
\text { Economy }\end{array}$ & $\begin{array}{c}\text { authority/central } \\
\text { co-ordination } \\
\text { body/for } \\
2021-27) \\
\text { Public } \\
\text { Procurement } \\
\text { Office } \\
\text { Beneficiaries }\end{array}$ & & \\
\hline ITMS2014+ & $\begin{array}{l}\text { - ITMS2014+ is not user-friendly or } \\
\text { intuitive, bringing high administrative } \\
\text { and bureaucratic burdens to } \\
\text { intermediate bodies and beneficiaries. } \\
\text { - Documents should be submitted } \\
\text { electronically; and requested only once } \\
\text { on the application portal rather than } \\
\text { multiple times at different stages of the } \\
\text { process. } \\
\text { - The benefits of a functioning and } \\
\text { effective electronic portal which avoids }\end{array}$ & $\begin{array}{l}\text { - Large-scale investment into } \\
\text { restructuring and updating an IT system } \\
\text { fit for purpose at the beginning will pay } \\
\text { off in the medium term. } \\
\text { - Organise a series of meetings to } \\
\text { discuss how to make the system user- } \\
\text { friendly by inviting relevant users such } \\
\text { as intermediate bodies' control officers } \\
\text { and beneficiaries. Appoint a task force } \\
\text { and co-ordinator to facilitate this } \\
\text { process, as it involves different } \\
\text { stakeholders with distinct priorities and } \\
\text { objectives. }\end{array}$ & High & $\begin{array}{l}\text { DATACENTR } \\
\text { UM }\end{array}$ & $\begin{array}{l}\text { Ministry of } \\
\text { Investments, } \\
\text { Regional } \\
\text { Development and } \\
\text { Informatization } \\
\text { (central } \\
\text { co-ordination } \\
\text { authority) }\end{array}$ & $\begin{array}{l}\text { Managing } \\
\text { authority (MoTC) } \\
\text { Intermediate } \\
\text { bodies (Ministry } \\
\text { of Education, } \\
\text { Science, } \\
\text { Research and } \\
\text { Sport, Ministry of } \\
\text { Economy) } \\
\text { Research } \\
\text { Agency } \\
\text { Beneficiaries } \\
\text { Audit authority }\end{array}$ & $\begin{array}{l}\text { Ministry of } \\
\text { Investments, } \\
\text { Regional } \\
\text { Development } \\
\text { and } \\
\text { Informatization } \\
\text { (central } \\
\text { co-ordination } \\
\text { authority) } \\
\text { Managing } \\
\text { authority } \\
\text { Intermediate } \\
\text { bodies }\end{array}$ & Long \\
\hline
\end{tabular}




\begin{tabular}{|c|c|c|c|c|c|c|c|c|}
\hline Initiative & Context & Recommendation & Priority & Responsible & Accountable & Consulted & Informed & $\begin{array}{l}\text { Estimated } \\
\text { time frame }\end{array}$ \\
\hline & $\begin{array}{l}\text { duplication of efforts are particularly } \\
\text { visible in Estonia which invests in } \\
\text { updated IT infrastructure at the } \\
\text { beginning of each programming period. } \\
\text { - In the Slovak Republic, the ITMS } \\
\text { portal should be improved or replaced } \\
\text { by a more user-friendly system (similar } \\
\text { to the Horizon } 2020 \text { system). Overall, } \\
\text { the H2020 process could serve as an } \\
\text { guide, as it is considerably more } \\
\text { efficient in spite of high requirements in } \\
\text { terms of information and documents } \\
\text { that are required. Such a system would } \\
\text { allow tracking progress by both } \\
\text { beneficiaries and intermediate bodies. } \\
\text { - Given the vast administrative } \\
\text { requirements for information, frequent } \\
\text { documents, annexes which often } \\
\text { necessitate regular corrections and } \\
\text { updates, the online portal should allow } \\
\text { for quick and simple corrective action. } \\
\text { - The government has a plan to update } \\
\text { the ITMS2014+ for the next } \\
\text { programming period } 2021-27 \text { and it } \\
\text { should recognise the challenges } \\
\text { identified by stakeholders (actual users } \\
\text { of the system). } \\
\text { - There currently are not any } \\
\text { performance indicators of ESIF public } \\
\text { procurement procedures. } \\
\text { - ITMS2014+ is not set up for financial } \\
\text { instruments specifics, mainly monitoring } \\
\text { and reporting. Data that are subject to }\end{array}$ & $\begin{array}{l}\text { - The Online Portal should enable: } \\
\text { 1. providing forms for machine readable } \\
\text { applications, and making this } \\
\text { mandatory (if possible) } \\
\text { 2. At least checking whether all } \\
\text { documents are submitted } \\
\text { 3. Making simple checks of validity, } \\
\text { such as checks of electronic signatures } \\
\text { on documents, dates of issuance, etc. } \\
\text { 4 Performing "mathematical } \\
\text { correctness" or similar tests } \\
\text { automatically on machine-readable data } \\
\text { (perhaps controlled ex post by a } \\
\text { human) } \\
\text { 5. Potential use of artificial intelligence } \\
\text { tools for more sophisticated checks (for } \\
\text { example, tax authorities to check for } \\
\text { fraud) } \\
\text { 6. Simplification of application forms } \\
\text { (e.g. through a grant application } \\
\text { generator) and their instructions } \\
\text { (pre-formatting, segmentation of fields, } \\
\text { auto-validation of fields, use of prompts, } \\
\text { default filling in of fields based on } \\
\text { earlier information, print preview, } \\
\text { tracking contract status, alerts on } \\
\text { achieved milestones, etc.). } \\
\text { 7. Indicators on public procurement } \\
\text { should be developed in order to } \\
\text { measure the performance of ESIF } \\
\text { public procurement procedures, not } \\
\text { only for monitoring the progress of } \\
\text { procurement processes, but also for } \\
\text { better policy making. An effective data } \\
\text { collection system should be developed } \\
\text { to calculate the indicators and access to } \\
\text { results should be given to relevant }\end{array}$ & & & & $\begin{array}{c}\text { Certifying } \\
\text { authority } \\
\text { Central } \\
\text { co-ordination } \\
\text { body }\end{array}$ & Beneficiaries & \\
\hline
\end{tabular}




\begin{tabular}{|c|c|c|c|c|c|c|c|c|}
\hline Initiative & Context & Recommendation & Priority & Responsible & Accountable & Consulted & Informed & $\begin{array}{l}\text { Estimated } \\
\text { time frame }\end{array}$ \\
\hline & $\begin{array}{l}\text { grant projects' monitoring are different } \\
\text { to the Finantial Instruments' monitoring. } \\
\text { The ITMS2014+ settings in the area of } \\
\text { monitoring reflects solely the grants' } \\
\text { system of monitoring. } \\
\text { - There is a significant challenge in } \\
\text { collecting data on ESIF public } \\
\text { procurement. ITMS2014+ does not } \\
\text { function as an effective data collection } \\
\text { system to measure the performance of } \\
\text { the ESIF public procurement } \\
\text { procedures. }\end{array}$ & $\begin{array}{l}\text { users. In the short term, the } \\
\text { Slovak Republic could consider } \\
\text { preparing the Excel database. }\end{array}$ & & & & & & \\
\hline Beneficiary support & $\begin{array}{l}\text { Communication } \\
\text { - Many issues arise concerning } \\
\text { follow-up of interactions with the } \\
\text { beneficiaries, who often need to deal } \\
\text { with different officers and varying } \\
\text { requests during the assessment cycle. } \\
\text { This process is slow, due to persistent } \\
\text { use of postal mail. } \\
\text { Preparation } \\
\text { - To help beneficiaries with the } \\
\text { fulfillment of formal requirements and to } \\
\text { reduce their error rate, consultation } \\
\text { services (workshops, seminars, etc.) in } \\
\text { the application processes need to be } \\
\text { effective. } \\
\text { - Official communication materials are } \\
\text { often difficult to understand for } \\
\text { beneficiaries. This problem has been } \\
\text { solved in Poland through guidelines } \\
\text { such as "Check which co-financing your } \\
\text { company can benefit from", "Checklist } \\
\text { for public procurement procedures", etc. }\end{array}$ & $\begin{array}{l}\text { - Simplify and intensify communication } \\
\text { to reduce beneficiaries' error rate. } \\
\text { - Human interaction needs to proceed } \\
\text { via digital exchanges and avoid paper } \\
\text { mail. E-mail, or messaging on specific } \\
\text { secure platforms, should be the norm. } \\
\text { Such communication would ensure } \\
\text { traceability of all interactions with the } \\
\text { beneficiary. } \\
\text { - Adapt delays for response by the } \\
\text { beneficiaries to the digital age } \\
\text { (e.g. eliminate the delay for the } \\
\text { beneficiary to claim registered mail). } \\
\text { - Develop clear guidelines anticipating } \\
\text { beneficiaries' needs and challenges to } \\
\text { reduce error rates. To accelerate the } \\
\text { verification of formal criteria, } \\
\text { pre-formatted documents and tools } \\
\text { could provide an effective instrument. } \\
\text { - Incorporate feedback to consultation } \\
\text { services provided by beneficiaries into }\end{array}$ & Medium & $\begin{array}{c}\text { Ministry of } \\
\text { Education, } \\
\text { Science, } \\
\text { Research and } \\
\text { Sport } \\
\text { Ministry of } \\
\text { Economy } \\
\text { Research } \\
\text { Agency }\end{array}$ & $\begin{array}{l}\text { Ministry of } \\
\text { Education, } \\
\text { Science, Research } \\
\text { and Sport } \\
\text { Ministry of } \\
\text { Economy }\end{array}$ & Beneficiaries & Beneficiaries & Medium \\
\hline
\end{tabular}




\begin{tabular}{|c|c|c|c|c|c|c|c|c|}
\hline Initiative & Context & Recommendation & Priority & Responsible & Accountable & Consulted & Informed & $\begin{array}{l}\text { Estimated } \\
\text { time frame }\end{array}$ \\
\hline & & $\begin{array}{l}\text { guidelines and an FAQ. Only the most } \\
\text { complex questions are then to be } \\
\text { filtered to human operators. }\end{array}$ & & & & & & \\
\hline \multirow[t]{2}{*}{$\begin{array}{l}\text { Simplification of } \\
\text { procedures }\end{array}$} & $\begin{array}{l}\text { Call-preparation phase } \\
\text { - Many authorities are involved in the } \\
\text { reviewing of draft calls, which prolongs } \\
\text { the process and adds to } \\
\text { misunderstandings. A state reform in } \\
\text { Estonia in } 2018 \text { significantly reduced } \\
\text { the number of counterparts involved } \\
\text { and merged institutions with the } \\
\text { managing authority. This has led to a } \\
\text { reduction in delegation of responsibility } \\
\text { control, procedures and } \\
\text { misunderstandings. Fewer agencies } \\
\text { also meant less and therefore more } \\
\text { efficient communication channels for } \\
\text { beneficiaries and a greater ease of } \\
\text { setting up a common IT infrastructure. } \\
\text { - In the call preparation phase, } \\
\text { multi-stage approvals, whereby a call of } \\
\text { project strategylintent is launched prior } \\
\text { to the actual call, have caused delays. } \\
\text { - As each call needs to be approved by } \\
\text { several committees (Council of } \\
\text { Technology Agency, RIS3), the process } \\
\text { of call preparation should be simplified. }\end{array}$ & $\begin{array}{l}\text { - Adopt simplification of tasks of } \\
\text { intermediate bodies' staff, such as the } \\
\text { ones which have been applied in the } \\
\text { context of the COVID calls. } \\
\text { - Shorten procedural deadlines at } \\
\text { intermediate bodies concerning contract } \\
\text { preparation, approval of change } \\
\text { requests, verification of the cost } \\
\text { effectiveness. } \\
\text { - Evaluate the costs and benefits of } \\
\text { multi-stage calls. } \\
\text { - Simplify call as well as grant } \\
\text { agreement amending procedures, } \\
\text { i.e. through so-called technical } \\
\text { amendments. }\end{array}$ & High & $\begin{array}{c}\text { Ministry of } \\
\text { Education, } \\
\text { Science, } \\
\text { Research and } \\
\text { Sport } \\
\text { Ministry of } \\
\text { Economy } \\
\text { Research } \\
\text { Agency }\end{array}$ & $\begin{array}{c}\text { Central } \\
\text { co-ordination body } \\
\text { Ministry of } \\
\text { Education, } \\
\text { Science, Research } \\
\text { and Sport } \\
\text { Ministry of } \\
\text { Economy }\end{array}$ & $\begin{array}{c}\text { Central } \\
\text { co-ordination } \\
\text { authority } \\
\text { Audit authority } \\
\text { Certifying } \\
\text { authority } \\
\text { Public } \\
\text { Procurement } \\
\text { Office } \\
\text { Beneficiaries }\end{array}$ & Beneficiaries & Medium \\
\hline & $\begin{array}{l}\text { Contracting phase } \\
\text { - Significant progress could be achieved } \\
\text { due to simplifications made possible by } \\
\text { the COVID pandemic. Possibilities with } \\
\text { regard to the continuation of those }\end{array}$ & $\begin{array}{l}\text { The overall administrative burden } \\
\text { should be significantly reduced. } \\
\text { - Timesheet requirements should be } \\
\text { significantly simplified and only key } \\
\text { personnel involved in the project should }\end{array}$ & High & $\begin{array}{l}\text { Ministry of } \\
\text { Education, } \\
\text { Science, } \\
\text { Research and } \\
\text { Sport }\end{array}$ & $\begin{array}{l}\text { Ministry of } \\
\text { Investments, } \\
\text { Regional } \\
\text { Development and } \\
\text { Informatization }\end{array}$ & $\begin{array}{l}\text { Central } \\
\text { co-ordination } \\
\text { body } \\
\text { Managing } \\
\text { authorities/ }\end{array}$ & Beneficiaries & Short \\
\hline
\end{tabular}




\begin{tabular}{|c|c|c|c|c|c|c|c|c|}
\hline Initiative & Context & Recommendation & Priority & Responsible & Accountable & Consulted & Informed & $\begin{array}{l}\text { Estimated } \\
\text { time frame }\end{array}$ \\
\hline & $\begin{array}{l}\text { measures which have proven effective } \\
\text { should be considered. } \\
\text { - To accelerate the overall assessments } \\
\text { of the projects, the phases of } \\
\text { administrative verification and scientific } \\
\text { evaluation should run in parallel where } \\
\text { feasible. } \\
\text { - The OECD views the Dutch justified } \\
\text { trust approach with only sporadic } \\
\text { ex post controls of fulfillment of } \\
\text { administrative requirements as a } \\
\text { possible consideration. Experience from } \\
\text { the Netherlands showed no increase in } \\
\text { misuse. } \\
\text { - Measures to further simplify } \\
\text { implementation procedures need to be } \\
\text { explored. For example, the Ministry of } \\
\text { Economy has come to an agreement } \\
\text { which stipulates that the small and } \\
\text { medium-sized enterprise status is only } \\
\text { checked on the date of the contract } \\
\text { signature rather than throughout the } \\
\text { whole implementation process, which } \\
\text { used to require multiple verifications of } \\
\text { the SME status, which was a lenghty } \\
\text { undertaking. }\end{array}$ & $\begin{array}{l}\text { be included. } \\
\text { - Rather than specifying the hourly } \\
\text { wage and activities, focus on the key } \\
\text { activities and monthly remuneration. } \\
\text { - Administrative verification and } \\
\text { scientific evaluation should run in } \\
\text { parallel as much as possible. The } \\
\text { selection of evaluators, for instance, } \\
\text { could occur while the administrative } \\
\text { verfication is still ongoing } \\
\text { - Keep the budget column of additional } \\
\text { comments for each budget line in a } \\
\text { separate document outside the } \\
\text { contract. This would allow changes in } \\
\text { comments in the implementation phase } \\
\text { without the need to request approval as } \\
\text { is the case with changes to information } \\
\text { provided within the contract. } \\
\text { - Develop a common methodology at } \\
\text { the national level for the assessment of } \\
\text { the size category, cumulation of } \\
\text { de minimis aid and determining the } \\
\text { undertaking in difficulty. }\end{array}$ & & $\begin{array}{c}\text { Ministry of } \\
\text { Economy } \\
\text { Research } \\
\text { Agency }\end{array}$ & $\begin{array}{c}\text { (central } \\
\text { co-ordination body) } \\
\text { Ministry of } \\
\text { Education, } \\
\text { Science, Research } \\
\text { and Sport } \\
\text { Ministry of } \\
\text { Economy }\end{array}$ & $\begin{array}{l}\text { intermediate } \\
\text { bodies } \\
\text { Public } \\
\text { Procurement } \\
\text { Office } \\
\text { Audit authority } \\
\text { Antimonopoly } \\
\text { Office (state aid } \\
\text { issue) } \\
\text { Beneficiaries }\end{array}$ & & \\
\hline & $\begin{array}{l}\text { The control system brings high } \\
\text { administrative burdens: } \\
\text { - Control processes are delayed due to } \\
\text { the waiting time for a number of } \\
\text { approvers to sign the approval within } \\
\text { the intermediate bodies, even if control } \\
\text { officers complete their tasks quickly. } \\
\text { - Both ex ante and ex post controls are } \\
\text { carried out intensely in the } \\
\text { Slovak Republic. }\end{array}$ & $\begin{array}{l}\text { Control } \\
\text { - Independently veridy the control flow } \\
\text { and approval processes inside the } \\
\text { intermediate bodies to allow for further } \\
\text { improvements in terms of reducing its } \\
\text { overall timeline and avoiding } \\
\text { redundancy and duplication of tasks. } \\
\text { - Review the overall control system of } \\
\text { ESIF public procurement, with an } \\
\text { evidence-based analysis on the }\end{array}$ & High & $\begin{array}{c}\text { Public } \\
\text { Procurement } \\
\text { Office }\end{array}$ & $\begin{array}{c}\text { Ministry of } \\
\text { Investments, } \\
\text { Regional } \\
\text { Development and } \\
\text { Informatization } \\
\text { (central } \\
\text { co-ordination body) }\end{array}$ & $\begin{array}{l}\text { Ministry of } \\
\text { Education, } \\
\text { Science, } \\
\text { Research and } \\
\text { Sport } \\
\text { Ministry of } \\
\text { Economy } \\
\text { Research } \\
\text { Agency } \\
\text { Audit authority }\end{array}$ & Beneficiaries & Medium \\
\hline
\end{tabular}




\begin{tabular}{|c|c|c|c|c|c|c|c|c|}
\hline Initiative & Context & Recommendation & Priority & Responsible & Accountable & Consulted & Informed & $\begin{array}{l}\text { Estimated } \\
\text { time frame }\end{array}$ \\
\hline & $\begin{array}{l}\text { - Beneficiaries are required to submit } \\
\text { the same documents they already } \\
\text { submitted in the previous steps of the } \\
\text { control. } \\
\text { - Beneficiaries are required to submit } \\
\text { documents both electronically and in } \\
\text { hard copies. } \\
\text { - The result of control is notified by mail. } \\
\text { - The Public Procurement Office will } \\
\text { take over these roles of intermediate } \\
\text { bodies under the ESIF programming } \\
\text { period 2021-27, and will be responsible } \\
\text { for carrying out both ex ante and } \\
\text { ex post controls. } \\
\text { Market research } \\
\text { - Obtaining three price quotations (up } \\
\text { until October } 2020 \text {, two in the revised } \\
\text { version } 8 \text { ) is mandatory to determine } \\
\text { the estimated value of the contract for a } \\
\text { low-value procurement above } \\
\text { EUR } 500 \text { 000 under the ESIF public } \\
\text { procurement, while it is not required by } \\
\text { the Public Procurement Act: } \\
\text { - obtaining the price quotation itself is a } \\
\text { challenging and painstaking task } \\
\text { - it is very challenging to obtain the } \\
\text { price quotation for the innovative goods } \\
\text { and services required for R\&l activities } \\
\text { - obtaining the price quotation is a } \\
\text { repetitive procedure throughout the } \\
\text { ESIF project cycle. } \\
\text { - This strict regulation is not a common } \\
\text { practice in other EU countries that take } \\
\text { initiatives to decrease administrative } \\
\text { burdens related to the market research; } \\
\text { for example, preparing the list of }\end{array}$ & $\begin{array}{l}\text { trade-off between administrative } \\
\text { burdens (cost and time) and } \\
\text { transparency/effectiveness in } \\
\text { preventing errors in public procurement. } \\
\text { - Expand electronic submission of } \\
\text { documents (document submission and } \\
\text { notification of the result through } \\
\text { ITMS2014+ or an eventual replacement } \\
\text { system without mail transactions, } \\
\text { unless necessary). } \\
\text { - Provide the Public Procurement Office } \\
\text { adequate financial and human } \\
\text { resources to carry out control } \\
\text { processes under the programming } \\
\text { period 2021-27. } \\
\text { Market research } \\
\text { - Consider the possibility of streamlining } \\
\text { the market research requirement, in } \\
\text { particular for low-value contracts } \\
\text { - Consider preparing the price lists for } \\
\text { common goods and services related to } \\
\text { R\&l activities, such as travel costs, } \\
\text { accommodation costs, conference } \\
\text { services, etc. } \\
\text { - Develop detailed guidelines on how to } \\
\text { simplify and justify limited market } \\
\text { research when procuring innovative } \\
\text { goods or services (not previously } \\
\text { available) to allow beneficiaries to } \\
\text { reduce this step of the process. } \\
\text { Cancellation of tender } \\
\text { - Beneficiaries should not be forced to } \\
\text { cancel the tender due to the low } \\
\text { number of bids (in particular, a single } \\
\text { bid), as long as the situation is justified } \\
\text { and follows the Public Procurement Act }\end{array}$ & & & & Beneficiaries & & \\
\hline
\end{tabular}




\begin{tabular}{|c|c|c|c|c|c|c|c|c|}
\hline Initiative & Context & Recommendation & Priority & Responsible & Accountable & Consulted & Informed & $\begin{array}{l}\text { Estimated } \\
\text { time frame }\end{array}$ \\
\hline & $\begin{array}{l}\text { average market prices for specific } \\
\text { goods/services that beneficiaries can } \\
\text { use to justify the calculation of the cost. } \\
\text { Cancellation of tender } \\
\text { - In practice, beneficiaries are forced to } \\
\text { cancel public procurement processes } \\
\text { with only one bid, although no } \\
\text { regulatory frameworks (Public } \\
\text { Procurement Act nor ESIF regulations) } \\
\text { make it mandatory. }\end{array}$ & $\begin{array}{l}\text { (e.g. it satisfies the selection and } \\
\text { contract award criteria stipulated in the } \\
\text { tender documents with a lower price } \\
\text { than the estimated values of the } \\
\text { contract). }\end{array}$ & & & & & & \\
\hline & $\begin{array}{l}\text { Register of Public Sector Partners } \\
\text { (RPVS) } \\
\text {-The registration requirement of the } \\
\text { RPVS hinders the smooth start of the } \\
\text { contract under ESIF-funded public } \\
\text { procurement. } \\
\text { - Detailed information is not available to } \\
\text { identify specific factors that cause such } \\
\text { difficulties during the registration } \\
\text { procedure. }\end{array}$ & $\begin{array}{l}\text { - The government of the } \\
\text { Slovak Republic should analyse the } \\
\text { elements that lead to the bottlenecks in } \\
\text { the registration (including the impact on } \\
\text { foreign bidders) as well as the actual } \\
\text { practices, including the actual time } \\
\text { spent to complete the registration. }\end{array}$ & Medium & $\begin{array}{l}\text { Ministry of } \\
\text { Justice }\end{array}$ & Ministry of Justice & $\begin{array}{l}\text { Central } \\
\text { co-ordination } \\
\text { body }\end{array}$ & $\begin{array}{l}\text { Ministry of } \\
\text { Education, } \\
\text { Science, } \\
\text { Research and } \\
\text { Sport } \\
\text { Ministry of } \\
\text { Economy } \\
\text { Research } \\
\text { Agency } \\
\text { Audit authority } \\
\text { Beneficiaries }\end{array}$ & Medium \\
\hline $\begin{array}{l}\text { Public procurement } \\
\text { for innovation }\end{array}$ & $\begin{array}{l}\text { - Currently, public procurement for } \\
\text { innovation (PPI) is not a common } \\
\text { practice in the Slovak Republic. } \\
\text { - There are few actual examples of } \\
\text { using PPI under ESIF-funded R\&I } \\
\text { projects. } \\
\text { - The role of public procurement as an } \\
\text { instrument for stimulating innovation } \\
\text { has been increasingly emphasised in } \\
\text { the Slovak Republic, but it has not yet } \\
\text { been fully recognised by stakeholders, } \\
\text { such as the managing authority, } \\
\text { intermediate bodies, audit institutions or }\end{array}$ & $\begin{array}{l}\text { - It could be beneficial to consider the } \\
\text { possibility of setting up a target for PPI } \\
\text { implementation for the ESIF R\&I } \\
\text { projects in terms of percentage of total } \\
\text { public procurement (number of } \\
\text { procedures and/or amounts), as well as } \\
\text { of collecting the systematic monitoring } \\
\text { of the data on PPI. } \\
\text { - Consider the possibility of carrying out } \\
\text { ESIF pilot projects that require the use } \\
\text { of PPI schemes such as } \\
\text { pre-commercial procurement and } \\
\text { innovative parntershipsPI. }\end{array}$ & High & $\begin{array}{l}\text { Ministry of } \\
\text { Investments, } \\
\text { Regional } \\
\text { Development } \\
\text { and } \\
\text { Informatization } \\
\text { (managing } \\
\text { authority for } \\
\text { 2021-27) }\end{array}$ & $\begin{array}{l}\text { Ministry of } \\
\text { Investments, } \\
\text { Regional } \\
\text { Development and } \\
\text { Informatization } \\
\text { (central } \\
\text { co-ordination body) }\end{array}$ & $\begin{array}{c}\text { Public } \\
\text { Procurment } \\
\text { Office } \\
\text { Audit authority }\end{array}$ & $\begin{array}{l}\text { Ministry of } \\
\text { Education, } \\
\text { Science, } \\
\text { Research and } \\
\text { Sport } \\
\text { Ministry of } \\
\text { Economy } \\
\text { Research } \\
\text { Agency } \\
\text { Beneficiaries }\end{array}$ & Long \\
\hline
\end{tabular}




\begin{tabular}{|c|c|c|c|c|c|c|c|c|}
\hline Initiative & Context & Recommendation & Priority & Responsible & Accountable & Consulted & Informed & $\begin{array}{l}\text { Estimated } \\
\text { time frame }\end{array}$ \\
\hline & $\begin{array}{l}\text { beneficiaries. } \\
\text { - There is no target set for PPI in terms } \\
\text { of percentage of total public } \\
\text { procurement (number of procedures } \\
\text { and/or amounts), as well as no } \\
\text { systematic monitoring of the data on } \\
\text { public procurement for innovation. } \\
\text { - Poland has taken initiative to promote } \\
\text { the use of PPI: } \\
\text { - some intermediate bodies carry out } \\
\text { ESIF R\&I projects in which the use of } \\
\text { PPI schemes is mandatory } \\
\text { - the Public Procurement Office of } \\
\text { Poland provides methodological } \\
\text { assistance to support contracting } \\
\text { authorities to implement PPI, such as } \\
\text { consultation with the optional ex ante } \\
\text { control as well as the issuance of the } \\
\text { best practice book on PPI in Poland. }\end{array}$ & $\begin{array}{l}\text { - Provide more capacity-building } \\
\text { opportunities to stakeholders, including } \\
\text { beneficiaries, intermediate bodies and } \\
\text { audit institutions, in order to raise } \\
\text { awareness of PPI and promote its use } \\
\text { in ESIF R\&I projects. } \\
\text { - Organise regular seminars to } \\
\text { exchange PPI practices between the } \\
\text { Public Procurement Office and other } \\
\text { relevant stakeholders. }\end{array}$ & & & & & & \\
\hline Conflict of opinions & $\begin{array}{l}\text { - Streamlining views of all governance } \\
\text { bodies involved in ESIF is crucial to } \\
\text { avoid misunderstandings and false } \\
\text { rejections of applications and reduce } \\
\text { delays. } \\
\text { - Conflicting opinions among different } \\
\text { stakeholders (managing authority, } \\
\text { intermediate body, the Pubic } \\
\text { Procurement Office, audits, } \\
\text { beneficiaries) brings legal uncertainty } \\
\text { on the control system of the ESIF public } \\
\text { procurement. Decisions taken after the } \\
\text { long control processes are not regarded } \\
\text { as final, legitimate, nor legally binding. }\end{array}$ & $\begin{array}{l}\text { - Ensure that the audit authority and the } \\
\text { PPO have a unified view regarding } \\
\text { public procurement procedures and on } \\
\text { the requirements for audit trail to reduce } \\
\text { the scope of checklists. } \\
\text { - Further reinforce a collaboration } \\
\text { mechanism among control and audit } \\
\text { authorities to share different views to } \\
\text { avoid any discrepancy in the opinions } \\
\text { among different authorities } \\
\text { - Create a database with a typology of } \\
\text { control decisions for further } \\
\text { standardisation and harmonisation of } \\
\text { the control process. It could also } \\
\text { support the newly established }\end{array}$ & High & $\begin{array}{l}\text { Ministry of } \\
\text { Investments, } \\
\text { Regional } \\
\text { Development } \\
\text { and } \\
\text { Informatization } \\
\text { (managing } \\
\text { authority for } \\
\text { 2021-27) }\end{array}$ & $\begin{array}{c}\text { Ministry of } \\
\text { Investments, } \\
\text { Regional } \\
\text { Development and } \\
\text { Informatization } \\
\text { Public } \\
\text { Procurement Act } \\
\text { Audit authority }\end{array}$ & $\begin{array}{l}\text { Ministry of } \\
\text { Investments, } \\
\text { Regional } \\
\text { Development } \\
\text { and } \\
\text { Informatization } \\
\text { Public } \\
\text { Procurement Act } \\
\text { Audit authority } \\
\text { Beneficiaries } \\
\text { Ministry of } \\
\text { Education, } \\
\text { Science, } \\
\text { Research and } \\
\text { Sport } \\
\text { Ministry of } \\
\text { Economy }\end{array}$ & Beneficiaries & Medium \\
\hline
\end{tabular}




\begin{tabular}{|c|c|c|c|c|c|c|c|c|}
\hline Initiative & Context & Recommendation & Priority & Responsible & Accountable & Consulted & Informed & $\begin{array}{l}\text { Estimated } \\
\text { time frame }\end{array}$ \\
\hline & & $\begin{array}{l}\text { governance mechanism for the next } \\
\text { programming period by preserving } \\
\text { institutional memory. }\end{array}$ & & & & $\begin{array}{l}\text { Research } \\
\text { Agency }\end{array}$ & & \\
\hline $\begin{array}{l}\text { Financial } \\
\text { instruments }\end{array}$ & $\begin{array}{l}\text { - Confronted with difficulties in } \\
\text { disbursement which would lead to } \\
\text { decommittment, and the need for funds } \\
\text { for SMEs during the pandemic, a large } \\
\text { share of ESIF resources has been } \\
\text { transferred from Thematic objectives } 1 \\
\text { and } 2 \text { towards Thematic objectives } 3 \\
\text { and } 4 \text {, and finally disbursed through } \\
\text { financial instruments for a total amount } \\
\text { of EUR } 719.9 \text { million. } \\
\text { - The instrument met high demand due } \\
\text { to the very favourable conditions (one } \\
\text { of the guarantees covering } 90 \% \text { of } \\
\text { loss), and was very rapidly disbursed. } \\
\text { However, leverage achieved was very } \\
\text { low (leverage factor } 1.1 \text { compared to } \\
\text { usual values of about } 6 \text { ). } \\
\text { - Compared to benchmark countries } \\
\text { with allocations through financial } \\
\text { instruments of } 3-13 \% \text {, the } \\
\text { Slovak Republic's } 28 \% \text { are much } \\
\text { higher. }\end{array}$ & $\begin{array}{l}\text { - In crisis situations, governments often } \\
\text { reallocate funding foreseen for R\&I, } \\
\text { which is not seen as urgent. } \\
\text { Nevertheless, the experience of OECD } \\
\text { countries shows that retaining constant } \\
\text { funding for R\&I over the long term is } \\
\text { essential for the sustainable } \\
\text { development of knowledge-based } \\
\text { economies. } \\
\text { - As part of the envisioned ex post } \\
\text { evaluations of the specific objectives, } \\
\text { an impact analysis into the outcome of } \\
\text { the financial instruments is foreseen. } \\
\text { Such analysis should reflect on the } \\
\text { impact achieved on the economy in the } \\
\text { short term (crisis relief) versus reduced } \\
\text { funding available for research and } \\
\text { innovation in the medium and long } \\
\text { term. The result should inform policy } \\
\text { action in future crisis situations. }\end{array}$ & Medium & $\begin{array}{l}\text { Ministry of } \\
\text { Economy }\end{array}$ & $\begin{array}{l}\text { Ministry of } \\
\text { Economy }\end{array}$ & Beneficiaries & $\begin{array}{l}\text { Ministry of } \\
\text { Investments, } \\
\text { Regional } \\
\text { Development } \\
\text { and } \\
\text { Informatization } \\
\text { (central } \\
\text { co-ordination } \\
\text { authority) } \\
\text { (managing } \\
\text { authority for } \\
2021-27 \text { ) } \\
\text { Managing } \\
\text { authority } \\
\text { lintermediate } \\
\text { bodies } \\
\text { Beneficiaries }\end{array}$ & Medium \\
\hline Expert evaluators & $\begin{array}{l}\text { Incentives and conditions } \\
\text { • Higher remuneration may be } \\
\text { warranted to incentivise more } \\
\text { professionals to perform ESIF project } \\
\text { evaluations. In Poland, an evaluator } \\
\text { receives around EUR 430, in the } \\
\text { Czech Republic this is project- } \\
\text { dependent and may range from } \\
\text { EUR } 100 \text { to EUR } 500 \text {, or up to } \\
\text { EUR } 900 \text { if special expertise is } \\
\text { required. With about EUR } 100-200 \text { per }\end{array}$ & $\begin{array}{l}\text { - Higher remuneration may attract more } \\
\text { qualified evaluators. } \\
\text { - Significantly reduce the length of } \\
\text { evaluation manuals. The allocated } \\
\text { time frame for the evaluation should } \\
\text { realistically reflect the amount of time } \\
\text { the evaluator needs to study the rules } \\
\text { and definitions. } \\
\text { - In particular in niche expertise areas, }\end{array}$ & High & $\begin{array}{c}\text { Ministry of } \\
\text { Education, } \\
\text { Science, } \\
\text { Research and } \\
\text { Sport } \\
\text { Ministry of } \\
\text { Economy } \\
\text { Research } \\
\text { Agency }\end{array}$ & $\begin{array}{l}\text { Ministry of } \\
\text { Investments, } \\
\text { Regional } \\
\text { Development and } \\
\text { Informatization } \\
\text { (managing } \\
\text { authority/central } \\
\text { co-ordination } \\
\text { bodyfor 2021-27) } \\
\text { Ministry of } \\
\text { Education, }\end{array}$ & $\begin{array}{c}\text { Public } \\
\text { Procurement } \\
\text { Office } \\
\text { Audit authority } \\
\text { Research } \\
\text { Agency }\end{array}$ & $\begin{array}{l}\text { Ministry of } \\
\text { Education, } \\
\text { Science, } \\
\text { Research and } \\
\text { Sport } \\
\text { Ministry of } \\
\text { Economy } \\
\text { Research } \\
\text { Agency } \\
\text { Audit authority } \\
\text { Beneficiaries }\end{array}$ & Long \\
\hline
\end{tabular}




\begin{tabular}{|c|c|c|c|c|c|c|c|c|}
\hline Initiative & Context & Recommendation & Priority & Responsible & Accountable & Consulted & Informed & $\begin{array}{l}\text { Estimated } \\
\text { time frame }\end{array}$ \\
\hline & $\begin{array}{l}\text { evaluation, the Slovak Republic pays } \\
\text { less than the benchmark countries. } \\
\text { - Evaluation manuals are too long } \\
\text { (160 pages). Evaluators are paid for ten } \\
\text { hours to complete the entire evaluation } \\
\text { process. This is not enough to even } \\
\text { read the manual. Manuals in } \\
\text { benchmark countries are } 25-60 \text { pages } \\
\text { long. } \\
\text { Evaluator selection criteria } \\
\text { - After irregularities in 2017, the } \\
\text { introduction of strict criteria for } \\
\text { evaluation selection was necessary; } \\
\text { however, in some cases, the criteria } \\
\text { might be too strict and some } \\
\text { compensation for shortcomings in some } \\
\text { criteria may be justified. } \\
\text { - In Poland, the general requirements } \\
\text { for evaluators is to have a PhD; } \\
\text { however, this may be compensated by } \\
\text { a Bachelor of Science degree and ten } \\
\text { years' experience } \\
\text { - Not all evaluators are equally } \\
\text { qualified, which in addition to the } \\
\text { subjective criteria may, in cases, lead to } \\
\text { a lack of accountability and fraudulent } \\
\text { outcomes. } \\
\text { Evaluation criteria } \\
\text { - The evaluation criteria are in part } \\
\text { highly subjective, sometimes leading to } \\
\text { different outcomes between evaluators. } \\
\text { Only a relatively small share of all } \\
\text { criteria are in fact related to } \\
\text { innovativeness, which somewhat } \\
\text { undermines the purpose of the } \\
\text { evaluation to find and support }\end{array}$ & $\begin{array}{l}\text { some flexibility from intermediate } \\
\text { bodies regarding the criteria for the } \\
\text { selection of evaluators is advisable if } \\
\text { evaluators do not fulfil all criteria but } \\
\text { compensate the missing diploma } \\
\text { (e.g. Ph.D) with a Masters degree } \\
\text { combined with extensive professional } \\
\text { experience and track record in the field. } \\
\text { - Evaluate the performance of the } \\
\text { evaluators themselves frequently to } \\
\text { ensure quality evaluations and } \\
\text { accountability. } \\
\text { - Make criteria for evaluation as } \\
\text { objective as possible to streamline } \\
\text { results across evaluators. } \\
\text { - Particular prominence and more } \\
\text { emphasis for innovativeness criteria are } \\
\text { warranted to ensure that the most } \\
\text { innovative projects are supported. } \\
\text { - Provide training for Slovak evaluators } \\
\text { by Horizon } 2020 \text { staff. } \\
\text { - Try to establish exchange ("twinning") } \\
\text { programmes, whereby a Horizon } 2020 \\
\text { person would come to the } \\
\text { Slovak Republic to work on calls and } \\
\text { share experience, and perhaps a } \\
\text { Slovak staff member would go to } \\
\text { Brussels. } \\
\text { - Establish contacts with Horizon } 2020 \\
\text { teams to seek information about, for } \\
\text { example, costs and availability of } \\
\text { equipment. } \\
\text { - Explore possibilities to liaise with }\end{array}$ & & & $\begin{array}{c}\text { Science, Research } \\
\text { and Sport } \\
\text { Ministry of } \\
\text { Economy }\end{array}$ & & & \\
\hline
\end{tabular}




\begin{tabular}{|c|c|c|c|c|c|c|c|c|}
\hline Initiative & Context & Recommendation & Priority & Responsible & Accountable & Consulted & Informed & $\begin{array}{l}\text { Estimated } \\
\text { time frame }\end{array}$ \\
\hline & $\begin{array}{l}\text { innovative projects. } \\
\text { Horizon } 2020 \text { synergies } \\
\text { - In contrast to ESIF calls, the } \\
\text { evaluation process with regard to } \\
\text { Horizon } 2020 \text { projects is shorter and the } \\
\text { response by evaluators is } \\
\text { straightforward according to } \\
\text { beneficiaries. } \\
\text { - The Horizon } 2020 \text { expert evaluator } \\
\text { database including international experts } \\
\text { with experience in their field could serve } \\
\text { as a best practice solution. } \\
\text { - The Horizon } 2020 \text { process, therefore, } \\
\text { could serve as a role model to enhance } \\
\text { efficiency In particular, the relevant } \\
\text { Horizon } 2020 \text { evaluators in Brussels } \\
\text { could provide support if needed. }\end{array}$ & $\begin{array}{l}\text { Horizon } 2020 \text { staff regarding specific } \\
\text { expertise on scientific equipment which } \\
\text { may not be available within the } \\
\text { Research Agency. }\end{array}$ & & & & & & \\
\hline Foreign evaluators & $\begin{array}{l}\text { Foreign evaluators } \\
\text { - Including international experts in the } \\
\text { process of the scientific evaluation } \\
\text { could help reduce delays by expanding } \\
\text { the choice of available evaluators. As } \\
\text { these evaluators tend to be } \\
\text { knowledgeable about global markets } \\
\text { and developments, it is likely that the } \\
\text { quality of assessment would improve. } \\
\text { - In addition, making use of foreign } \\
\text { evaluators ensures independence and } \\
\text { avoids conflicts of interest. } \\
\text { - For the Slovak Research and } \\
\text { Development Agency's projects and in } \\
\text { benchmark countries, applications are } \\
\text { to be submitted in English regardless, } \\
\text { which showcases that it is feasible to } \\
\text { request applicants to provide } \\
\text { translations; this should not be a } \\
\text { significant barrier. As in the benchmark }\end{array}$ & $\begin{array}{l}\text { - Enhanced use of foreign evaluators } \\
\text { for research projects could help } \\
\text { alleviate shortages, in particular in } \\
\text { niche fields of expertise where it is } \\
\text { difficult to find evaluators with all of the } \\
\text { criteria (i.e. independence). } \\
\text { - At least the scientific part of the } \\
\text { application should be requested in } \\
\text { English. } \\
\text { - To find foreign evaluators, heads of } \\
\text { foreign institutions should be proactively } \\
\text { contacted and asked to advertise the } \\
\text { roles among their staff rather than } \\
\text { contacting individuals separately. }\end{array}$ & High & $\begin{array}{c}\text { Ministry of } \\
\text { Education, } \\
\text { Science, } \\
\text { Research and } \\
\text { Sport } \\
\text { Ministry of } \\
\text { Economy } \\
\text { Research } \\
\text { Agency }\end{array}$ & $\begin{array}{l}\text { Ministry of } \\
\text { Investments, } \\
\text { Regional } \\
\text { Development and } \\
\text { Informatization } \\
\text { (managing } \\
\text { authority/central } \\
\text { co-ordination } \\
\text { bodyfor 2021-27) } \\
\text { Ministry of } \\
\text { Education, } \\
\text { Science, Research } \\
\text { and Sport } \\
\text { Ministry of } \\
\text { Economy }\end{array}$ & $\begin{array}{c}\text { Public } \\
\text { Procurement } \\
\text { Agency } \\
\text { Audit authority } \\
\text { Research } \\
\text { Agency }\end{array}$ & $\begin{array}{l}\text { Ministry of } \\
\text { Education, } \\
\text { Science, } \\
\text { Research and } \\
\text { Sport } \\
\text { Ministry of } \\
\text { Economy } \\
\text { Research } \\
\text { Agency } \\
\text { Audit authority } \\
\text { Beneficiaries }\end{array}$ & Long \\
\hline
\end{tabular}




\begin{tabular}{|c|c|c|c|c|c|c|c|c|}
\hline Initiative & Context & Recommendation & Priority & Responsible & Accountable & Consulted & Informed & $\begin{array}{l}\text { Estimated } \\
\text { time frame }\end{array}$ \\
\hline & $\begin{array}{l}\text { countries, applications could be } \\
\text { submitted in English, if it is known } \\
\text { beforehand that international evaluators } \\
\text { will be used. }\end{array}$ & & & & & & & \\
\hline
\end{tabular}

Source: Prepared based on discussion with Slovakian stakeholders. 


\section{References}

(n.a.) (2017), Market prices of goods and services, European Social Fund Agency of Lithuania, https://www.esf.lt/t/dokumentai-ir-leidiniai/projektu-vykdytoju-pirkimai-perkanciosiomsorganizacijoms/664 (accessed on 16 April 2021).

Audit Authority (2017), Protocol on the Result of the Inspection of Implementation of Calls of the Programming Period 2014-2020 II, Audit Authority, Bratislava.

Central Coordination Authority (2014), ESIF Management System, https://www.partnerskadohoda.gov.sk/zakladne-dokumenty (accessed on 20 December 2020).

Central Coordination Authority (n.d.), Methodological Instructions of Central Coordination Authority, Government Office of the Slovak Republic, EU Funds Coordination Section, Bratislava, https://www.partnerskadohoda.gov.sk/metodicke-pokyny-cko-a-uv-sr (accessed on 18 December 2020).

CompraNet (2019), Contratos, https://sites.google.com/site/cnetuc/contrataciones (accessed on 18 February 2020).

Computer Security Incident Response Team Slovakia (2014), ITMS DataCentrum, DataCentrum, Bratislava, http://www.itms.datacentrum.sk (accessed on 15 December 2020).

Delos Santos, J. (2018), Understanding Responsibility Assignment Matrix (RACI Matrix), ProjectManagement.com, https://project-management.com/understanding-responsibility-assignmentmatrix-raci-matrix (accessed on 8 June 2021).

ESFA (2017), "Market prices of goods and services", web page, European Social Fund Agency, Vilnius, https://www.esf.It/lt/dokumentai-ir-leidiniai/projektu-vykdytoju-pirkimaiperkanciosioms-organizacijoms/664.

European Commission (2021), "ESIF 2014-2020: Fin. implementation (total costs) by thematic objective for EU (filters by fund + year), 2014-2020", Cohesion Data, https://cohesiondata.ec.europa.eu/2014-2020/ESIF-2014-2020-Fin-Implementation-totalcosts-by-T/vyid-jfhd?cookies=disabled.

European Commission (2020), "Research and innovation", European Structural \& Investment Funds Data, https://cohesiondata.ec.europa.eu/themes/1. 
European Commission (2017), Quality of Public Administration: A Toolbox for Practitioners, European Commission, Brussels, https://ec.europa.eu/social/main.jsp?catld=738\&langld=en\&publd=8055\&type=2\&furtherPubs =no (accessed on 18 December 2020).

Ministry of Economy (2020), Methodological Document for Beneficiaries on application of the Principles of the Public Procurement for Innovation within the Tenders Cofinanced from the Operational Programme Integrated Infrastructure under the Ministry of Economy.

Ministry of Economy (2020), Methodological Document for Beneficiaries on the Application of the Principles of the Public Procurement for Innovation within the Tenders Cofinanced from the Operational Programme Integrated Infrastructure under the Ministry of Economy, Ministry of Economy, Bratislava.

Ministry of Economy (2016), Guideline on the Public Procurement Process for Demand-driven Projects and National Projects of the Operational Programme Integrated Infrastructure Under the Ministry of Economy of the SR, Ministry of Economy, Bratislava, https://www.opvai.sk/media/102120/prirucka-k-procesu-vo dop-a-np-op-ii 33.pdf (accessed on 18 December 2020).

OECD (2020), Strengthening Governance of EU Funds under Cohesion Policy: Administrative Capacity Building Roadmaps, OECD Multi-level Governance Studies, OECD Publishing, Paris, https://dx.doi.org/10.1787/9b71c8d8-en.

OECD (2019), Reforming Public Procurement: Progress in Implementing the 2015 OECD Recommendation, OECD Public Governance Reviews, OECD Publishing, Paris, https://dx.doi.org/10.1787/1de41738-en.

OECD (2017), Public Procurement for Innovation: Good Practices and Strategies, OECD Public Governance Reviews, OECD Publishing, Paris, https://dx.doi.org/10.1787/9789264265820en.

OECD (2015), OECD Recommendation of the Council on Public Procurement, OECD, Paris, http://www.oecd.org/gov/public-procurement/recommendation/OECD-Recommendation-onPublic-Procurement.pdf (accessed on 28 May 2018).

Office, Public Procurement (2015), Public Procurement Act (Act No. 343/2015 Coll.), Ministry of Justice, Bratislava, https://www.slov-lex.sk/pravne-predpisy/SK/ZZ/2015/343/20200327 (accessed on 20 December 2020).

Polish Public Procurement Office (2020), Public Procurement of Innovation, Public Procurement Office, Warsaw, http://www.ccpg.com.pl (accessed on 16 April 2021).

Public Procurement Office (2020), Basic Steps and Procurement Procedures - Financial Thresholds, https://www.uvo.gov.sk/metodika-zadavania-zakaziek-5ae.html (accessed on 21 December 2020).

Public Procurement Office (2020), Basic Steps and Procurement Procedures: Financial Thresholds, Public Procurement Office, Bratislava, https://www.uvo.gov.sk/metodikazadavania-zakaziek-5ae.html.

Public Procurement Office (2017), Innovation in Public Procurement, Public Procurement Office, Bratislava, https://www.uvo.gov.sk/legislativametodika-dohlad/zodpovedne-vereineobstaravanie/materialy-na-stiahnutie-5d5.html (accessed on 17 December 2020). 
Public Procurement Office (n.d.), Working Group on Strategic Procurement, Public Procurement [19] Office, Bratislava, https://www.uvo.gov.sk/legislativametodika-dohlad/zodpovedne-verejneobstaravanie-5c8.html (accessed on 17 December 2020). 


\title{
Annex A. List of calls
}

\author{
Table A.1. Research Agency calls
}

Call for applications for a non-repayable financial contribution to support the participation of Slovak research institutions in international research projects aimed at combating the pandemic caused by COVID-19

Call for applications for a non-repayable financial contribution for phased projects of university science parks and research centres (Phase II) for less developed regions

Call for proposals for a non-repayable financial contribution to support international research projects approved under the $\mathbf{H 2 0 2 0}$ programme

Call for applications for a non-repayable financial contribution to support team research centres outside the Bratislava region

Call for applications for the provision of a non-repayable financial contribution to support the mobilisation of excellent research teams in the areas of specialisation RIS3 SK outside the Bratislava region

Call for proposals for a non-repayable financial contribution to support research and development capacities in the field of vehicles for the 21st century

Call for proposals for a non-repayable financial contribution to support research and development capacities in the field of industry for the 21 st century

Call for proposals for a non-repayable financial contribution to support research and development capacities in the field of healthy food and the environment

Call for applications for the provision of a non-repayable financial contribution to support research and development capacities in the field of Digital Slovakia and the creative industry

Call for proposals for a non-repayable financial contribution to support research and development capacities in the field of public health and health technologies

Call for applications for a non-repayable financial contribution to support the systemic public research infrastructure in the domain population health and health technologies

Call for applications for a non-repayable financial contribution to support the mobilisation and use of the potential of research institutions in combating the COVID-19 pandemic and reducing the negative effects of the pandemic

Call for proposals for a non-repayable financial contribution to support long-term strategic research - Vehicles for the 21st century 
Call for proposals for a non-repayable financial contribution to support long-term strategic research - Industry for the 21st century

Call for proposals for a non-repayable financial contribution to support long-term strategic research - Healthy food and the environment

Call for applications for a non-repayable financial contribution to support long-term strategic research - Digital Slovakia and the creative industries

Call for proposals for a non-repayable financial contribution to support long-term strategic research - Population health and health technologies

Call for applications for a non-repayable financial contribution for phased projects of university science parks and research centres (Phase II) for a more developed region

Call for applications for the provision of a non-repayable financial contribution in support of team research centres in the Bratislava region

Call for applications for the provision of a non-repayable financial contribution to support the mobilisation of excellent research teams in the areas of specialisation RIS3 SK in the Bratislava region

Call for applications for a non-repayable financial contribution to support centres of excellence of transnational importance - II. stage

Table A.2. Ministry of Education, Science, Research and Sport's national projects ACCORD

CLOUD II

NISPEZ II

NITT II

POPVAT II

SK4ERA

Table A.3. Ministry of Economy's calls and national projects

Monitoring podnikatel'ského prostredia v súlade s uplatňovaním princípu "Think Small First" (kód výzvy: OPValMH/NP/2016/3.3.1/4.1.1-04) 
Národný projekt NPC II - BA kraj (kód výzvy: OPVal-MH/NP/2016/4.1.1-03)

Národný projekt NPC v regiónoch (kód výzvy: OPVal-MH/NP/2016/3.1.1/3.3.1-02)

OP OPVal-MH / DP / 2017 / 1.2.2-11 Call for proposals for a non-repayable financial contribution to support innovation through industrial research and experimental development within the field of vehicles for the 21 st century

OPII-MH/DP/2020/10.3-29 Call for applications for a non-repayable financial contribution aimed at supporting the networking of companies in the Bratislava region

OPII-MH/DP/2020/11.3-23 Call for applications for the provision of a non-repayable financial contribution aimed at supporting the development of SMEs within the EC initiative aimed at the transformation of the Horná Nitra coal region

OPII-MH/DP/2020/11.3-25 Call for proposals for a non-repayable financial contribution aimed at supporting the development of SME entrepreneurship and co-operation with secondary vocational schools

OPII-MH/DP/2020/11.3-26 Call for applications for the provision of NFP aimed at supporting SMEs within the endogenous potential of tourism development in selected regions of the Prešov Self-Governing Region (PSK) within the EC Catching-up Regions Initiative

OPII-MH/DP/2020/11.3-27 Call for applications for the provision of NFP aimed at supporting SMEs within the endogenous potential of tourism development in selected regions of the Banská Bystrica Self-Governing Region (BBSK) within the EC Catching-up Regions Initiative

OPII-MH/DP/2020/9.5-28 Call for applications for a non-repayable financial contribution to support business networking

OPVal-MH / DP / 2016 / 1.2.2-02 Call for applications for a non-repayable financial contribution to support innovation and technology transfer

OPVal-MH/DP/2016/3.1.1-03 Call for applications for a non-repayable financial contribution aimed at supporting new and start-up micro, small and medium-sized enterprises

OPVal-MH/DP/2016/3.3.1-04 Call for applications for a non-repayable financial contribution aimed at supporting existing micro, small and medium-sized enterprises

OPVal-MH/DP/2017/1.2.2-12 Call for proposals for a non-repayable financial contribution to support innovation through industrial research and experimental development under the industry for the 21 st century domain

OPVal-MH/DP/2017/1.2.2-12 Call for proposals for a non-repayable financial contribution to support innovation through industrial research and experimental development under the healthy food and environment domain

OPVal-MH/DP/2017/3.3.1-08 Call for applications for a non-repayable financial contribution aimed at supporting SMEs in the least developed districts

OPVal-MH/DP/2017/3.3.1-09 Call for proposals for a non-repayable financial contribution aimed at improving the performance and functionality standards for micro, small and medium-sized enterprises

OPVal-MH/DP/2017/3.3.1-10 Call for proposals for a non-repayable financial contribution aimed at improving the performance and functionality standards for micro, small and medium-sized enterprises through the implementation of REACH

OPVal-MH/DP/2017/3.3.1-14 Call for applications for a non-repayable financial contribution aimed at supporting micro, small and medium-sized enterprises operating in the field of service provision in the least developed districts

OPVal-MH/DP/2017/4.1.1-07 Call for applications for the provision of a non-repayable financial contribution aimed at supporting SMEs in the field of creative industries in the Bratislava region

OPVal-MH/DP/2018/1.2.2-15 Call for proposals for a non-repayable financial contribution to support smart innovation in industry 
OPVal-MH/DP/2018/1.2.2-16 Call for proposals for a non-repayable financial contribution to support innovation through industria research and experimental development under the domains of public health and health technologies

OPVal-MH/DP/2018/1.2.2-17 Call for applications for a non-repayable financial contribution aimed at supporting innovation through industrial research and experimental development within the domain Digital Slovakia and the creative industry

OPVal-MH/DP/2018/1.2.2-21 Call for proposals for a non-repayable financial contribution to support smart innovation in industry

OPVal-MH/DP/2018/2.2.2-20 Call for applications for a non-repayable financial contribution aimed at supporting innovation through industrial research and experimental development in all RIS3 SK domains in the Bratislava region

OPVal-MH/DP/2018/3.2.1-18 Call for proposals for a non-repayable financial contribution aimed at supporting the involvement of SMEs in EU programs

OPVal-MH/DP/2018/4.1.1-19 Call for applications for the provision of a non-repayable financial contribution aimed at supporting the involvement of SMEs in the Bratislava region

OPVal-MH/DP/2019/3.1.1-3.3.1-22 Call for proposals for a non-repayable financial contribution aimed at supporting the implementation of social innovation in the SME environment

Podpora internacionalizácie MSP (kód výzvy: OPVal-MH/NP/2017/3.2.1/3.3.1-05)

Podpora rozvoja kreatívneho priemyslu na Slovensku (kód výzvy: OPVal-MH/NP/2017/3.3.1/4.1.1-06)

Podpora rozvoja kreatívneho priemyslu na Slovensku (kód výzvy: OPVal-MH/NP/2017/3.3.1/4.1.1-06)

Zvýšenie inovačnej výkonnosti slovenskej ekonomiky (kód výzvy: OPVal-MH/NP/2016/1.2.2/2.2.2-01)

Zvýšenie inovačnej výkonnosti slovenskej ekonomiky (kód výzvy: OPVal-MH/NP/2016/1.2.2/2.2.2-01) 